\title{
Effect of axle load spreading and support stiffness on the dynamic response of short span railway bridges
}

ERIK AXELSSON ANNELIE SYK

Master of Science Thesis Stockholm, Sweden 2013 



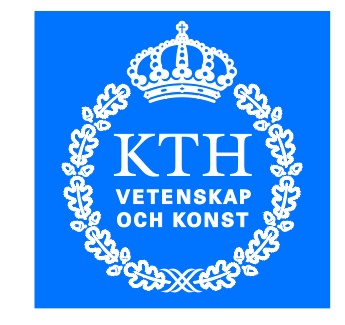

KTH Architecture and the Built Environment

\section{Effect of axle load spreading and support stiffness on the dynamic response of short span railway bridges}

Erik Axelsson

Annelie Syk

June 2013

TRITA-BKN. Master Thesis 391, 2013

ISSN 1103-4297

ISRN KTH/BKN/EX-391-SE 
(C) Erik Axelsson and Annelie Syk, 2013

KTH Royal Institute of Technology

Department of Civil and Architectural Engineering

Division of Structural Design and Bridges

Stockholm, Sweden, 2013 


\section{Preface}

This master thesis was initiated by the Department of Civil and Architectural Engineering at The Royal Institute of Technology, KTH.

We would like to thank Jean-Marc Battini for his positive guidance and great commitment throughout the project. We would further like to thank Mahir Ülker-Kaustell for sharing his knowledge, helping us move forward when stuck and answering our questions. We would also like to thank Therese Arvidsson for taking the time to help us although not involved in the project. Last but not least we would like to thank our fellow students for gilding our time working with the project.

Stockholm, June 2013

Erik Axelsson and Annelie Syk 



\section{Abstract}

In this thesis the effect of axle load spreading through ballast and the effect of support stiffness has been investigated on short span railway bridges. Two types of bridges, simply supported bridges and bridges with integrated backwalls, have been modeled with 2D beam elements. When analyzing the load spreading effect, two types of load shapes have been considered. The first one is the load shape proposed in Eurocode where the axle load is modeled with three point loads where $50 \%$ of the axle load acts on the sleeper located underneath the wheel and $25 \%$ on the two adjacent sleepers, respectively. Therefrom the loads are further distributed through the sleepers and the ballast. The second load shape that has been studied is a triangular load shape. These two load shapes have been modeled both with different numbers of point loads and as distributed line loads to see how the dynamic response of the bridges is affected and thereby find what level of accuracy that is required to capture the full effect of the load spreading. For the bridges with integrated backwalls the supports were also modeled as springs with varying stiffness to see how the dynamic response was affected. The response was measured in terms of vertical acceleration and bending moment.

From the simulations the conclusion can be drawn that the triangular load shape gives significantly lower bridge responses than the Eurocode load shape. It is further found that modeling the axle loads with point loads can give spurious acceleration peaks, which in the case of bridges with integrated backwalls often are critical. For these bridges it is necessary to enhance the accuracy of the load spread, either by increasing the number of point loads or using a distributed line load. From the spring support simulations, it can be seen that support stiffness has great influence on the dynamic response of bridges with integrated backwalls. For certain values the response is increased, whereas for other values a large reduction is obtained.

Keywords: short span railway bridges, dynamic response, finite element analysis, load spread, support stiffness 



\section{Sammanfattning}

I denna avhandling har effekten av hur axellaster sprids genom ballast och effekten av stödens styvhet undersökts för korta järnvägsbroar. Två typer av broar, fritt upplagda broar och ändskärmsbroar, har modellerats med balkelement i 2D. Vid analys av lastspridningen genom ballast har två typer av lastformer använts. Den ena lastformen är den som föreslås i Eurokod varvid axellasten delas upp i tre punktlaster där 50\% verkar på slipern under axeln och 25\% verkar på respektive intilliggande slipers. Lasten distribueras sedan vidare genom slipersen och ballasten. Den andra lastformen som har studerats är en triangulär lastform. De två lastformerna har modellerats dels med olika antal punktlaster och dels som utbredda linjelaster för att se hur den dynamiska responsen av broarna påverkas och därmed avgöra vilken nivå av noggrannhet som krävs för att fånga den fulla effekten av lastspridningen. För ändskärmsbroar har stöden även modellerats som fjädrar med varierande styvhet för att se hur den dynamiska responsen påverkas. Responsen mäts i termer av vertikal acceleration och böjmoment.

Från simuleringarna kan slutsatsen dras att den triangulära lastformen ger märkbart lägre respons än Eurokod-lastformen. Vidare har det framkommit att modellering av axellaster med punktlaster kan ge falska accelerationstoppar som i fallet med ändskärmsbroarna ofta är kritiska. För dessa broar är det nödvändigt att öka noggrannheten av lastspridningen, antingen genom att öka antalet punktlaster eller genom att använda en utbredd linjelast. Från simuleringarna med fjäderstöd kan man se att stödens styvhet har stor påverkan på den dynamiska responsen för ändskärmsbroar. För vissa styvhetsvärden ökar responsen, medan den för andra kan ge en betydande reduktion.

Nyckelord: korta järnvägsbroar, dynamisk respons, analys med finita element, lastspridning, stödstyvhet 



\section{Contents}

Preface

Abstract

Sammanfattning $\quad$ v

Nomenclature $\quad$ xi

1 Introduction 1

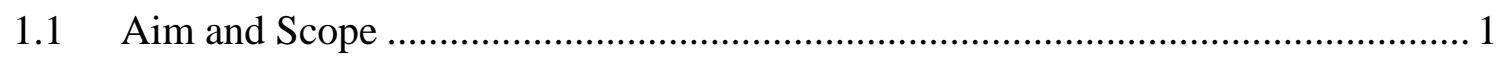

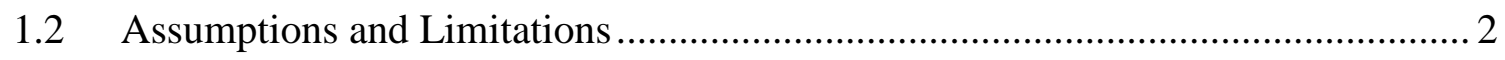

2 Literature Review 3

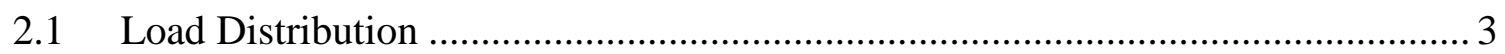

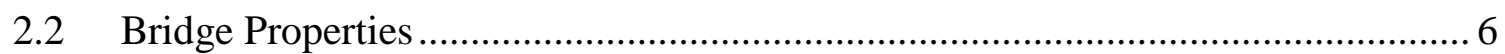

2.3 Soil-Foundation Interaction........................................................................ 7

3 Theory 9

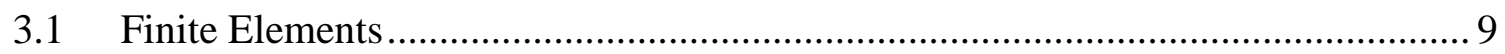

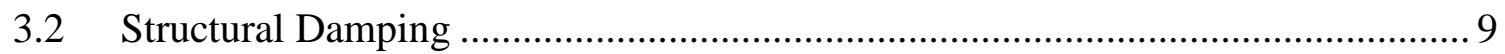

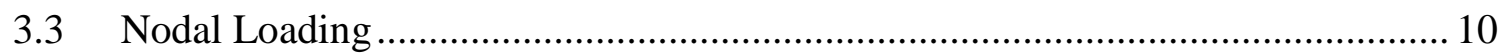

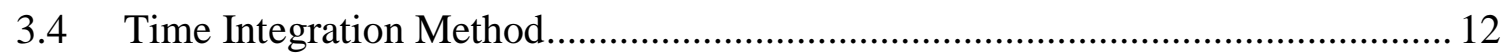

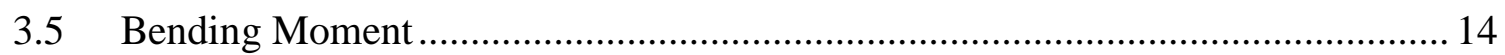

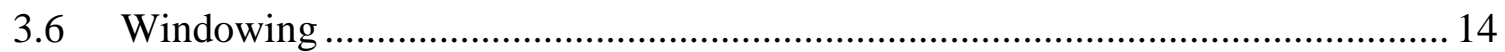

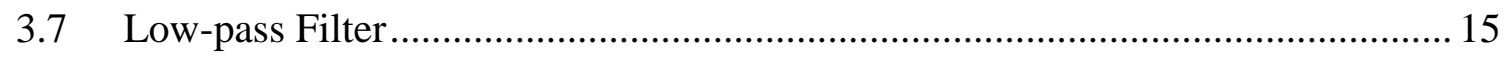

4 Bridge Models $\quad 17$

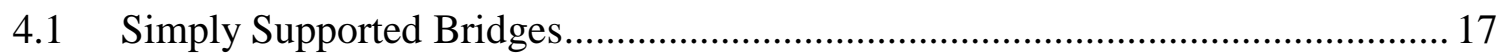

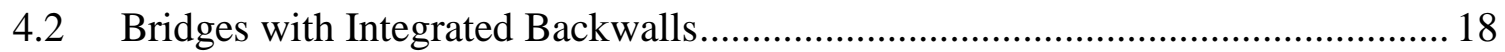

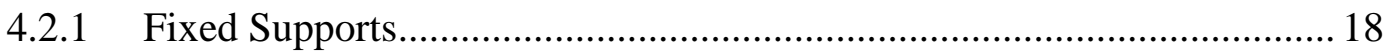

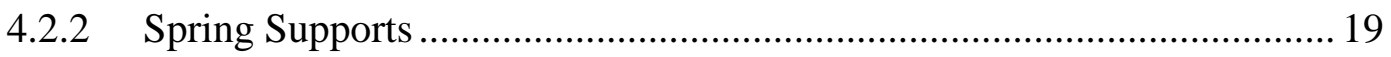

5 Loads $\quad 21$

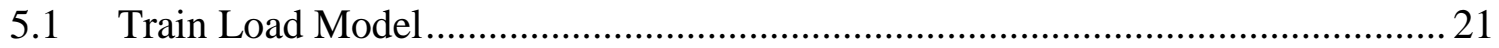




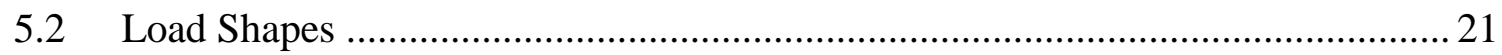

5.3 Programming the Load Shapes in Matlab .......................................................... 23

5.3.1 Eurocode Point Load Function ............................................................... 24

5.3.2 Eurocode Distributed Line Load Function............................................... 25

5.3.3 Triangle Point Load Function …............................................................. 26

5.3.4 Triangle Distributed Line Load Function.................................................. 27

$6 \quad$ Quality Assurance $\quad 29$

6.1 Choice of Mesh Size and Time Step …............................................................. 29

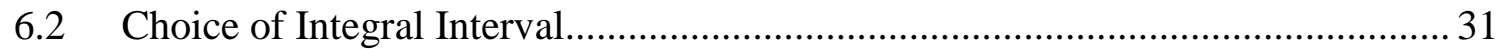

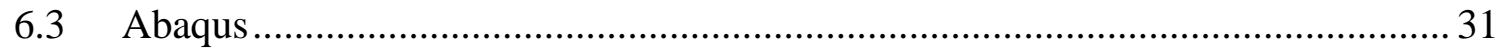

6.3.1 Amplitude Functions ......................................................................... 33

7 Results $\quad 35$

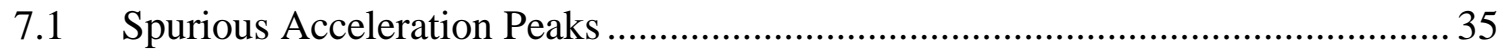

7.2 Accelerations - Simply Supported Bridges........................................................ 37

7.2.1 Point Loads versus Distributed Line Loads ............................................. 37

7.2.2 Distributed Eurocode Loads versus Distributed Triangle Loads .............. 42

7.3 Bending Moments - Simply Supported Bridges .................................................. 44

7.3.1 Point Loads versus Distributed Line Loads ........................................... 46

7.3.2 Distributed Eurocode Loads versus Distributed Triangle Loads ............. 48

7.4 Accelerations - Bridges with Integrated Backwalls.............................................. 49

7.4.1 Point Loads versus Distributed Line Loads .............................................. 49

7.4.2 Distributed Eurocode Loads versus Distributed Triangle Loads .............. 54

7.5 Bending Moments - Bridges with Integrated Backwalls ...................................... 56

7.5.1 Point Loads versus Distributed Line Loads .............................................. 57

7.5.2 Distributed Eurocode Loads versus Distributed Triangle Loads ............. 59

7.6 Bridges with Integrated Backwalls with Spring Supports..................................... 59

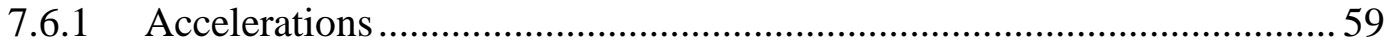

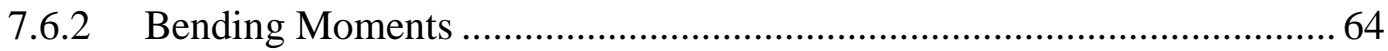

$8 \quad$ Conclusions and Further Research $\quad 67$

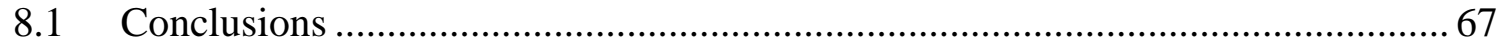

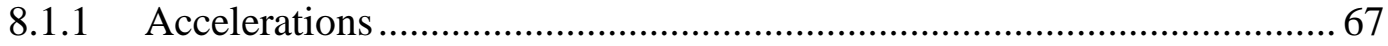

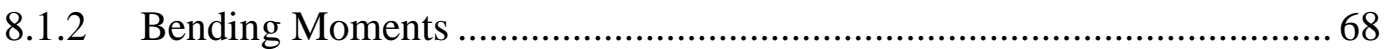

8.1.3 Bridges with Integrated Backwalls with Spring Supports ...................... 69

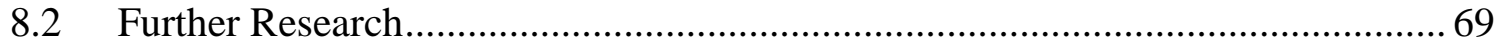


$\begin{array}{lll}\text { A Matlab Code } & 73\end{array}$

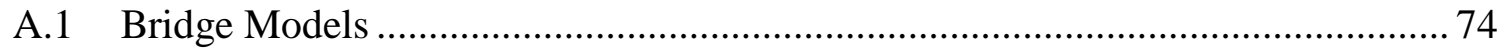

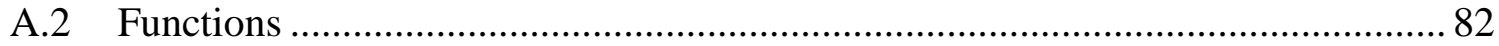

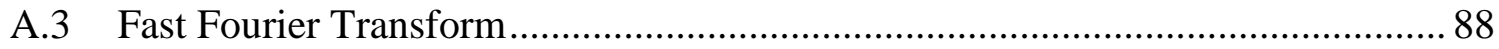





\section{Nomenclature}

$\alpha \quad$ Rayleigh damping coefficient associated with the mass matrix

$\beta \quad$ Rayleigh damping coefficient associated with the stiffness matrix

$b \quad$ Length of Eurocode load distribution under one sleeper [m]

[c] Element damping matrix

c Train speed $[\mathrm{m} / \mathrm{s}]$

$d_{p} \quad$ Distance between point loads within the load shapes [m]

EC3-15 Eurocode load distribution represented by 3-15 point loads

ECdist Eurocode distributed line load

EI Bending stiffness $\left[\mathrm{Nm}^{2}\right]$

$\left\{F_{e}\right\} \quad$ Nodal load vector $[\mathrm{N}, \mathrm{Nm}]$

$\left\{F_{S}\right\} \quad$ Section force vector $[\mathrm{N}, \mathrm{Nm}]$

$h \quad$ Height of ballast layer [m]

HSLM High Speed Load Model

[k] Element stiffness matrix

$k \quad$ Spring stiffness [N/m]

$L \quad$ Bridge length [m]

$L_{e} \quad$ Element length [m]

$L_{e s} \quad$ Length of end spans [m]

$l_{s} \quad$ Length of triangular load spread [m]

[m] Element mass matrix

$M \quad$ Mass/length $[\mathrm{kg} / \mathrm{m}]$

$\lfloor N\rfloor \quad$ Shape/interpolation functions

$n_{0}, f_{1} \quad$ Fundamental frequency $[\mathrm{Hz}]$

$N_{p} \quad$ Number of point loads representing the load shapes

$\omega_{i}, \omega_{j} \quad$ Natural circular frequencies of modes $i$ and $j$, used to define Rayleigh damping [rad/s]

$P \quad$ Axle load $[\mathrm{N}]$

$R^{\prime} \quad$ Reduction of acceleration [\%]

$\Delta t \quad$ Time step/time increment [s]

Tri17-21 Triangle load distribution represented by 17-21 point loads

Tridist Triangle distributed line load

$v \quad$ Train speed $[\mathrm{km} / \mathrm{h}]$

$\Delta x \quad$ Interval size of distributed line loads [m]

$\zeta \quad$ Damping ratio 



\section{Chapter 1}

\section{Introduction}

High speed trains have lately become more common and are today used in countries such as France, Spain, Italy, Japan and China. The development is pushed forward to decrease the travel time between cities, as a more environmentally-friendly alternative to flying. As the speed of the trains increases, new requirements emerge on the rails and the railway bridges.

When designing railway bridges aimed for high speed trains, the dynamic requirements are often critical. Today, when using numerical analysis, the train axle loads are often modeled as moving point forces. However, one effect of the ballast underneath the track is to spread these point forces. A previous master thesis has shown that the spread in the ballast significantly reduces the dynamic response of the bridge (Rehnström \& Widén, 2012). In general, the reduction of the response is greater in bridges with short span lengths. The thesis indicates that modeling the axle loads as point forces is conservative, and the response of the bridge is overestimated with overdesign as a possible consequence. In other words, the models used today often do not fully reflect real load cases of trains passing a bridge, and thus the dynamic response of the modeled bridge does not correspond to reality.

\subsection{Aim and Scope}

The purpose of the research has been to study the load spreading aspect of the ballast in detail and to propose simple load models which take the spreading effect in the ballast into consideration. Such simple models are interesting for bridge engineers who need to perform dynamic analyses. Two types of bridges have been studied; simply supported bridges and bridges with integrated backwalls. The studied bridges have spans between five and ten meters.

It is previously known that simple beam models of bridges with integrated backwalls can have problems with high accelerations due to the end spans. Therefore, not only has the load spreading effect studied, but also how the stiffness of the supports affects the dynamic response of the bridges. This was done by modeling the supports as springs of varying stiffness.

To investigate how the load models affect the bridges, the response was measured in terms of vertical acceleration and bending moment. The simulations were made in Matlab and to 
verify the results, a selected number of simulations were also made in the commercial finite element software Abaqus.

Two types of load models are studied, the first one has the shape prescribed in Eurocode where the axle load is first distributed over three sleepers with $50 \%$ of the load acting on the middle sleeper and 25\% acting on the two adjacent sleepers respectively, and from there the loads are distributed through the sleepers and the ballast. The second one is a triangular load shape. The load shapes are further described in section 5.2.

\subsection{Assumptions and Limitations}

Within the limits of this research three main restrictions have been made to reduce the extent of the study.

1. All bridges in this thesis have been modeled with 2D beam elements. Certain 3D effects of the bridge structures are thereby missed.

2. The materials have been assumed to be linearly elastic.

3. The bridges have been assumed to be viscously damped.

4. The axle loads to be distributed in the ballast are represented by point forces instead of springs. In reality trains are vibrating as they move and thus imply vertical accelerations in the axles and wheels. The train load acting on a bridge should thereby be calculated considering both the acceleration of gravity and the vertical acceleration of the train. By using point forces the load is instead represented by the train weight only. The variation caused by the vertical acceleration is thereby neglected and the load is instead assumed to be constant. The full dynamic response of the bridges is thereby missed.

5. The ballast may also contribute with additional stiffness to the total bridge stiffness. This aspect is not considered in this study.

6. When modeling the soil-foundation interaction, the damping of the fill material and its additional mass has not been considered. 


\section{Chapter 2}

\section{Literature Review}

\subsection{Load Distribution}

Rehnström and Widén (2012) have studied how the axle loads are spread through the ballast and how considering the ballast spreading effect of the axle loads affects the response, i.e. the vertical acceleration, of three different bridges as trains are passing. By implementing a 2D finite element model, a vertical stress distribution at the interface between the ballast and the bridge superstructure from the axle load on the rail was found. Figure 2.1 shows an example of calculated stress distributions for ballast heights of $0.4 \mathrm{~m}$ and $0.65 \mathrm{~m}$ and for three different values of the ballast stiffness, $E_{b}$. Shown in the figures is also the load distribution prescribed in Eurocode EN 1991-2. From the figure it can be seen that, especially when using a ballast height of $0.65 \mathrm{~m}$, the shape of the calculated stress distributions could be approximated with a triangle with a base of approximately three meters. When analyzing the response of the three bridges when using ballast distribution, the above mentioned load distribution was represented by 22 point loads. It was shown that the maximum vertical accelerations of the bridge decks were significantly lowered when using load distributions instead of single point loads.

The above mentioned results from Rehnström and Widén have been the basis for the choice of studied load shapes in this master thesis.

Johansson et al. (2011) have studied how the bridge response is influenced by a number of load distributing models. The load model proposed in Eurocode, consisting of three point loads acting on three adjacent sleepers, was analyzed in 2D. The study was performed on 1734 simply supported bridges with spans between 8-60 m, fundamental frequencies between $1.5-80 \mathrm{~Hz}$ and damping ratios between $0.5-3 \%$. The effect of the load distribution, $k_{\mathrm{LS}}$, was defined as

$$
k_{\mathrm{LS}}=\frac{a_{\mathrm{max}, \mathrm{MLS}}}{a_{\mathrm{max}, \mathrm{ULS}}}
$$

where $a_{\max , \mathrm{MLS}}$ and $a_{\max , \mathrm{ULS}}$ are the maximum vertical accelerations with and without load distribution, respectively.

The study intended that the advantageous effect of the load distribution is related to the fundamental frequency of the bridge. If the bridge has a fundamental frequency less than 

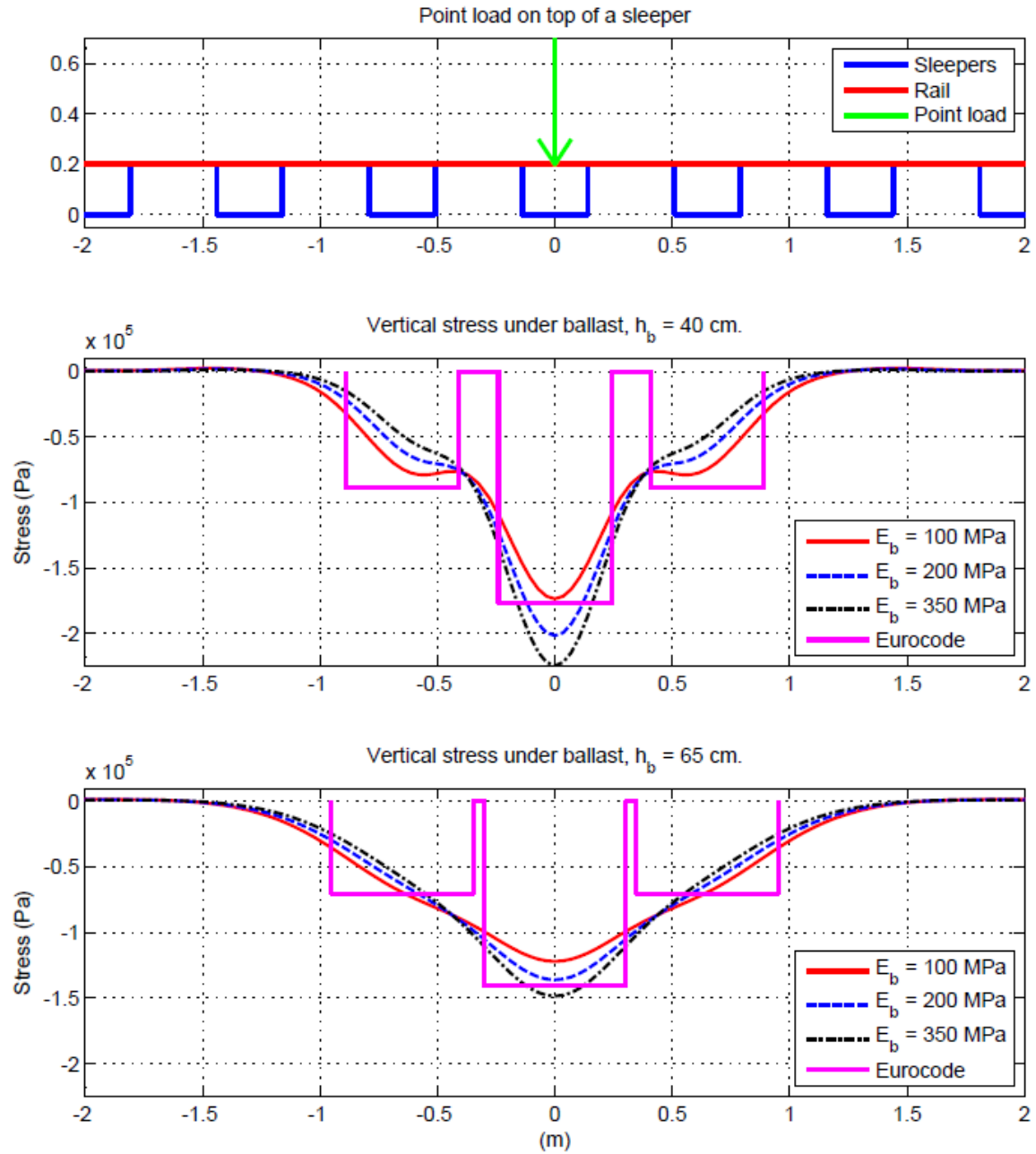

Figure 2.1: Calculated stress distributions for different values of the ballast stiffness, $E_{b}$, compared with the distribution prescribed in Eurocode (Rehnström \& Widén, 2012, p. 12).

$8 \mathrm{~Hz}$, the effect of the load distribution is negligible, i.e. $k_{\mathrm{LS}} \approx 1$. The reduction factor is then decreasing linearly to $50 \mathrm{~Hz}$ where $k_{\mathrm{LS}} \approx 0.4$. A plot of the load distributing effect against fundamental frequency is depicted in figure 2.2.

Further, five load distributing models were analyzed in 3D. One was the model prescribed in Eurocode including load distribution through the ballast from three adjacent sleepers, see figure 2.3a. Another model is idealizing each axle load as a distributed triangle load acting over a length of three meters, see figure $2.3 \mathrm{~b}$. The acceleration results from a train passage over a short span bridge when using the triangle load distribution were compared to the results of a model where the rail and ballast were modeled with beam and solid elements, respectively. It was found that the triangular load shape gave the most similar acceleration results to the model with rail and ballast of all load shapes used in the study.

Martínez-Rodrigo et al. (2009) implemented a model which simulates the axle loads as distributed load-prints when entering and exiting the bridge, whereas point loads are used while the axles are on the bridge. In this way, the distributive effect of rails, sleepers and ballast was considered and problems with unrealistically high frequency modal distributions as the train axles enter and exit the bridge were avoided. 


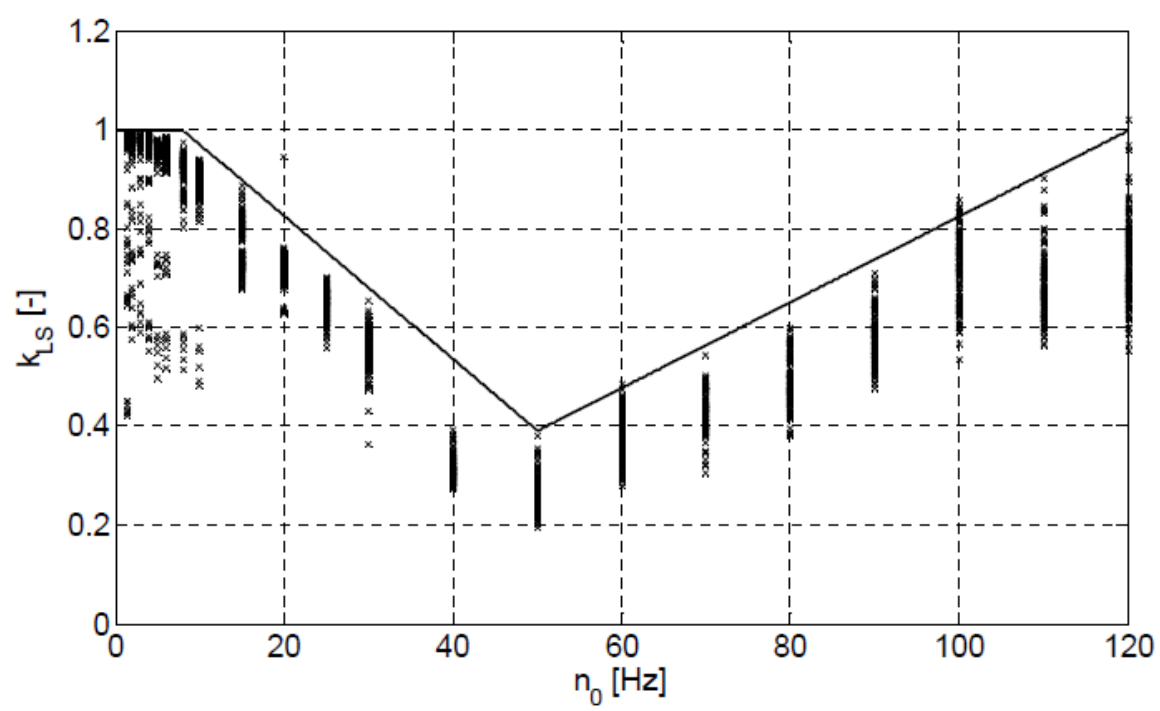

Figure 2.2: $k_{\mathrm{LS}}$ for different fundamental frequencies. The continuous line shows a simplified relation proposed in the report (Johansson et al., 2011, p. 35).

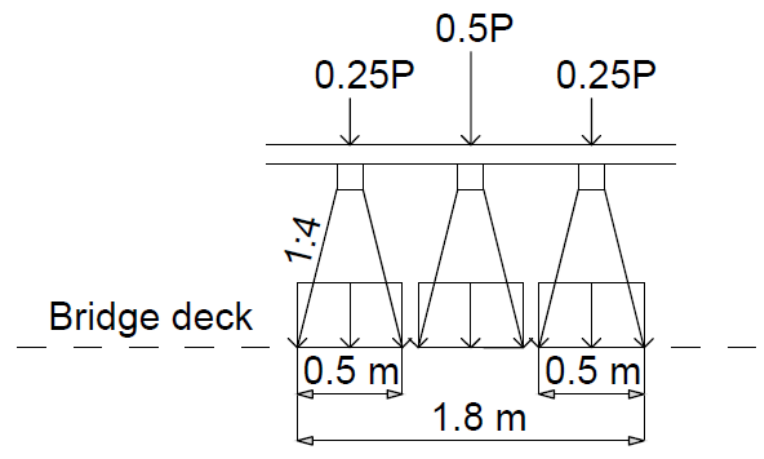

(a)

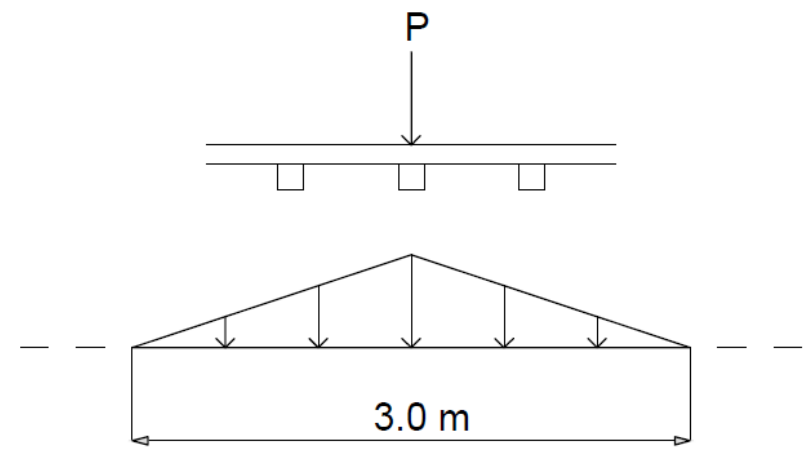

(b)

Figure 2.3: (a) Load distribution prescribed in Eurocode (b) Triangular load distribution, after Johansson et al. (2011). Only the longitudinal distributions are shown since all analyses in this thesis are in 2D.

Museros et al. (2002) found a relation between reductions of the accelerations, $R^{\prime}$, and the wavelength, $\lambda=$ velocity/fundamental frequency. The reductions were obtained comparing the accelerations when using load distribution and when using single point loads and were calculated as

$$
R^{\prime}=\frac{a_{\max , c}-a_{\max , d}}{a_{\max , c}} \cdot 100
$$

The load distribution used in the article was a uniformly distributed line load acting over a length of approximately $1 \mathrm{~m}$. Figure 2.4 shows the reduction of the accelerations as function of the wavelength. The analytical expression for the lower bound is

$$
R^{\prime}=127.35 \lambda^{-1.9}
$$




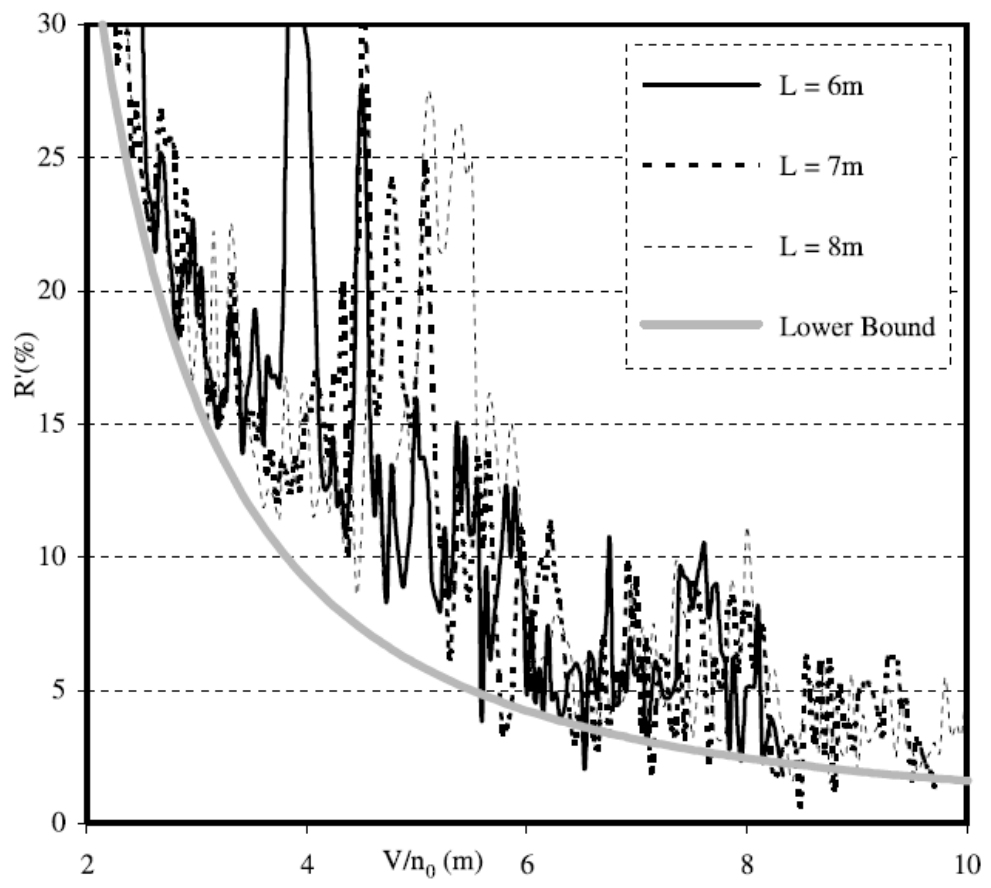

Figure 2.4: Reduction of the accelerations, $R^{\prime}$, as a function of the wavelength (Museros et al., 2002).

\subsection{Bridge Properties}

Johansson et al. (2011) analyzed over 1000 railway bridges along three railway lines in Sweden. Analyzing each and every one of the bridges in detail would have been extremely time consuming and a probabilistic method was used instead. Unknown parameters such as bending stiffness and mass were then assumed to be stochastic. Boundaries for the stochastic variables were defined by compiling data from a representative number of bridges, in this case 45 beam and slab bridges.

For the fundamental frequency a log-linear relation to the bridge length was used, which previously has been confirmed in several publications, e.g. Frýba (1996). The fundamental frequency can be calculated as

$$
\log \left(n_{0}\right)=b_{n 0}+a_{n 0} \log (L) \pm t_{\alpha / 2} S_{e} \sqrt{1+\frac{1}{n}+\frac{\left(\log (L)-\log \left(L_{m}\right)\right)^{2}}{S_{x x}}}
$$

with $a_{n 0}, b_{n 0}, t_{\alpha / 2}, s_{e}, n, \log \left(L_{m}\right)$ and $S_{x x}$ given in table 2.1 below.

Table 2.1: Coefficients to use in equation (2.4) for a $90 \%$ prediction interval.

$$
a_{n 0}[\mathrm{~Hz}] b_{n 0}[-] \quad t_{\alpha / 2}[-] \quad s_{e}[-] \quad n[-] \log \left(L_{m}\right)[-] \quad S_{x x}[-]
$$

$\begin{array}{lllllll}-1.57 & 2.67 & 1.65 & 0.10 & 46 & 1.06 & 3.32\end{array}$


In the same way, a linear relation was found between the bridge's mass and length. The mass can be calculated as

$$
M=b_{M}+a_{M} L \pm t_{\alpha / 2} S_{e} \sqrt{1+\frac{1}{n}+\frac{\left(L-L_{m}\right)^{2}}{S_{x x}}}
$$

with $a_{M}, b_{M}, t_{\alpha / 2}, s_{e}, n, L_{m}$ and $S_{x x}$ given in table 2.2 below.

Table 2.2: Coefficients to use in equation (2.5) for a $90 \%$ prediction interval.

\begin{tabular}{ccccccc}
$a_{M}\left[\right.$ ton $\left./ \mathrm{m}^{2}\right]$ & $b_{M}[\mathrm{ton} / \mathrm{m}]$ & $t_{\alpha / 2}[-]$ & $s_{e}\left[\mathrm{ton} / \mathrm{m}^{2}\right]$ & $n[-]$ & $L_{m}[\mathrm{~m}]$ & $S_{x x}[\mathrm{~m}]$ \\
\hline 0.68 & 7.65 & 1.65 & 3.18 & 41 & 13.2 & 2385.8
\end{tabular}

Equations (2.4) and (2.5) are valid for single track railway bridges.

\subsection{Soil-Foundation Interaction}

In structural analysis, supports are often modeled as fixed in the vertical direction. However, in reality supports are never completely fixed. The supporting ground that the foundation is constructed on allows for a certain degree of flexibility, depending on the nature and deformability of the soil. Gazetas (1991) developed an engineering procedure to estimate dynamic spring and dashpot coefficients of flexibly-supported foundations subjected to dynamic loads. 



\section{Chapter 3}

\section{Theory}

\subsection{Finite Elements}

The finite elements used when modeling the bridge structures are Euler-Bernoulli 2D beam elements. Axial deformations are omitted, giving the elements two degrees of freedom (d.o.f.) at each node; vertical translation and rotation (Cook et al., 2002, p. 24). The stiffness matrix of an element becomes a 4 by 4 matrix as seen below

$$
[\boldsymbol{k}]=\frac{E I_{Z}}{L^{3}}\left[\begin{array}{cccc}
12 & 6 L & -12 & 6 L \\
6 L & 4 L^{2} & -6 L & 2 L^{2} \\
-12 & -6 L & 12 & -6 L \\
6 L & 2 L^{2} & -6 L & 4 L^{2}
\end{array}\right]
$$

and the consistent mass matrix is

$$
[\boldsymbol{m}]=\frac{m}{420}\left[\begin{array}{cccc}
156 & 22 L & 54 & -13 L \\
22 L & 4 L^{2} & 13 L & -3 L^{2} \\
54 & 13 L & 156 & -22 L \\
-13 L & -3 L^{2} & -22 L & 4 L^{2}
\end{array}\right]
$$

When modeling the bridge structures in Abaqus, the same elements as above are used, denoted B23.

\subsection{Structural Damping}

To model the internal structural damping of the bridges, Rayleigh damping was used. This damping is defined (see for example Chopra, 2012, p. 457) as 


$$
[\boldsymbol{c}]=\alpha[\boldsymbol{m}]+\beta[\boldsymbol{k}]
$$

where

$$
\alpha=\zeta \frac{2 \omega_{i} \omega_{j}}{\omega_{i}+\omega_{j}}, \quad \beta=\zeta \frac{2}{\omega_{i}+\omega_{j}}
$$

The coefficients $\alpha$ and $\beta$ are determined from two eigenmodes $i$ and $j$ of the structure, both assumed to have the same damping ratio $\zeta$. The modes should be chosen so that the value of the damping ratio is reasonable for all modes contributing significantly to the response. Figure 3.1 shows how the damping ratio varies with the frequency. For the bridges studied in this thesis the first and third modes were used to determine the Rayleigh coefficients.

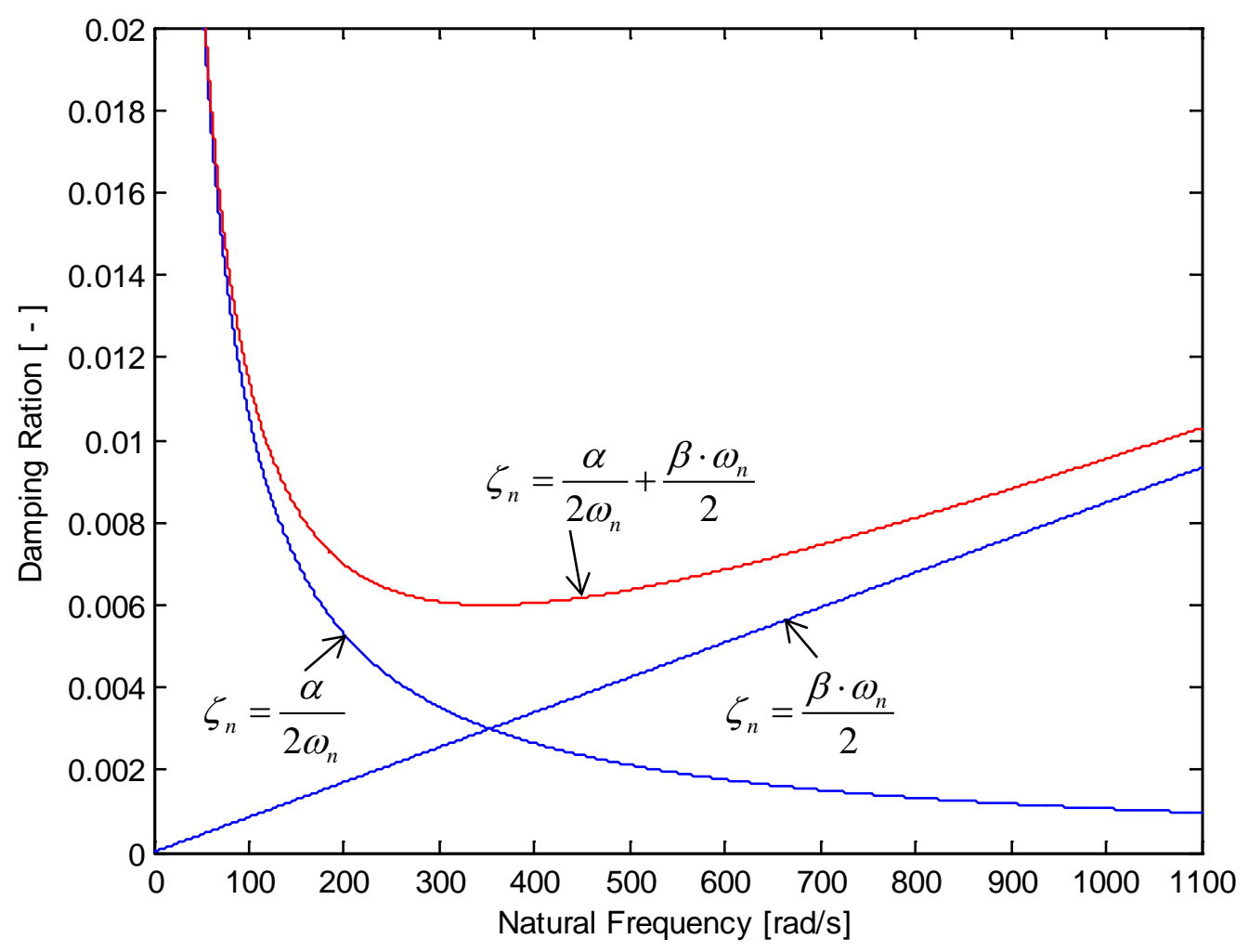

Figure 3.1: Rayleigh damping.

\subsection{Nodal Loading}

In finite element analysis loads can only be applied at nodes. When a load is acting in between two nodes, the load needs to be transferred to the nodes. This is done by using shape functions, also known as interpolation functions, denoted $[N\rfloor$. The nodal loads are calculated as 


$$
\left\{F_{e}\right\}=\left\{\begin{array}{c}
F_{1} \\
M_{1} \\
F_{2} \\
M_{2}
\end{array}\right\}=P\lfloor N\rfloor^{T}=P\left[\begin{array}{c}
1-\frac{x}{L} \\
0 \\
\frac{x}{L} \\
0
\end{array}\right\rfloor
$$

when using Timoshenko shape functions, i.e. linear interpolation, and

$$
\left\{F_{e}\right\}=\left\{\begin{array}{c}
F_{1} \\
M_{1} \\
F_{2} \\
M_{2}
\end{array}\right\}=P\lfloor N\rfloor^{T}=P\left[\begin{array}{c}
1-3\left(\frac{x}{L}\right)^{2}+2\left(\frac{x}{L}\right)^{3} \\
x\left(1-\frac{x}{L}\right)^{2} \\
3\left(\frac{x}{L}\right)^{2}-2\left(\frac{x}{L}\right)^{3} \\
\frac{x^{2}}{L}\left(\frac{x}{L}-1\right)
\end{array}\right]
$$

when using Euler-Bernoulli shape functions, i.e. cubic interpolation. $x$ is the distance from the load to the first node of the element. For all point load distributions in this thesis, Timoshenko shape functions are used, while Euler-Bernoulli are used for the distributed line loads. EulerBernoulli shape functions give the same results as Timoshenko shape functions for the point load distributions. This has been verified for a number of bridges.

When modeling the axle loads as a distributed line load, the following integral is used to calculate the nodal loads

$$
\left\{F_{e}\right\}=\int_{x_{1}}^{x_{2}}\lfloor N\rfloor^{T}\{q(x)\} d x
$$

where $x_{1}$ and $x_{2}$ are the $\mathrm{x}$-coordinates of the load, see figure 3.2. The integral is calculated numerically with the trapezoidal rule. The load function $q(x)$ is defined in the same coordinate system as the bridge, placed next to the bridge, see figure 3.3. The load function is then moved over the bridge and for each time step the numerical integral is calculated for every element. 


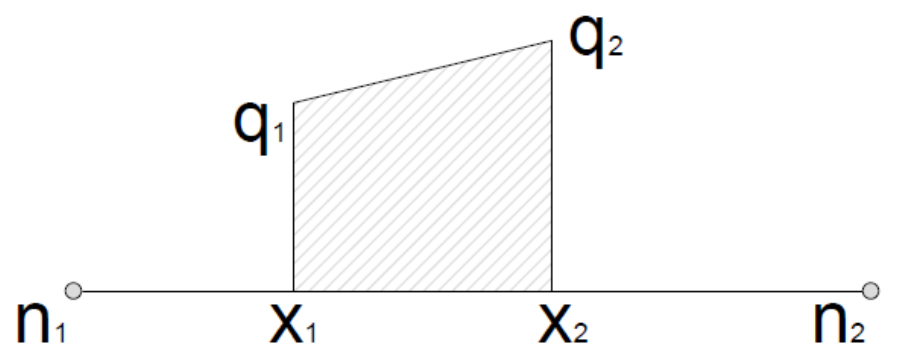

Figure 3.2: Schematic picture of the load acting on an element.

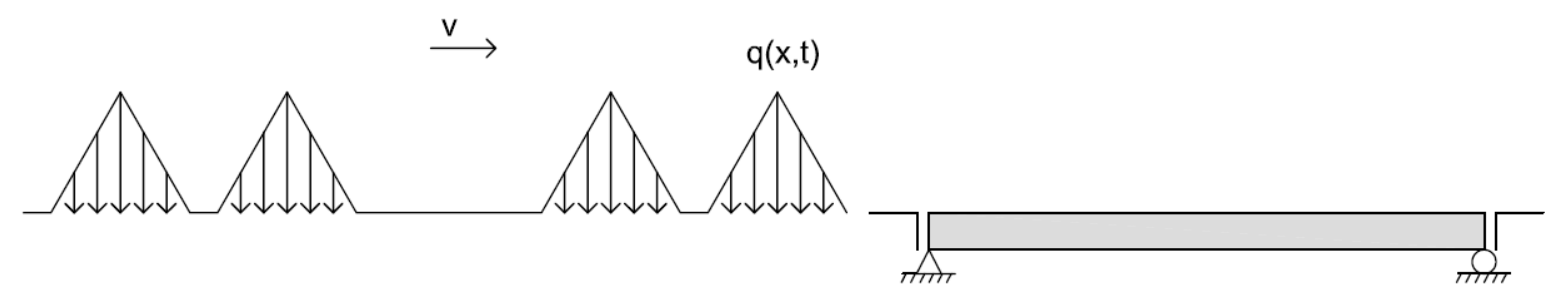

Figure 3.3: Distributed line load, $q(x, t)$.

\subsection{Time Integration Method}

The time integration method used in this thesis is the constant average acceleration method, also known as Newmark's method with $\gamma=1 / 2$ and $\beta=1 / 4$ (Chopra, 2012, p. 175). Here, $\gamma$ and $\beta$ are algorithm parameters defining the variation of acceleration over a time step and determining the stability and accuracy characteristics of the method. This is an implicit direct integration method which is unconditionally stable for any time step, $\Delta t$. The equation to be solved at every time step is

$$
m \ddot{u}_{i+1}+c \dot{u}_{i+1}+k u_{i+1}=p_{i+1}
$$

where $\ddot{u}_{i+1}$ and $\dot{u}_{i+1}$ can be expressed as

$$
\begin{gathered}
\ddot{u}_{i+1}=\frac{4}{(\Delta t)^{2}}\left(u_{i+1}-u_{i}\right)-\frac{4}{\Delta t} \dot{u}_{i}-\ddot{u}_{i} \\
\dot{u}_{i+1}=\frac{2}{\Delta t}\left(u_{i+1}-u_{i}\right)-\dot{u}_{i}
\end{gathered}
$$

Substituting equations (3.9) and (3.10) into equation (3.8) at time $i+1$ gives

$$
\hat{k} u_{i+1}=\hat{p}_{i+1}
$$


where $\hat{k}$ and $\hat{p}$ are

$$
\begin{gathered}
\hat{k}=k+\frac{2}{\Delta t} c+\frac{4}{(\Delta t)^{2}} m \\
\hat{p}_{i+1}=p_{i+1}+\left[\frac{4}{(\Delta t)^{2}} m+\frac{2}{\Delta t} c\right] u_{i}+\left[\frac{4}{\Delta t} m+c\right] \dot{u}_{i}+m \ddot{u}_{i}
\end{gathered}
$$

The displacement at time $i+1$ can now be calculated since $\hat{k}$ and $\hat{p}$ are known from the system properties $m, c$ and $k$, and the state of the system at time $i$ defined by $u_{i}, \dot{u}_{i}$ and $\ddot{u}_{i}$. Equation (3.11) yields

$$
u_{i+1}=\frac{\hat{p}_{i+1}}{\hat{k}}
$$

With the displacement known, the acceleration and the velocity at time $i+1$ can be calculated from equations (3.9) and (3.10). To be able to start the time-stepping computations, the acceleration at time $t=0$ is needed. This can be calculated from the equation of motion as

$$
\ddot{u}_{0}=\frac{p_{0}+c \dot{u}_{0}+k u_{0}}{m}
$$

When running implicit dynamic analyses in Abaqus, it uses the Hilber-Hughes-Taylor (HHT) method (Dassault Systèmes Simulia Corp., 2011a). This is a generalization of the Newmark method with controllable numerical damping. The amount of numerical damping is controlled by the parameters $\alpha, \beta$ and $\gamma$. These parameters can be defined by the user in Abaqus to adjust the amount of numerical damping. In this thesis, $\alpha$ has been set to $0, \beta$ to $1 / 4$ and $\gamma$ to $1 / 2$ meaning there is no numerical damping and that the HHT method becomes the constant average acceleration method. This is done to make the results from Abaqus comparable with the results from Matlab. Note that $\alpha$ and $\beta$ are not to be confused with the Rayleigh damping coefficients in section 3.2. 


\subsection{Bending Moment}

The section forces, including bending moments, are calculated in the nodes at every time step $i$ as

$$
\left\{F_{s}\right\}=\left\{\begin{array}{c}
F_{s 1} \\
M_{s 1} \\
F_{s 2} \\
M_{s 2}
\end{array}\right\}=[\boldsymbol{k}]\left\{u_{i}\right\}
$$

where $\boldsymbol{k}$ is the stiffness matrix of the element and $u_{i}$ is the displacement vector. At every node, except at the ends of the bridge, the bending moment is calculated twice, one time for each element that the node is part of. The values considered in the results are calculated as the mean values of the two bending moments, $M_{j, i}$ and $M_{j, i+1}$, see figure 3.4.

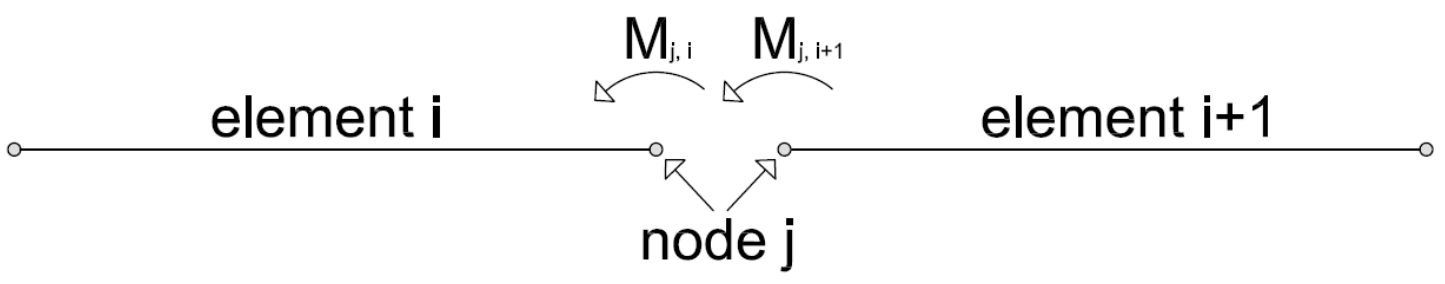

Figure 3.4: Every node, except at the ends of the bridge, gets two values of the bending moment, $M_{j, i}$ and $M_{j i+1}$. When interpreting the results, the mean value of the two is considered.

\subsection{Windowing}

To analyze which frequencies and modes that contribute to the response of the bridges, the acceleration signal was transformed from time domain to frequency domain. This was done with an algorithm called Fast Fourier Transform (FFT) (Agilent Technologies, 2000, p. 25). To save computational time, the time of the simulations was set to capture the train passage and only a few periods of free vibrations afterwards. Thereby, the acceleration signal starts at zero but does not necessarily end at zero. However, the FFT algorithm is based upon the assumption that this time record is repeated throughout time. This is not the case when the time record has been cut off after a few periods of free vibrations, and problems with leakage can occur. To avoid leakage of energy into other frequencies in the frequency domain due to this cut-off, a window is applied to the signal which gives it the value of zero in the beginning and in the end (Agilent Technologies, 2000, p. 36). In this thesis a Tukey window is used. The Tukey window is a rectangular window with the shape of half a cosine period at the ends (The MathWorks, Inc., 2012), see figure 3.5. 

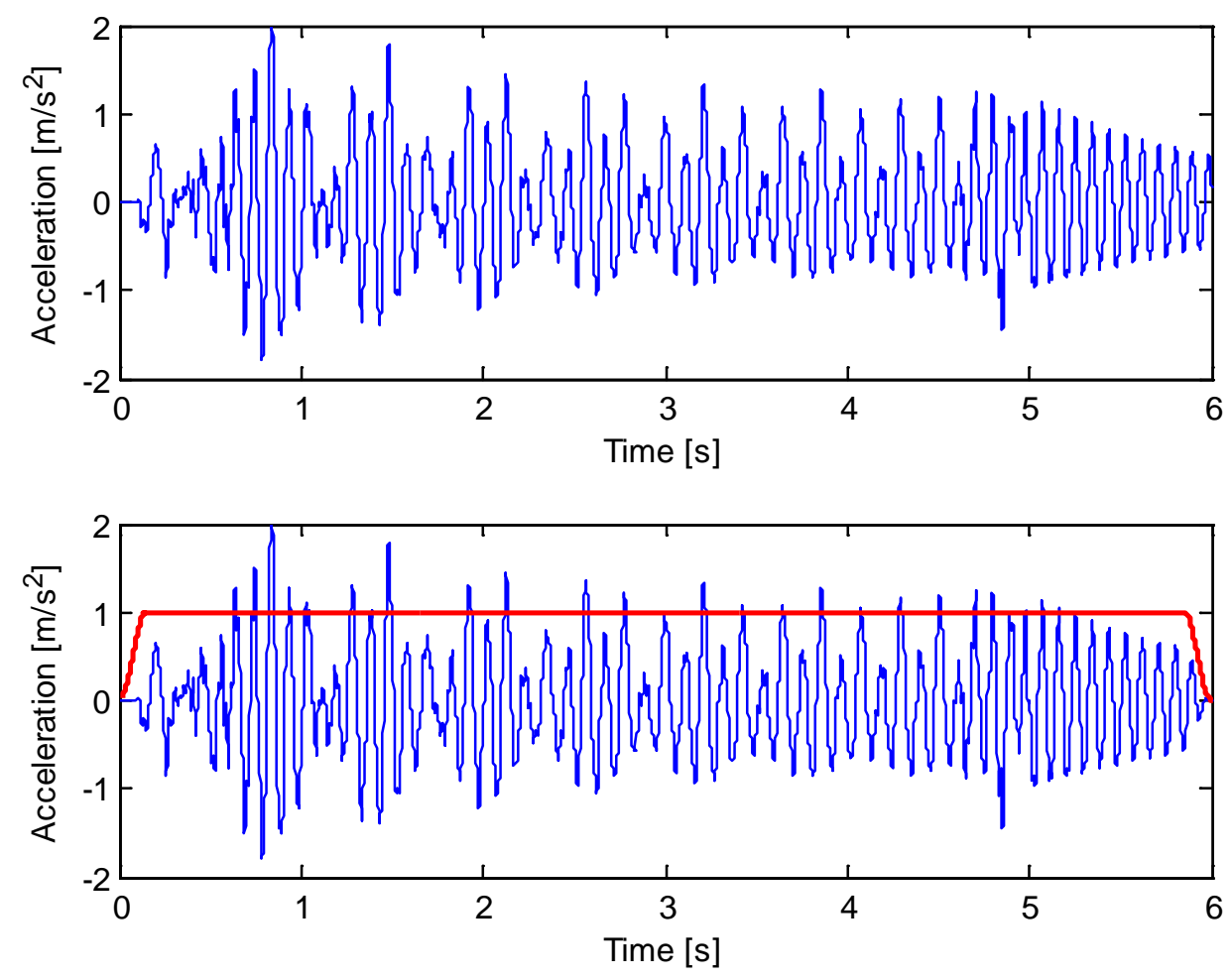

Figure 3.5: Acceleration plot in time domain. A Tukey window function has been applied to the lower curve. The red line visualizes the window function.

\subsection{Low-pass Filter}

The rate at which the response of the bridge structures are sampled, called the sampling frequency $f_{\mathrm{s}}[\mathrm{Hz}]$, is inversely proportional to the time step. Thus, the sampling frequency increases as the time step is decreased. For example, with a time step of $0.0001 \mathrm{~s}$ the sampling frequency is $10 \mathrm{kHz}$, meaning that the highest input frequency is just below $5 \mathrm{kHz}$ according to the Nyquist Criterion (Agilent Technologies, 2000, p. 30-31). In Eurocode it is prescribed that only frequencies up to the highest of $30 \mathrm{~Hz}, 1.5 f_{1}$ or $f_{3}$ need to be considered, where $f_{1}$ and $f_{3}$ are the first and third eigenfrequencies of the studied structure, respectively (CEN, 2004). To limit the input frequency range, a low-pass filter is applied. A low-pass filter passes all desired frequencies below a certain cutoff frequency whilst rejecting the frequencies above (Agilent Technologies, 2000, p. 31). Figure 3.6 shows an unfiltered and filtered acceleration plot in time domain, respectively. In this thesis a cutoff frequency of $1.2 f_{3}$ is used.

The filter used in this thesis is a Butterworth lowpass filter, see figure 3.7. The Butterworth filter is characterized by a magnitude response that is maximally flat in the passband and monotonic overall (The MathWorks, Inc., 2012). 

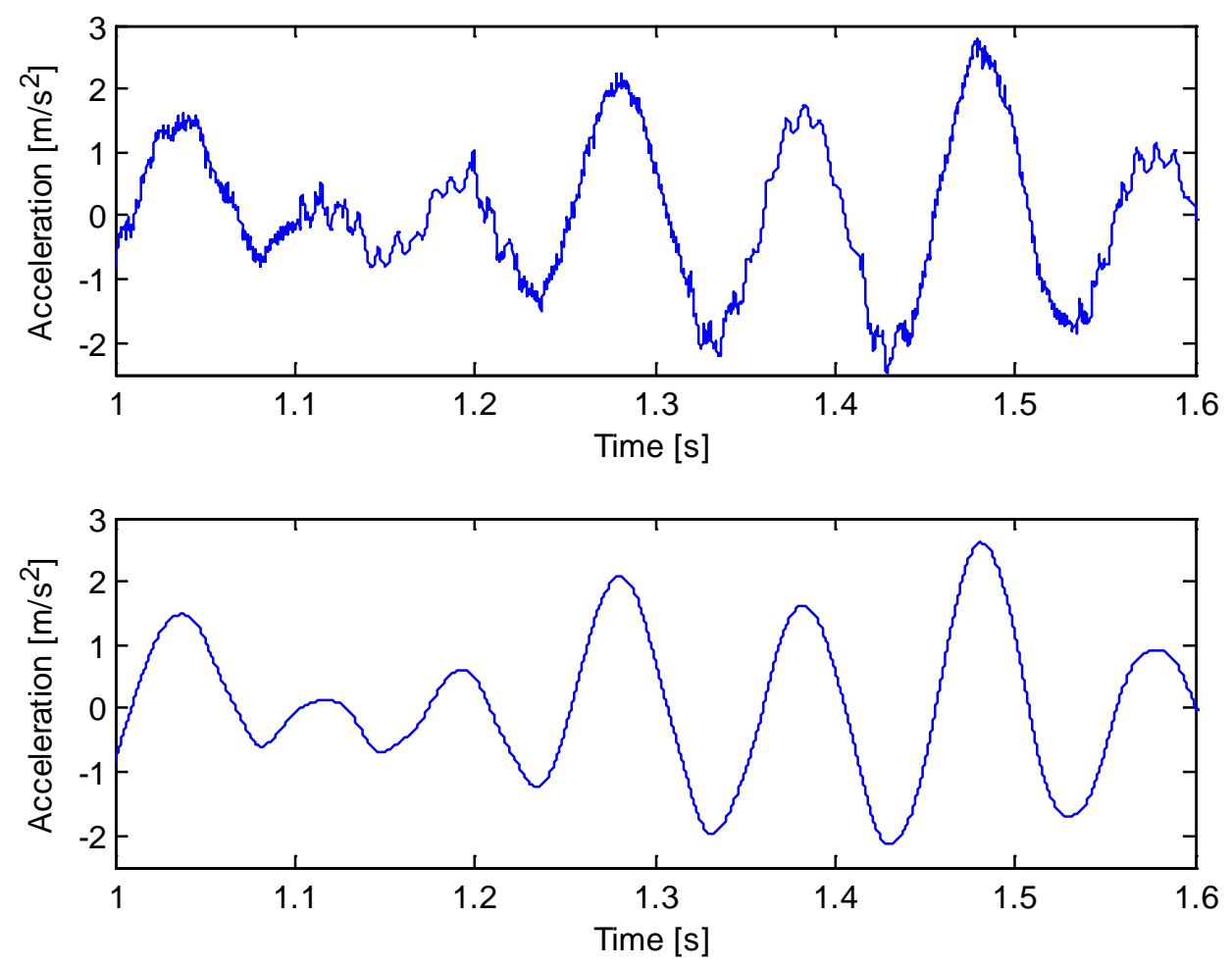

Figure 3.6: Acceleration plot in time domain. A lowpass filter has been applied to the lower curve.

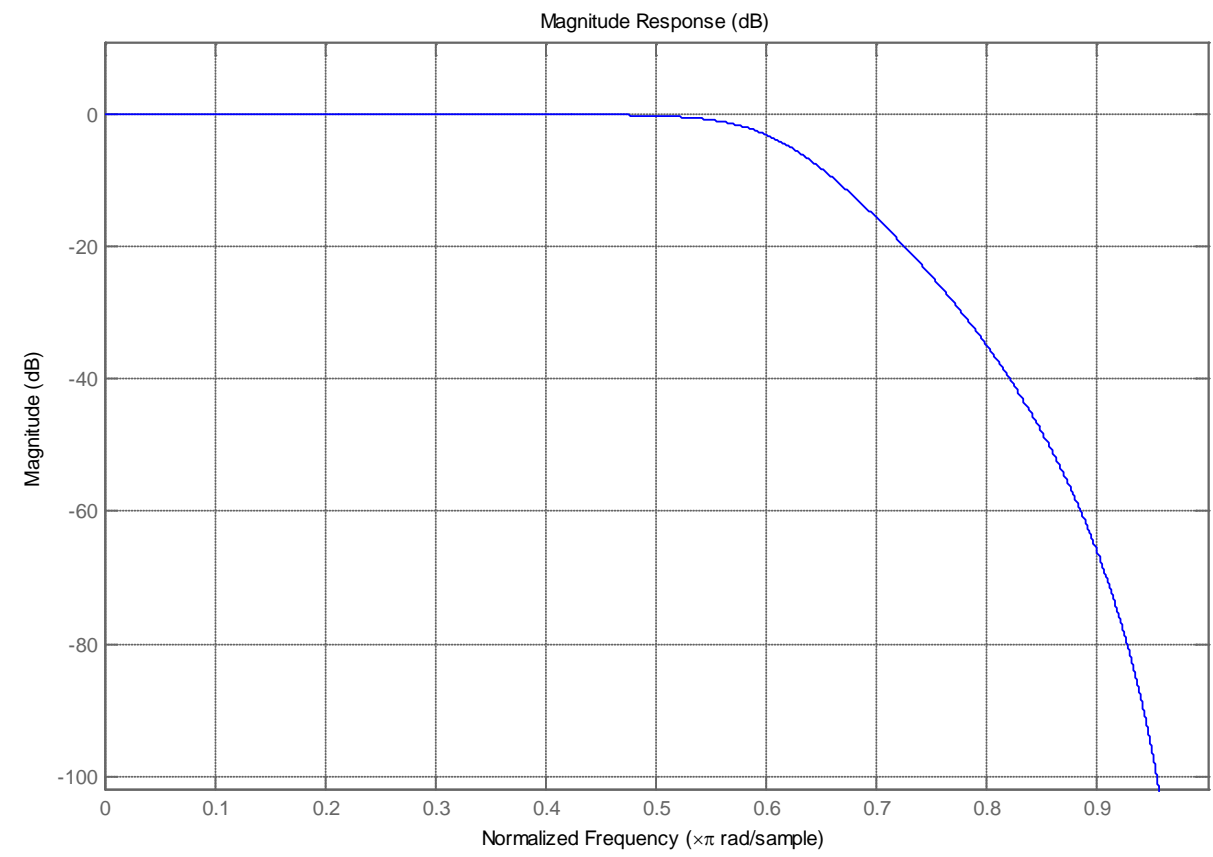

Figure 3.7: Visualization of a fifth order Butterworth lowpass filter, which has been used within this thesis. 


\section{Chapter 4}

\section{Bridge Models}

Two types of bridges have been studied in this thesis; simply supported bridges and bridges with integrated backwalls. Further description of the bridge types follows in sections 4.1 and 4.2 below.

For all bridges, a damping ratio of $1 \%$ has been used.

\subsection{Simply Supported Bridges}

The properties of the simply supported bridge models have been determined in accordance with equations (2.4) and (2.5). These equations give an interval for the properties, i.e. mass and fundamental frequency, for a given bridge length. For each bridge length, three sets of properties have been chosen; one in the middle of the intervals and one in the lower and upper boundary of the intervals, respectively. Once the length, mass and fundamental frequency of the bridges had been chosen, the bending stiffness was calculated as

$$
2 \pi n_{0}=\pi^{2} \sqrt{\frac{E I}{M L^{4}}} \rightarrow E I=\frac{4 n_{0}^{2}}{\pi^{2}} M L^{4}
$$

The parameters of the simply supported bridges are shown in figure 4.1. Span lengths from 5 to 10 meters have been analyzed, with properties according to table 4.1. A convergence study showed that a mesh size of 0.25 meters was sufficient to capture the full response of the simply supported bridges, see chapter 6 .

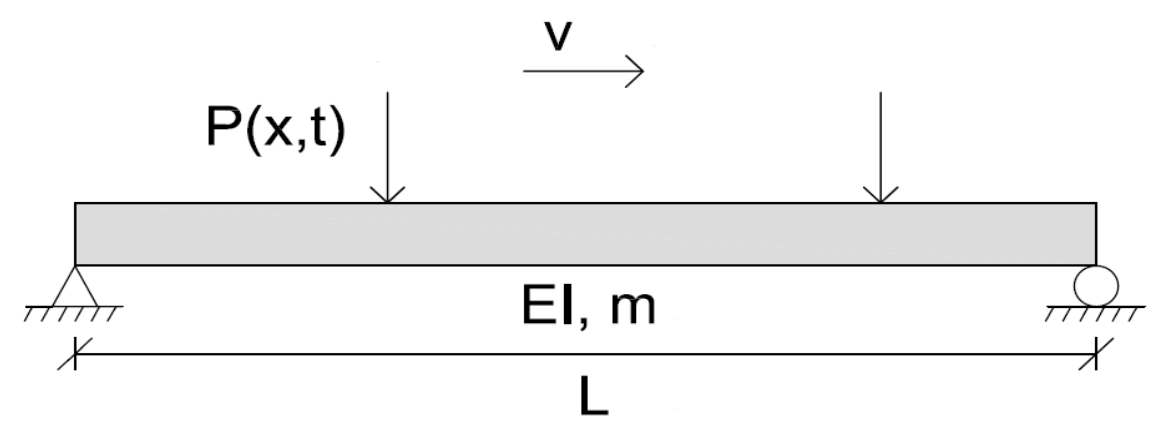

Figure 4.1: Parameters of the simply supported bridges. 
Table 4.1: Properties of the simply supported bridges analyzed.

\begin{tabular}{cc|cccccc} 
& Bridge Length $[\mathrm{m}]$ & 5 & 6 & 7 & 8 & 9 & 10 \\
\hline \multirow{3}{*}{ Set 1} & $M[\mathrm{~kg} / \mathrm{m}]$ & 5700 & 6400 & 7100 & 7800 & 8400 & 9100 \\
& $n_{0}[\mathrm{~Hz}]$ & 55.3 & 41.4 & 32.4 & 26.3 & 21.8 & 18.5 \\
& $E I\left[\mathrm{GNm}{ }^{2}\right]$ & 4.41 & 5.76 & 7.27 & 8.94 & 10.6 & 12.6 \\
\hline \multirow{3}{*}{ Set 2} & $M[\mathrm{~kg} / \mathrm{m}]$ & 11100 & 11700 & 12400 & 13100 & 13800 & 14500 \\
& $n_{0}[\mathrm{~Hz}]$ & 37.4 & 28.1 & 22.0 & 17.9 & 14.5 & 12.6 \\
& $E I\left[\mathrm{GNm}{ }^{2}\right]$ & 3.93 & 4.84 & 5.86 & 6.95 & 8.09 & 9.31 \\
\multirow{3}{*}{ Set 3 } & $M\left[\mathrm{~kg} / \mathrm{m}^{2}\right]$ & 16400 & 17100 & 17800 & 18400 & 19100 & 19800 \\
& $n_{0}[\mathrm{~Hz}]$ & 25.3 & 19.0 & 15.0 & 12.2 & 10.1 & 8.6 \\
& $E I\left[\mathrm{GNm}{ }^{2}\right]$ & 2.65 & 3.25 & 3.89 & 4.52 & 5.19 & 5.91
\end{tabular}

\subsection{Bridges with Integrated Backwalls}

\subsubsection{Fixed Supports}

The parameters of the bridges with integrated backwalls are shown in figure 4.2. The length of the midspan was given values of 7 and 9 meters, with end spans of 1 meter on each side. For the bridges with integrated backwalls, the same masses and stiffness that were calculated for the simply supported bridges with corresponding span lengths were used. Only the fundamental frequencies were recalculated with eigenvalue analysis. The properties of the bridges are shown in table 4.2.

For the bridges with integrated backwalls a mesh size of 0.05 meters was found to be sufficient to capture the full response from a train passage, see chapter 6 .

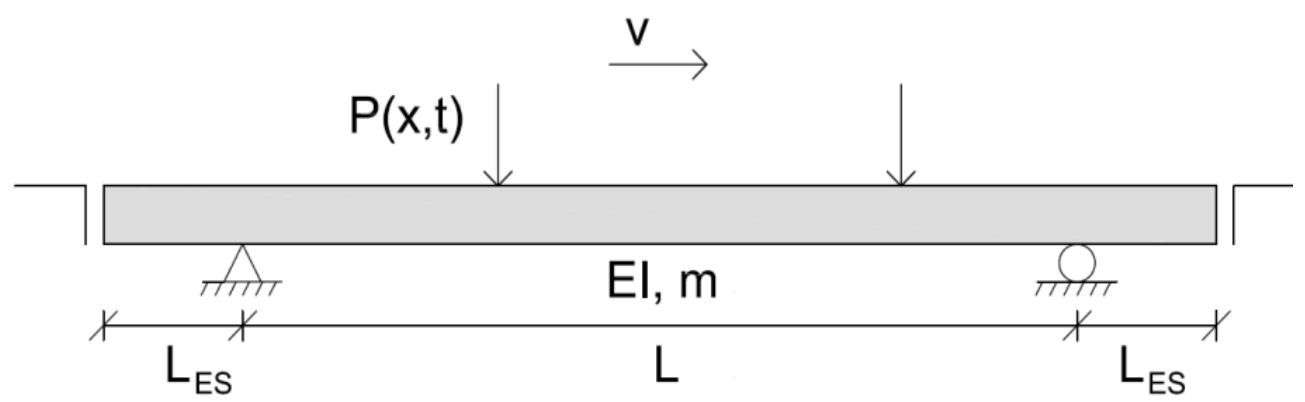

Figure 4.2: Parameters of the bridges with integrated backwalls, after Johansson et al. (2011). 
Table 4.2: Properties of the analyzed bridges with integrated backwalls.

\begin{tabular}{cc|cc} 
& Bridge Length $[\mathrm{m}]$ & $7(+2 \cdot 1$ m end spans $)$ & $9(+2 \cdot 1$ m end spans $)$ \\
\hline \multirow{3}{*}{ Set 1} & $M[\mathrm{~kg} / \mathrm{m}]$ & 7100 & 8400 \\
& $n_{0}[\mathrm{~Hz}]$ & 31.8 & 21.6 \\
& $E I\left[\mathrm{GNm}{ }^{2}\right]$ & 7.27 & 10.6 \\
\hline \multirow{3}{*}{ Set 2} & $M[\mathrm{~kg} / \mathrm{m}]$ & 17800 & 19100 \\
& $n_{0}[\mathrm{~Hz}]$ & 14.7 & 10.0 \\
& $E I\left[\mathrm{GNm}{ }^{2}\right]$ & 3.89 & 5.19
\end{tabular}

\subsubsection{Spring Supports}

The bridges described in section 4.2.1 above have also been studied with the supports modeled as springs, see figure 4.3. Different values of the spring stiffness, $k$, have been tested to evaluate how the bridge response is affected. The values of $k$ were chosen based on computational procedures prescribed by Gazetas (1991), and are depicted in table 4.3.

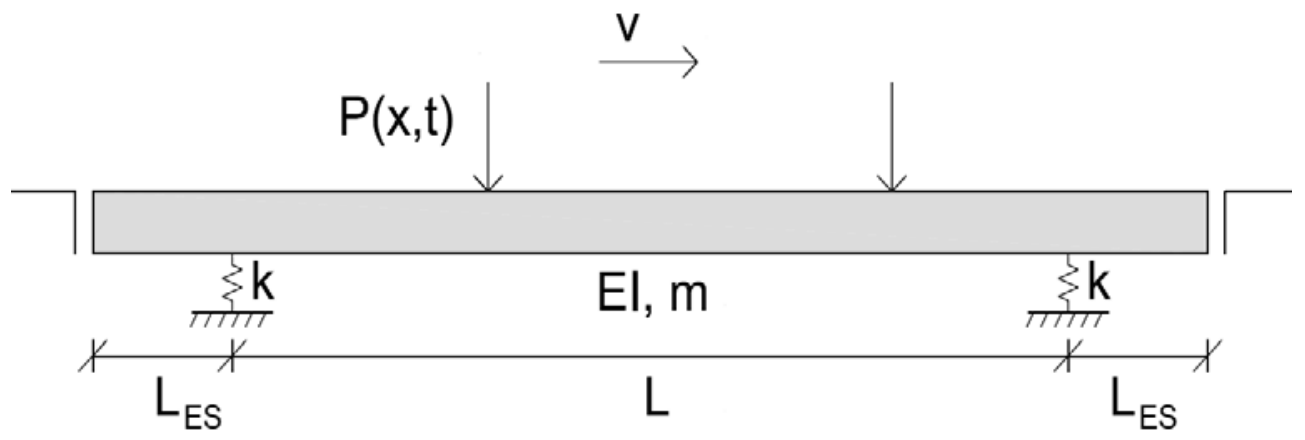

Figure 4.3: Parameters of bridges with integrated backwalls with spring supports, after Johansson et al. (2011).

Table 4.3: Values of spring stiffness, $k$.

\begin{tabular}{c} 
Spring Stiffness $k[\mathrm{GN} / \mathrm{m}]$ \\
\hline 0.5 \\
1 \\
2 \\
3 \\
5 \\
10 \\
20
\end{tabular}





\section{Chapter 5}

\section{Loads}

\subsection{Train Load Model}

The train model used when running the simulations is the HSLM-A1 train configuration from Eurocode EN 1991-2. This model is a system of point loads at different spacing, consisting of two power cars, two end coaches and 18 intermediate coaches, see figure 5.1. For HSLM-A1 $N=18, D=18 \mathrm{~m}, d=2 \mathrm{~m}$ and $P=170 \mathrm{kN}$.

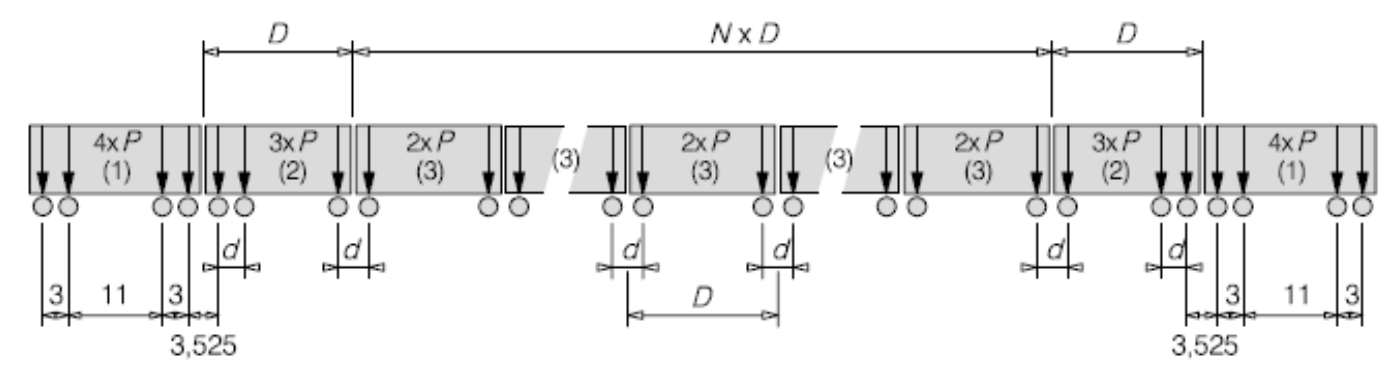

Figure 5.1: HSLM-A load model from Eurocode EN 1991-2.

\subsection{Load Shapes}

The point loads that the HSLM-A1 train model consists of are acting on the rail. They are then distributed longitudinally along the rail to the sleepers and then spread through the ballast before the load reaches the bridge superstructure.

To model this load spread through rails, sleepers and ballast, different load shapes are implemented when running the simulations. The load shapes studied are:

- The load shape prescribed in Eurocode EN 1991-2. This load shape is representing the distribution by the rail and consists of three point loads acting on three adjacent sleepers, see figure 5.2a, where $a$ is the distance between the sleepers. In this thesis a distance of $0.65 \mathrm{~m}$ is used. In the following chapters, this load shape is referred to as the EC3 load shape, since the axle load is divided into three point loads. 
- The load shape described above with sleeper and ballast distribution. The distribution through the ballast is 4:1 (height:width), see figure 5.2b. A sleeper width of $0.28 \mathrm{~m}$ and a ballast depth of $0.65 \mathrm{~m}$ are used for all simulations, giving $b$ a value of $0.605 \mathrm{~m}$. This load shape is represented by 9 and 15 point loads and will furthermore be referred to as the EC9 and EC15 load shapes, respectively. The load shapes are shown in figures 5.3a and 5.3c, respectively.

- The Eurocode load shape with sleeper and ballast distribution modeled as a distributed line load, see figure 5.3e. This load shape will be referred to as the ECdist load shape.

- A triangular load shape based on the results of Rehnström and Widén and spread over a length of three meters. This load shape is represented by 17 and 21 point loads and will be referred to as Tri17 and Tri21, respectively. The load shapes are shown in figures 5.3b and 5.3d, respectively.

- The triangular load shape described above, modeled as a distributed line load, see figure 5.3f. This load shape will be referred to as the Tridist load shape.

Common for all load shapes is that the sum of each axle is equal to $P=170 \mathrm{kN}$.
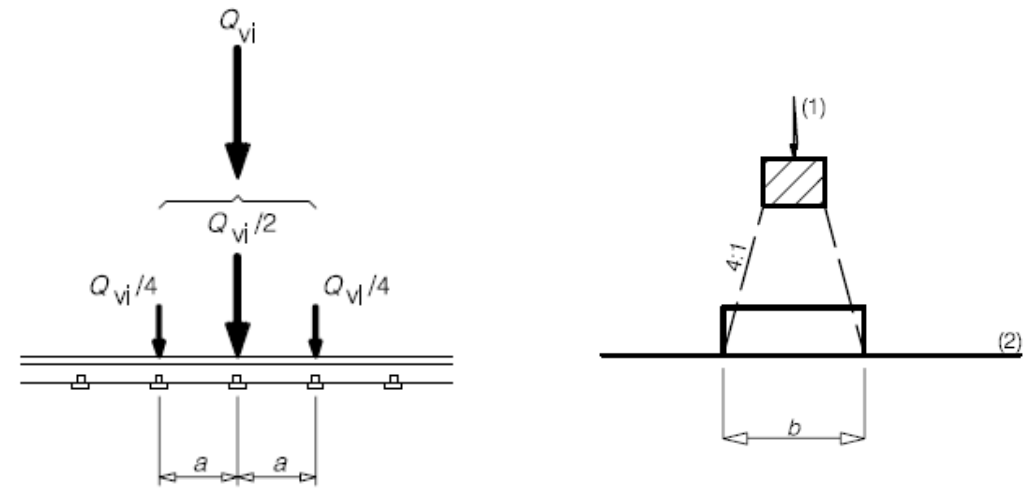

Figure 5.2: (a) Longitudinal distribution of an axle load $\mathrm{Q}_{\mathrm{vi}}$ by the rail. (b) Longitudinal distribution of load by sleeper and ballast (CEN/TC 250, 2002). 


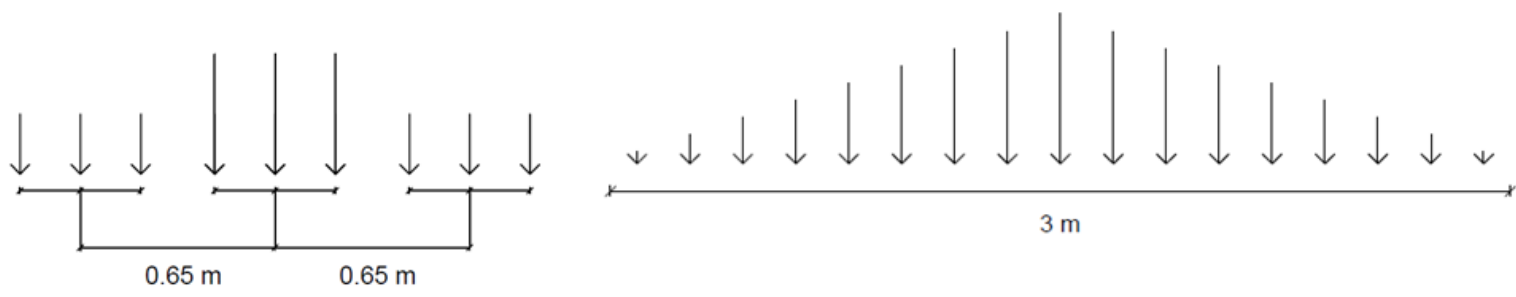

(a)

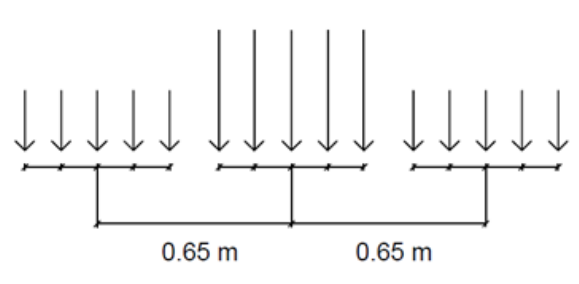

(c)

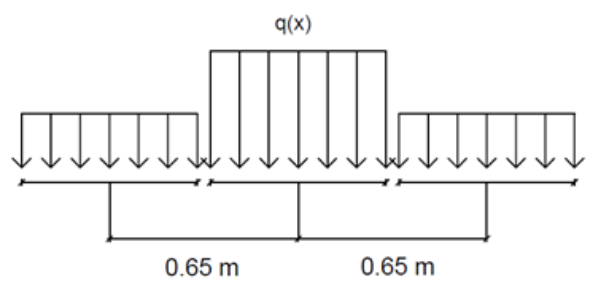

(e) (b)

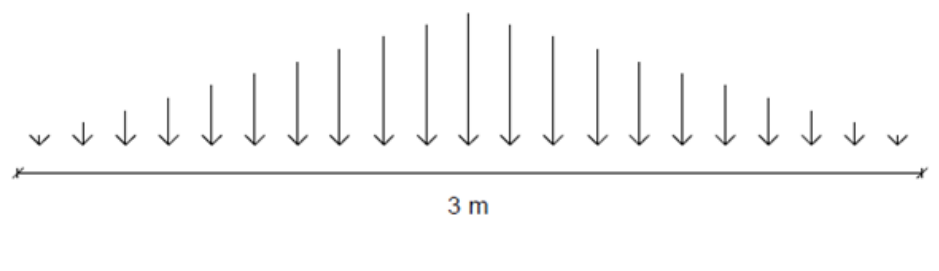

(d)

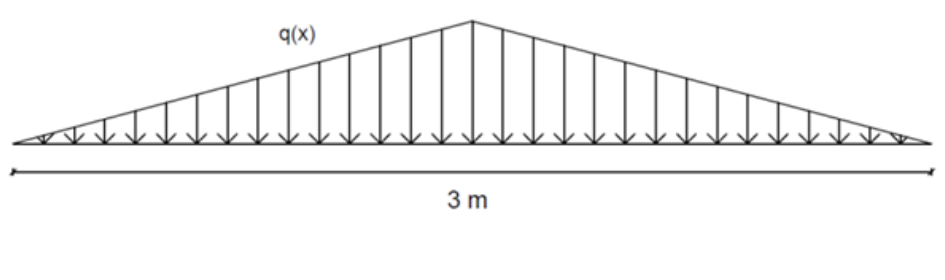

(f)

Figure 5.3: (a) The Eurocode load distribution with 9 point loads - EC9. (b) The triangle load distribution with 17 point loads - Tri17. (c) The Eurocode load distribution with 15 point loads - EC15. (d) The triangle load distribution with 21 point loads - Tri21. (e) The Eurocode load distribution as a distributed line load - ECdist. (f) The triangle load distribution as a distributed line load - Tridist.

\subsection{Programming the Load Shapes in Matlab}

When programming the load shapes described in section 5.2, four load spread functions have been written in Matlab. The functions are further developments of Matlab functions written by Rehnström and Widén (2012) and are the following:

- spread_ec - this function is used to model the load shape prescribed in Eurocode, with or without sleeper and ballast distribution, with an arbitrary, odd number of point loads $N_{p}$, where $N_{p}$ is the number of point loads under each sleeper.

- spread_ec_dist - this function is used to model the load shape prescribed in Eurocode with sleeper and ballast distribution, as a distributed line load divided into an arbitrary chosen interval $\Delta x$. 
- spread_tri - this function is used to model the triangular load shape with an arbitrary, odd number of point loads $N_{p}$. If one point load is chosen, the function models each train axle as one point load, i.e. without load spreading.

- spread_tri_dist - this function is used to model the triangular load shape as a distributed line load divided into an arbitrary chosen interval $\Delta x$.

Common for all load shape functions is that two vectors are required as input, containing relative axle positions and load amplitudes of all axles in the train, respectively. In this thesis, these vectors are denoted axle and axle_load. In addition to these two vectors, the functions require different additional input to run. In sections 5.3.1-5.3.4 below it is further explained how the functions work. Furthermore, all functions are attached in Appendix A.

\subsubsection{Eurocode Point Load Function}

Other than the two vectors mentioned above, the Eurocode point load function requires the number of point loads under each sleeper, $N_{p}$, and the height of the ballast layer, $h$, as input. The height of the ballast layer is needed to determine the width over which the loads are to be distributed with the inclination relationship 4:1. The function first calculates the magnitude of each point load based on $N_{p}$. In the function, the point loads are denoted $p_{1}, p_{2}$ and $p_{3}$ respectively, where the indices 1,2 and 3 represents the three adjacent sleepers that the point loads are acting underneath. $p_{1}, p_{2}$ and $p_{3}$ are calculated as

$$
\begin{gathered}
p_{1}=\frac{P}{4 N_{p}} \\
p_{2}=2 p_{1}=\frac{P}{2 N_{p}} \\
p_{3}=p_{1}=\frac{P}{4 N_{p}}
\end{gathered}
$$

where $P$ is the total load of one axle. After that the position of each point load is calculated based on $N_{p}$ and $h$. The distance between the point loads, $d_{p}$, is given by

$$
d_{p}=\frac{b}{N_{p}}
$$

where $b$ is the length of the spread underneath each sleeper, see figure 5.2b. Last, the function adds the positions and magnitudes of each point load to two vectors, axle_spread and axle_load_spread, which then are returned as output. Figure 5.5 shows how the magnitudes and positions of the point loads are distributed by the function. 

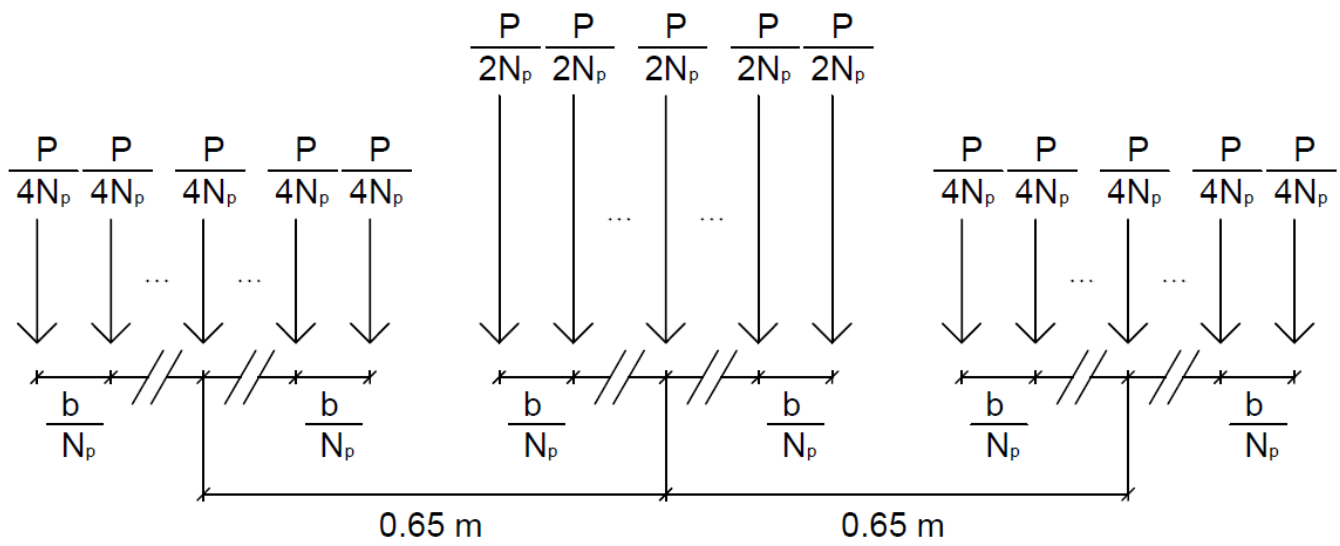

Figure 5.5: Schematic figure of how magnitudes and positions of the point loads are distributed by the Eurocode point load function.

\subsubsection{Eurocode Distributed Line Load Function}

The Eurocode distributed line load function requires the height of the ballast layer, $h$, and the integral interval, $\Delta x$, as input. The function first calculates three distributed line load functions, $q_{1}, q_{2}$ and $q_{3}$, where the indices 1,2 and 3 represents the three adjacent sleepers that the line loads are acting underneath. $q_{1}, q_{2}$ and $q_{3}$ are calculated as

$$
\begin{gathered}
q_{1}=\frac{P}{4 b} \\
q_{2}=2 q_{1}=\frac{P}{2 b} \\
q_{3}=q_{1}=\frac{P}{4 b}
\end{gathered}
$$

where $P$ is the total load of one axle and $b$ is the length of the spread underneath each sleeper, see figure 5.2b. After that the function calculates positions along the line loads at a spacing $\Delta x$. Last, the function adds the positions and corresponding values of the line loads to two vectors, axle_spread and axle_load_spread, which then are returned as output. For the Eurocode load distribution, the values of the line loads added to axle_load_spread adopt one of the three constant values $q_{1}, q_{2}$ or $q_{3}$. Figure 5.6 shows how the distributed line loads are divided into intervals of length $\Delta x$. 

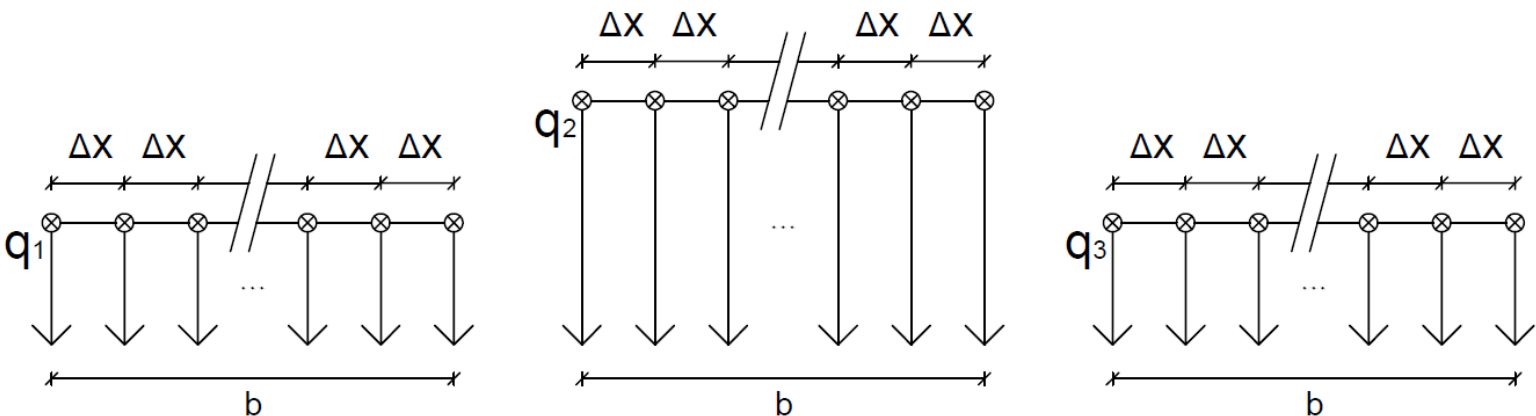

Figure 5.6: Schematic figure of how the distributed line loads are divided into intervals of length $\Delta x$ by the Eurocode distributed line load function.

\subsubsection{Triangle Point Load Function}

The triangle point load function works in the same way as the Eurocode point load function, only with other inputs. Instead of the height of the ballast layer this function needs the length to spread each axle load over, $l_{s}$. First the magnitude of the middle point load, $p_{\text {mid }}$, is calculated as

$$
p_{\text {mid }}=P k \cdot \frac{1}{k+2 \sum_{j=1}^{k-1} j}
$$

where $P$ is the total load of one axle and $k$ is

$$
k=\frac{N_{p}+1}{2}
$$

After that the other point loads, $p_{i}$, are calculated as

$$
p_{i}=p_{\text {mid }}\left(1-\frac{i}{k}\right)
$$

where $i=1,2,3, \ldots, k-1$. The distance between the point loads is given by

$$
d_{p}=\frac{l_{s}}{N_{p}}
$$

Figure 5.7 shows how the magnitudes and positions of the point loads are distributed by the function. 


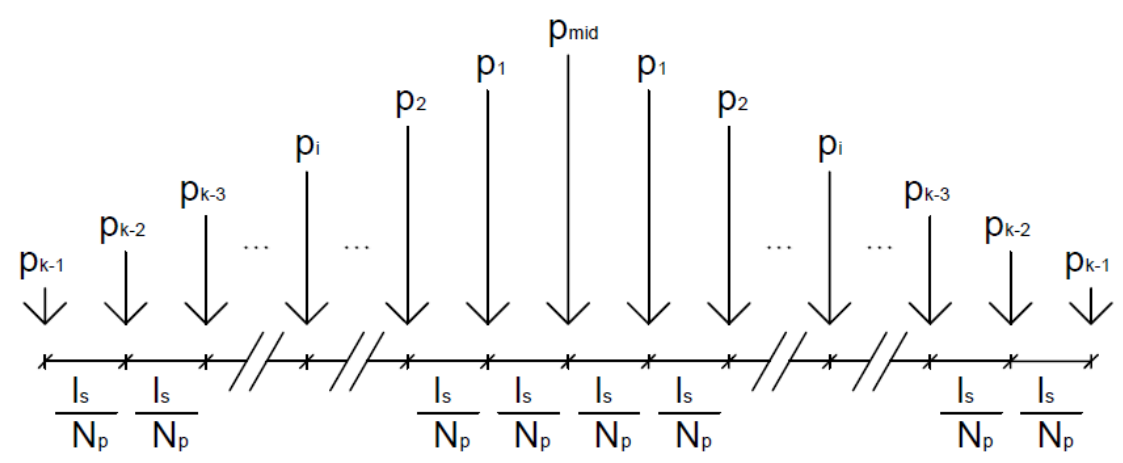

Figure 5.7: Schematic figure of how magnitudes and positions of the point loads are distributed by the triangle point load function.

\subsubsection{Triangle Distributed Line Load Function}

The triangle distributed line load function works in the same way as the Eurocode line load function, but instead of the height of the ballast layer the function requires the length to spread each axle load over, $l_{s}$, as input. The function first calculates the distributed line load for one train axle, divided into two parts $q_{1}$ and $q_{2}$ which are described as

$$
\begin{aligned}
& q_{1}(x)=\frac{2 P}{l_{s}}\left(\frac{2 x}{l_{s}}+1\right) \\
& q_{2}(x)=\frac{2 P}{l_{s}}\left(1-\frac{2 x}{l_{s}}\right)
\end{aligned}
$$

where $P$ is the total load of one axle and $x$ ranges from $-l_{s} / 2$ to 0 for $q_{1}$ and from 0 to $l_{s} / 2$ for $q_{2}$. The function then calculates positions along the line loads at a spacing of $\Delta x$ and adds the positions and corresponding values of the line loads to the vectors axle_spread and axle_load_spread respectively, which then are returned as output. Figure 5.8 shows how the distributed line loads are divided into intervals of length $\Delta x$.

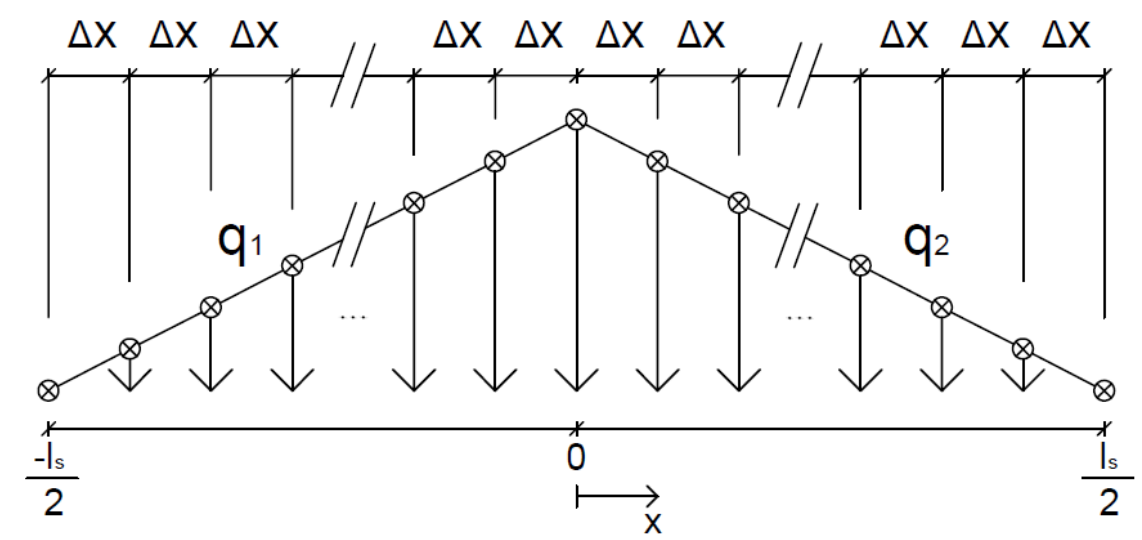

Figure 5.8: Schematic figure of how the distributed line loads are divided into intervals of length $\Delta x$ by the triangle distributed line load function. 



\section{Chapter 6}

\section{Quality Assurance}

\subsection{Choice of Mesh Size and Time Step}

To ensure that the mesh size and time step are adequate to capture the full response of the bridges and at the same time avoid unnecessarily long computational times, a convergence study was performed. A simply supported bridge with the following properties was analyzed:

Table 6.1: Properties of the simply supported bridge used for the convergence study.

\begin{tabular}{l|c} 
Length $L[\mathrm{~m}]$ & 10 \\
\hline Mass $M[\mathrm{~kg} / \mathrm{m}]$ & 9100 \\
\hline Fundamental frequency $n_{0}[\mathrm{~Hz}]$ & 18.5 \\
\hline Stiffness $E I\left[\mathrm{GNm}^{2}\right]$ & 12.6
\end{tabular}

An HSLM-A1 train was run over the bridge at a speed of $300 \mathrm{~km} / \mathrm{h}$ and the maximum vertical acceleration at the bridge's quarter point was studied for different mesh sizes and time steps. The results are shown in table 6.2.

Table 6.2: Maximum vertical acceleration $\left[\mathrm{m} / \mathrm{s}^{2}\right]$ at the bridge's quarter point for different mesh sizes and time steps.

\begin{tabular}{c|ccccc}
\hline Mesh size $[\mathrm{m}]$ & & & & & \\
\hline 0.001 & 0.5 & 0.25 & 0.125 & 0.05 & 0.025 \\
0.0005 & & & & & \\
0.00025 & 3.248 & 3.132 & 3.134 & 3.135 & 3.135 \\
0.0001 & 2.902 & 3.142 & 3.144 & 3.145 & 3.145 \\
0.00005 & 2.865 & 3.063 & 3.065 & 3.065 & 3.066 \\
0.000025 & 2.822 & $2.2 .969 ;$ & 2.971 & 2.972 & 2.972 \\
0.00001 & 2.814 & 2.958 & 2.960 & 2.960 & 2.961 \\
& 2.812 & 2.955 & 2.957 & 2.958 & 2.958 \\
& & 2.954 & 2.956 & 2.957 & 2.957
\end{tabular}


Full convergence considering both mesh size and time step is reached with a mesh size of $0.025 \mathrm{~m}$ and a time step of $0.00001 \mathrm{~s}$. In this thesis a mesh size of $0.25 \mathrm{~m}$ and a time step of $0.0001 \mathrm{~s}$ were chosen. This combination gives small errors and reasonable computational time.

With a time step of $0.0001 \mathrm{~s}$ the train will move $8.33 \mathrm{~mm}$ for every time increment when travelling at a speed of $300 \mathrm{~km} / \mathrm{h}$. To keep the computational time as low as possible, the time step is varied with the train speed so that the train always moves $8.33 \mathrm{~mm}$ for every time increment. The time step can be described as

$$
\Delta t=\frac{8.33 \cdot 10^{-3}}{c}
$$

where $c$ is the train speed in $\mathrm{m} / \mathrm{s}$.

The same procedure was used for a bridge with integrated backwalls with the following properties:

Table 6.3: Properties of the bridge with integrated backwalls used for the convergence study.

\begin{tabular}{l|c} 
Length $L[\mathrm{~m}]$ & $9(+2 \cdot 1$ m end spans $)$ \\
\hline Mass $M[\mathrm{~kg} / \mathrm{m}]$ & 8400 \\
\hline Fundamental frequency $n_{0}[\mathrm{~Hz}]$ & 21.6 \\
\hline Stiffness $E I\left[\mathrm{GNm}^{2}\right]$ & 10.6
\end{tabular}

The maximum vertical acceleration was measured at the bridge's end point, i.e. in node 1 . The results are shown in table 6.4.

Table 6.4: Maximum vertical acceleration $\left[\mathrm{m} / \mathrm{s}^{2}\right]$ at the bridge's end point, i.e. in node 1, for different mesh sizes and time steps.

\begin{tabular}{c|ccccc} 
Mesh size [m] & & & & & \\
\hline 0.001 & 0.5 & 0.25 & 0.125 & 0.05 & 0.025 \\
0.0005 & & & & & \\
0.00025 & 21.887 & 21.845 & 21.848 & 21.848 & 21.848 \\
0.0001 & 17.052 & 17.992 & 17.996 & 17.957 & 17.957 \\
0.00005 & 15.634 & 16.464 & 16.469 & 16.509 .1628 & 16.509 \\
0.000025 & 15.492 & 16.304 & 16.309 & 16.256 & 16.256 \\
0.00001 & 15.418 & 16.224 & 16.229 & 16.203 & 16.203 \\
& 15.381 & 16.184 & 16.189 & 16.178 & 16.178
\end{tabular}

A mesh size of $0.05 \mathrm{~m}$ and a time step of $0.0001 \mathrm{~s}$ are chosen. 


\subsection{Choice of Integral Interval}

As described in section 3.3, numerical integrations were performed over the finite elements when modeling the axle loads as distributed line loads. The line loads were divided into intervals of length $\Delta x$ and the integration was performed for every element and every time step. The smaller the interval, the more accurate solution. To make sure that the chosen intervals were small enough, a convergence study was made for every type of bridge and load distribution. An example of such a convergence study can be seen in figure 6.1 where different values of the integral interval were compared for a bridge where the triangular load distribution was used. For this bridge, an interval length of $0.05 \mathrm{~m}$ was chosen. This integral length was found to be satisfactory for the majority of the bridges. However, for a small number of bridges, a smaller integral interval was needed before convergence was found. All bridges studied have been integrated with integral intervals of either $0.05,0.01$ or $0.005 \mathrm{~m}$.

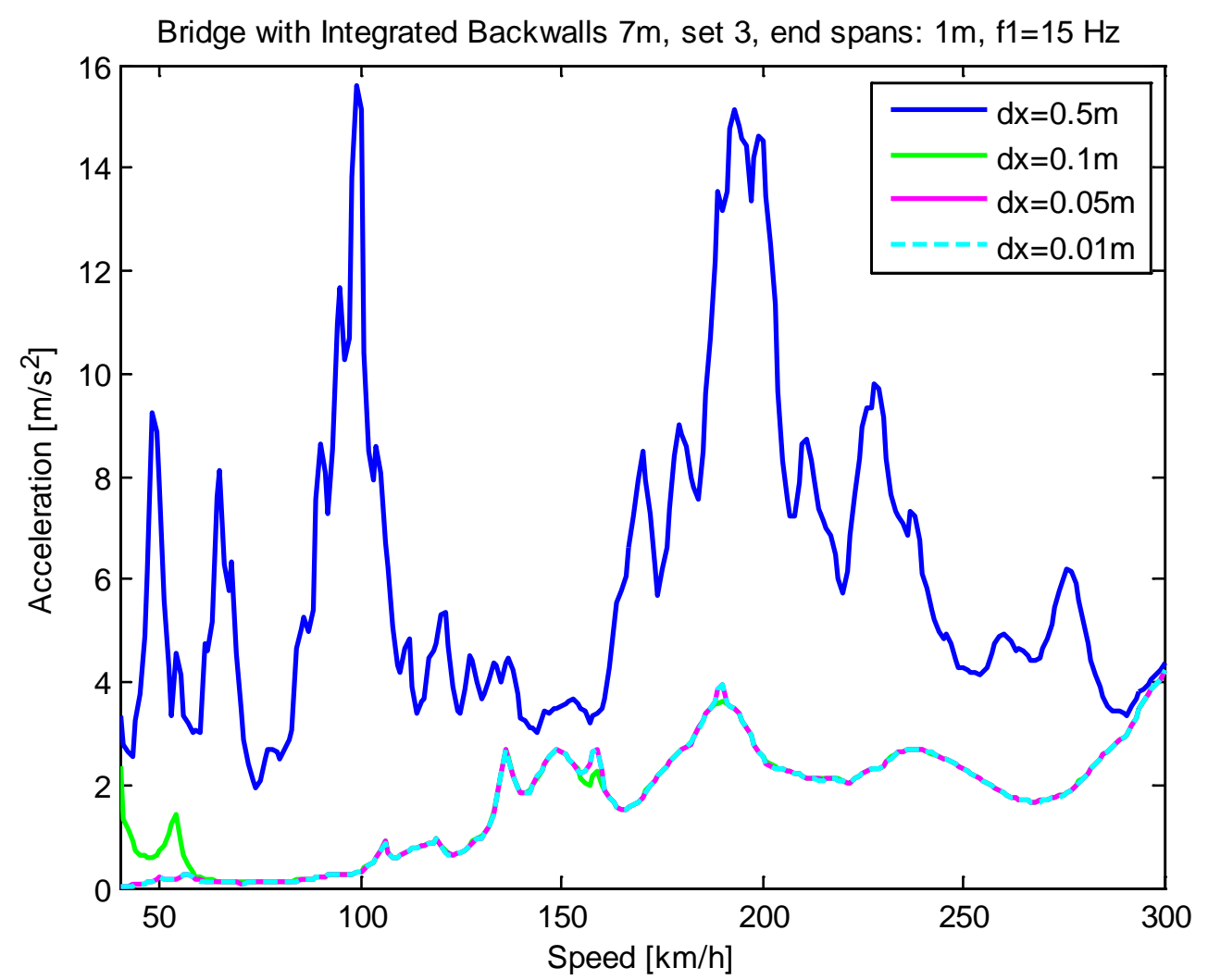

Figure 6.1: Results from convergence study of the integration interval $\Delta x$.

\subsection{Abaqus}

To ensure that the results obtained from Matlab are correct, a number of simulations were run in Abaqus FEA as a quality assurance. In order to make the bridge models and train passage simulations more adaptable to different inputs, scripting in Python was used. In this way bridge properties, train velocities and load shapes can easily be changed and the desired output automatically saved to file. Figures 6.2-6.3 show the results from a simply supported 
bridge when using the load shape EC3. The blue curves are generated in Matlab and the green, dashed curves are generated in Abaqus.

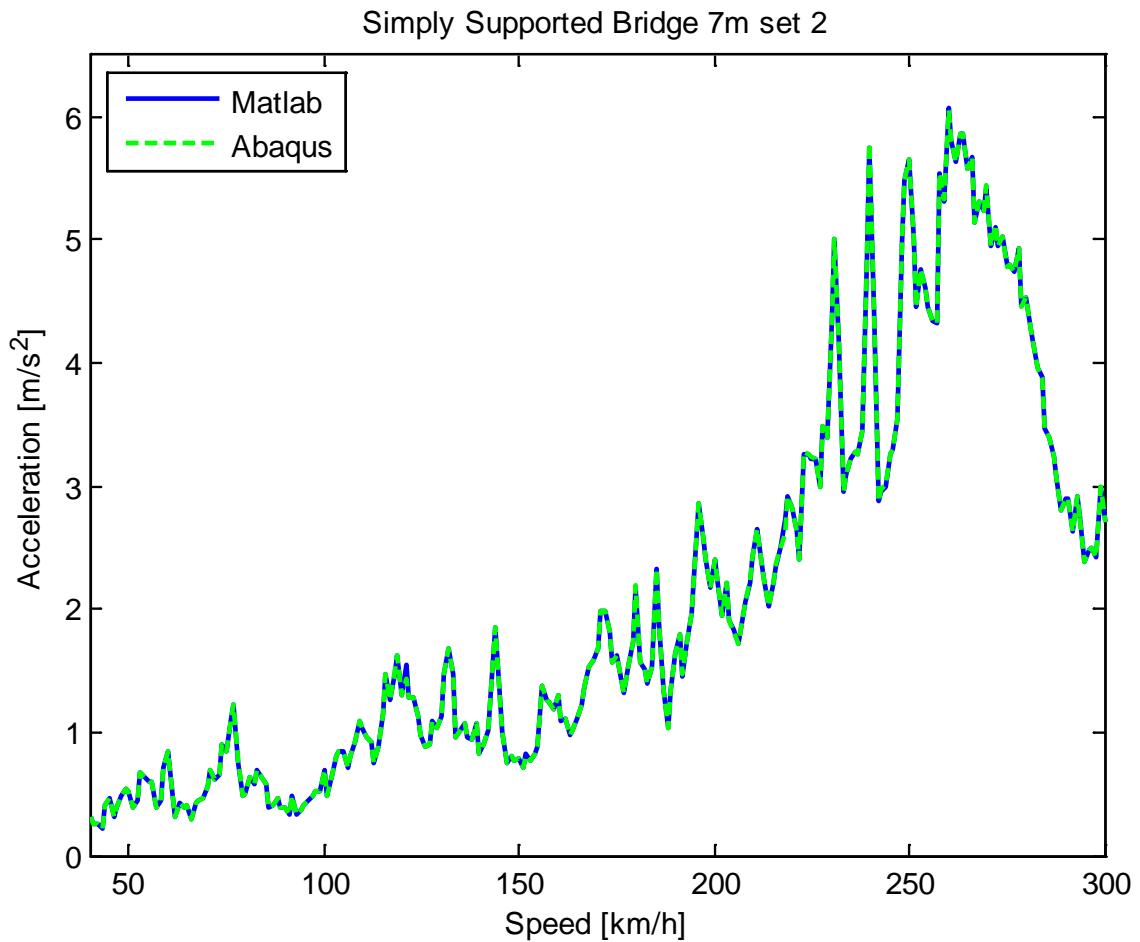

Figure 6.2: Speed-acceleration plot for a simply supported bridge showing results from Matlab and Abaqus simulations.

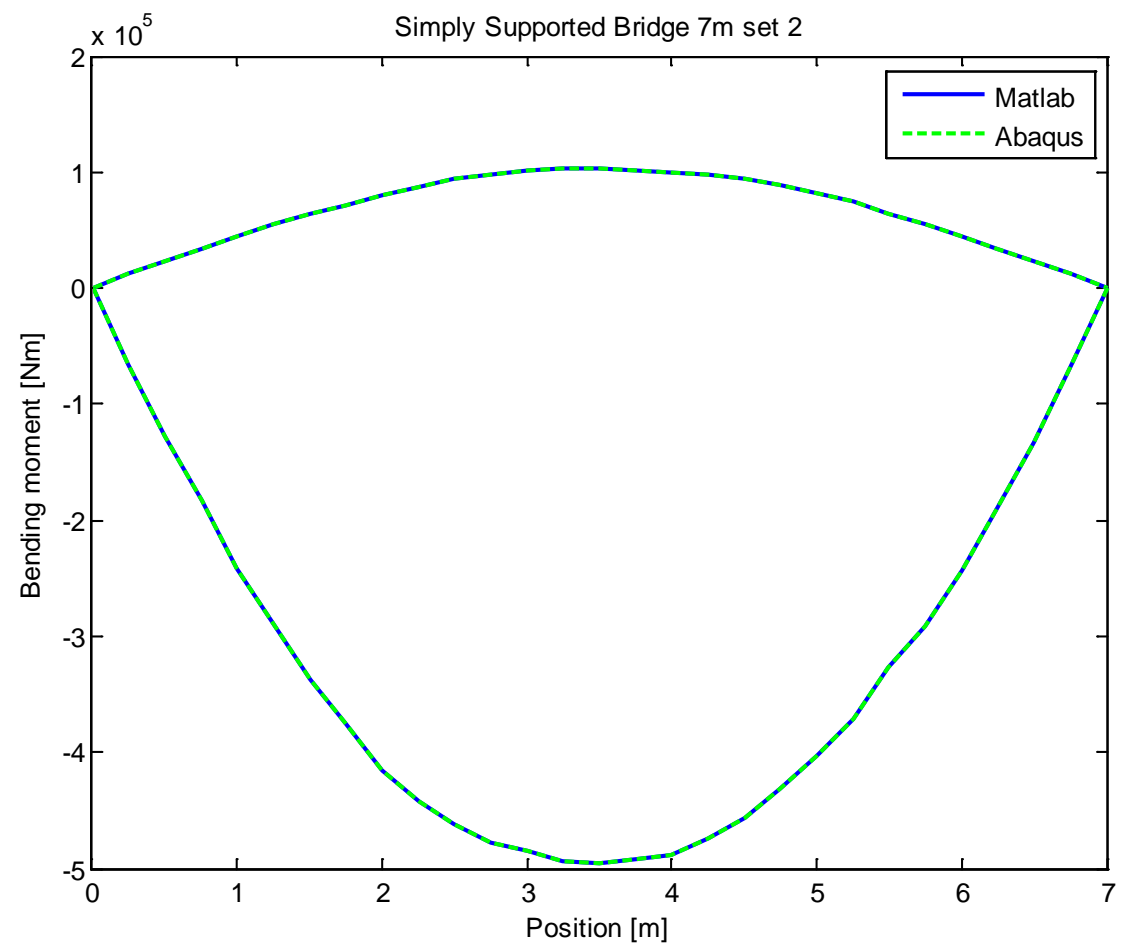

Figure 6.3: Moment diagram for a simply supported bridge showing results from Matlab and Abaqus simulations. 


\subsubsection{Amplitude Functions}

In Abaqus, point loads can only be applied at nodes (Dassault Systèmes Simulia Corp., 2011b). In order to simulate a train moving along the bridge, the nodal point loads need to vary in magnitude with time. This was attained by assigning amplitude functions to the point loads. When representing the train axles by single point loads, the amplitude functions are triangular as seen in figure 6.4.

For other load shapes the amplitude functions become more complicated. As an example the load distribution prescribed in Eurocode with sleeper distribution can be taken, represented by nine point loads per axle. Each point load is represented by a triangular amplitude function as seen in figure 6.5a. These amplitude functions then need to be superimposed into one total amplitude function to avoid problems with overlapping times, figure 6.5b. Figure 6.5c shows the superimposed, total amplitude function when representing each axle by 49 point loads.

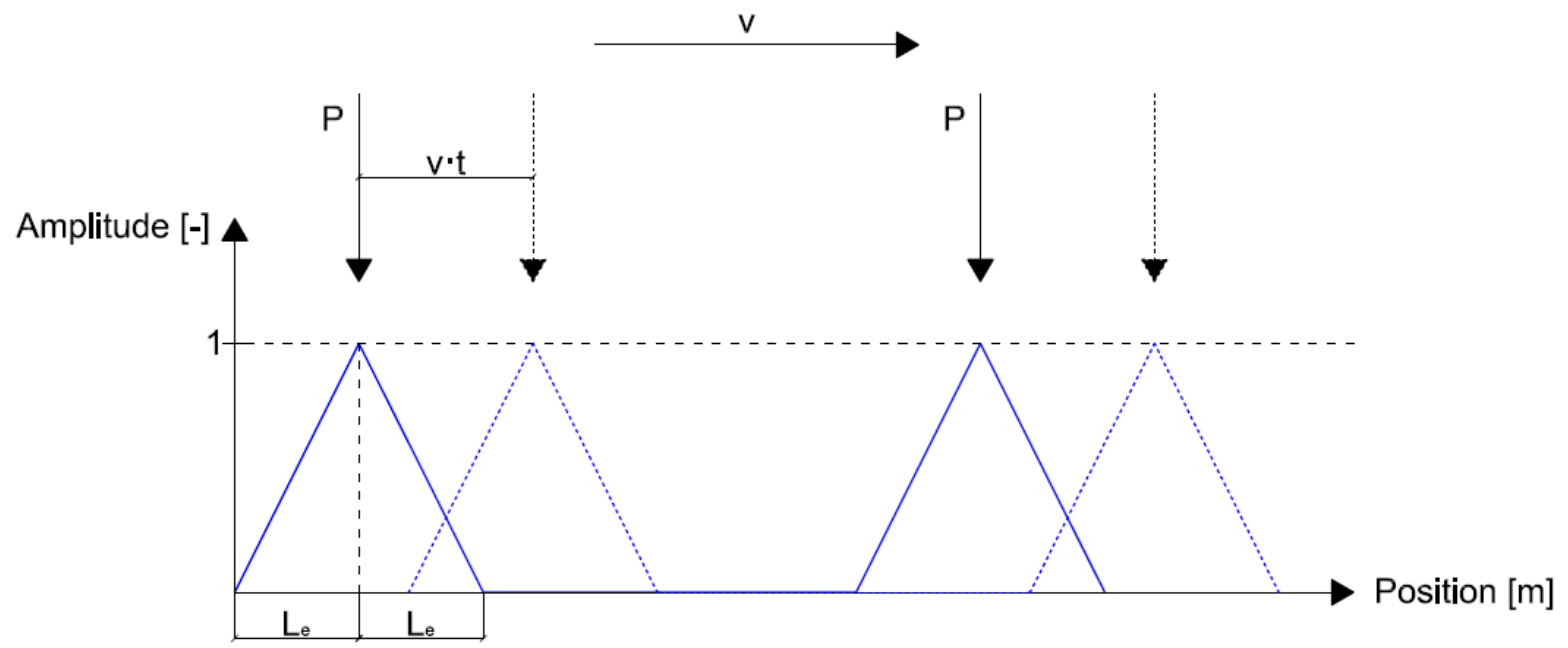

Figure 6.4: Amplitude function when representing each train axle by one point load, $P$. $L_{e}$ is the element length, $v$ is the train speed. 


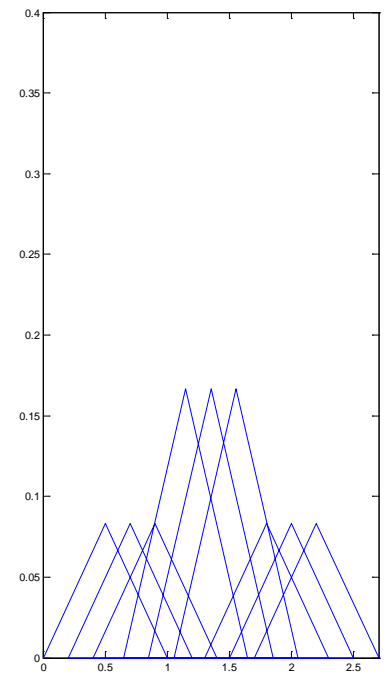

(a)

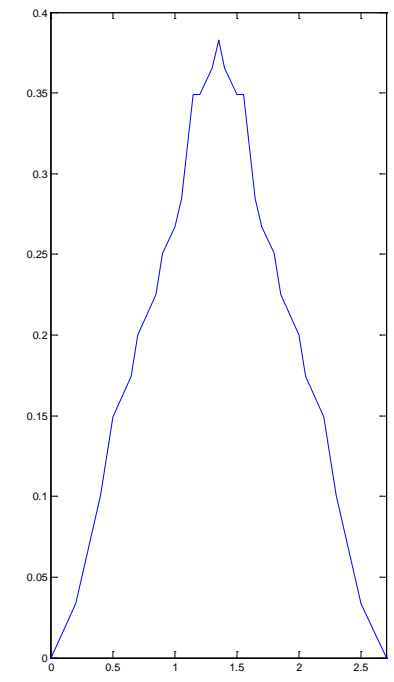

(b)

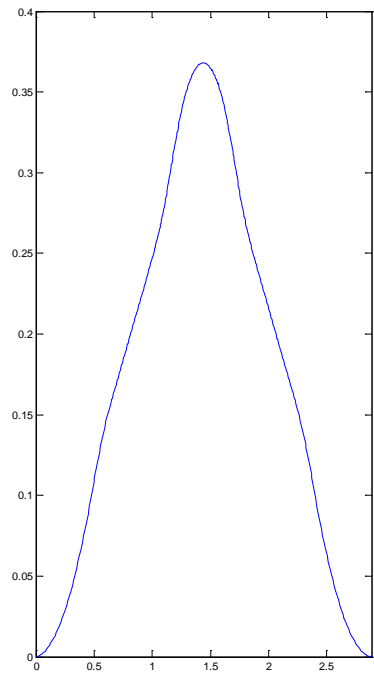

(c)

Figure 6.5: Amplitude functions for the load distribution prescribed in Eurocode with sleeper distribution. (a) Triangular amplitude functions for each point load, nine point loads. (b) Superimposed amplitude function, nine point loads. (c) Superimposed amplitude function, 49 point loads. 


\section{Chapter 7}

\section{Results}

\subsection{Spurious Acceleration Peaks}

When analyzing the results it has been discovered that depending on the number of point loads the load shape is divided into, spurious resonance peaks occur at different speeds, an example is shown in figure 7.1. The phenomenon has been observed both for simply supported bridges, see section 7.2.1, and bridges with integrated backwalls, see section 7.4.1. Further analysis indicates that this phenomenon is caused by the distance between the point loads. In Eurocode EN 1991-2 (CEN/TC 250, 2002, p. 86), equation (7.1) is given for estimation of resonant speeds for simply supported bridges. It gives a relation between critical train speed for resonance, $v_{c}$, eigenfrequencies of the bridge, $f_{i}$, and principal wavelength of frequency of excitation, $\lambda$, in this case the distance between the point loads.

$$
v_{c}=f_{i} \lambda
$$

By dividing the axle loads into 17 and 21 point loads with the triangular load shape, $\lambda$ becomes

$$
\lambda_{N p}=\frac{l s}{N_{p}} \rightarrow\left\{\begin{array}{l}
\lambda_{17}=\frac{3}{17}=0.176 m \\
\lambda_{21}=\frac{3}{21}=0.143 m
\end{array}\right.
$$

The first three natural frequencies of the bridge in figure 7.6 are $55 \mathrm{~Hz}, 221 \mathrm{~Hz}$ and $497 \mathrm{~Hz}$. Equations (7.1) and (7.2) give

$$
\begin{aligned}
& v_{c, 17}=f_{i} \lambda_{17}=\left\{\begin{array}{l}
55 \cdot 0.176 \cdot 3.6=35 \mathrm{~km} / \mathrm{h} \\
221 \cdot 0.176 \cdot 3.6=140 \mathrm{~km} / \mathrm{h} \\
497 \cdot 0.176 \cdot 3.6=315 \mathrm{~km} / \mathrm{h}
\end{array}\right. \\
& v_{c, 21}=f_{i} \lambda_{21}=\left\{\begin{array}{l}
55 \cdot 0.143 \cdot 3.6=28 \mathrm{~km} / \mathrm{h} \\
221 \cdot 0.143 \cdot 3.6=114 \mathrm{~km} / \mathrm{h} \\
497 \cdot 0.143 \cdot 3.6=256 \mathrm{~km} / \mathrm{h}
\end{array}\right.
\end{aligned}
$$


The peaks shown in figure 7.1 are due to excitation of the second and third modes of the bridge. As seen, the peaks occur at approximately the speeds calculated above.

By looking at acceleration data from a train passage in the frequency domain, this is verified. Figure 7.2 shows the transient spectrum for a train passage at speed $140 \mathrm{~km} / \mathrm{h}$. According to equation (7.3) this is a critical train speed for resonance with mode two when using $N_{p}=17$. As seen, a large peak is obtained around $221 \mathrm{~Hz}$, which is the second natural frequency of the bridge, for $N_{p}=17$ but not for $N_{p}=21$.

If these spurious peaks are to be avoided in the acceleration results when using point loads to model a load shape, the following condition must be fulfilled:

$$
\lambda_{N p}<\frac{v_{\min }}{f_{\max }}
$$

where $\lambda_{N p}$ is the distance between the point loads, $v_{\min }$ is the lowest speed being studied and $f_{\max }$ is the highest eigenfrequency included in the study. If a small enough load distance is used, the spurious peaks will fall outside the considered speed range. This formula is valid both for the triangle load shape and the Eurocode load shape.

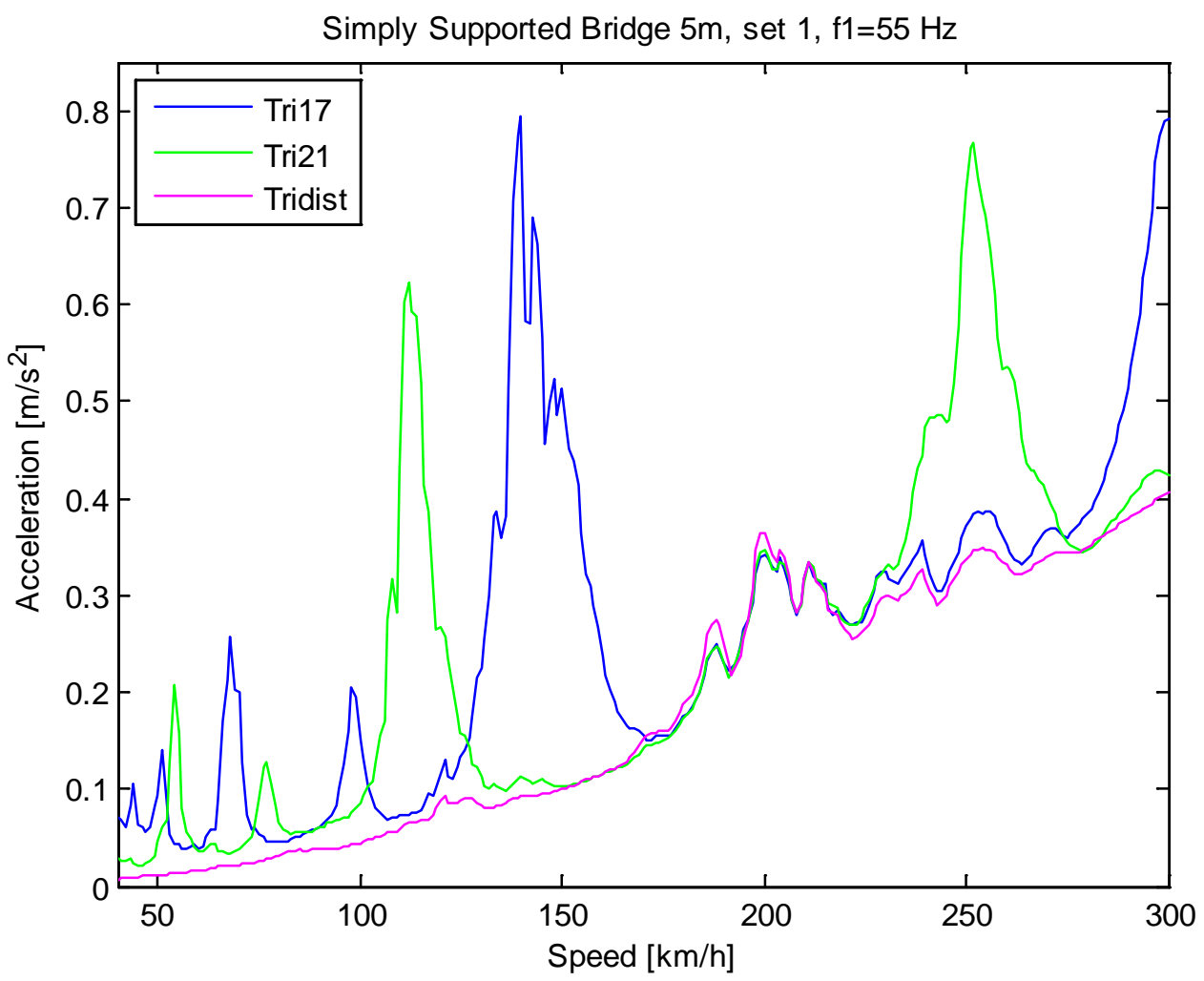

Figure 7.1: Example of how peaks caused by excitation of a bridge's natural frequencies occur at different train speeds depending on the number of point loads each axle is divided into. 


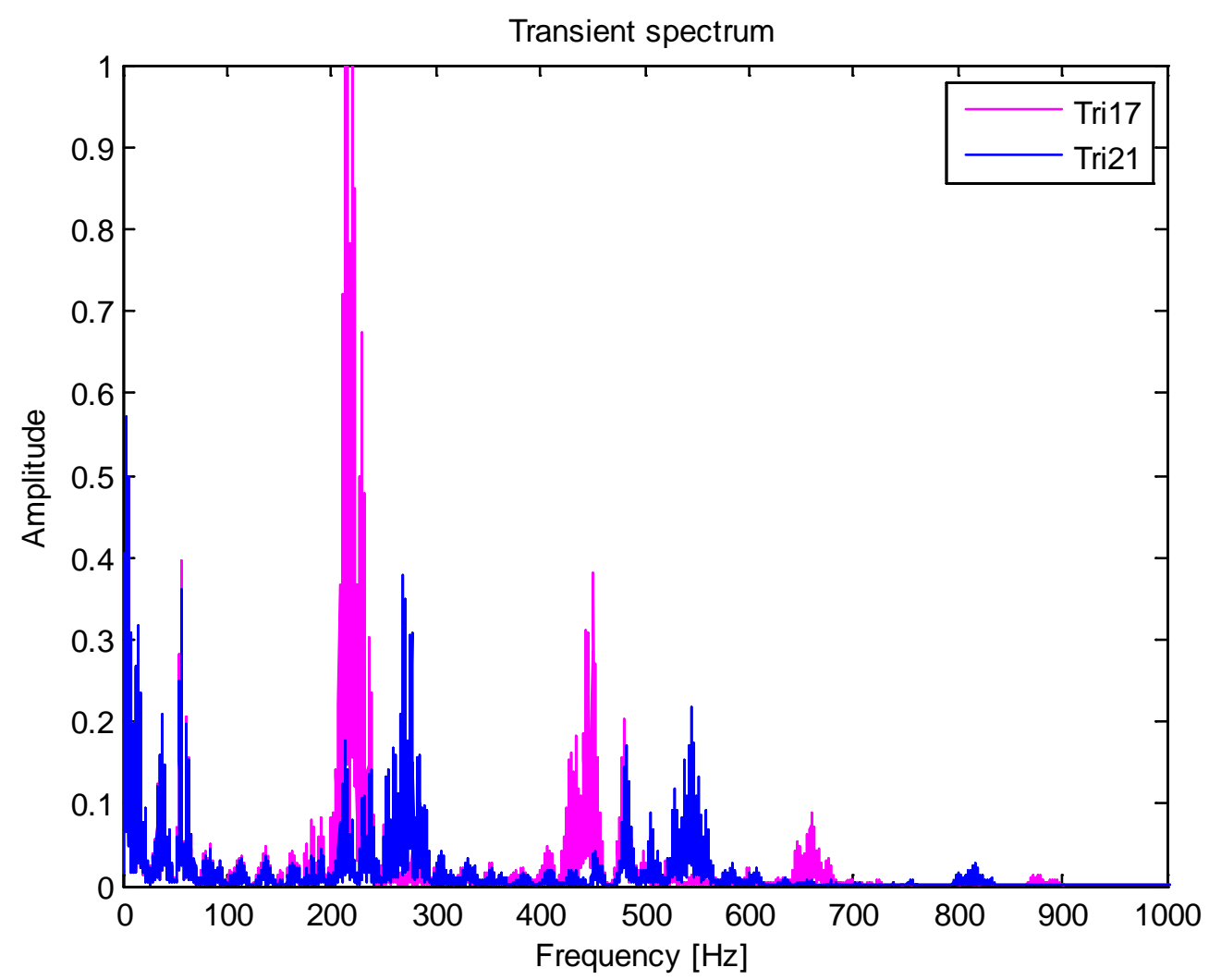

Figure 7.2: Transient spectrum for a train passage at speed $140 \mathrm{~km} / \mathrm{h}$. For $N_{p}=17$ a large peak occurs due to excitation of the second mode of the bridge.

\subsection{Accelerations - Simply Supported Bridges}

The maximum vertical accelerations of 18 simply supported bridges with properties according to table 4.1 have been calculated. The bridges are numbered from 1 to 18 in order of fundamental frequencies, where bridge number 1 is the bridge with the lowest fundamental frequency and bridge number 18 is the bridge with the highest. Simulations of an HSLM-A1 train passing over the bridges have been performed with speeds from $40 \mathrm{~km} / \mathrm{h}$ to $300 \mathrm{~km} / \mathrm{h}$, with a step of $1 \mathrm{~km} / \mathrm{h}$.

Comparisons between using different numbers of point loads and using distributed line loads for modeling the load distributions have been made and the results are presented below. The load shape EC3 is included as reference in all comparisons since it is recommended in the Eurocode.

\subsubsection{Point Loads versus Distributed Line Loads}

The load distributions can be modeled either with a chosen number of point loads or with a distributed line load, as mentioned in section 5.2. The difference between these two ways of modeling has been studied and the results are presented in this section. 


\section{The Eurocode Load Distribution}

The maximum accelerations obtained for the different load shapes EC3, EC9, EC15 and ECdist are shown in figure 7.3. In the figure it can be seen that the load shapes with sleeper distribution (EC9, EC15 and ECdist) give a reduction compared to EC3 that increases with increasing fundamental frequency of the bridges.

From the results it is found that the distributed Eurocode line load ECdist gives lower maximum accelerations compared to the Eurocode point loads (EC9 and EC15) for all bridges studied. However, as can be seen from figure 7.3, the different load distributions give very similar results for the majority of the bridges, why the gain in using a distributed line load instead of point load distributions in most cases is negligible.

For bridge number 17 it can be seen that using either ECdist or EC15 clearly lowers the maximum acceleration of the bridge compared to using EC3 or EC9. If one of these load distributions is used the bridge fulfills the Eurocode acceleration criterion, something it would not do with EC9. The speed-acceleration graph for this bridge is shown in figure 7.4. From the figure it can also be seen how the load shapes modeled with point loads cause peaks that disappear when the distributed line load is used. These peaks are spurious acceleration peaks caused by the phenomenon explained in section 7.1.

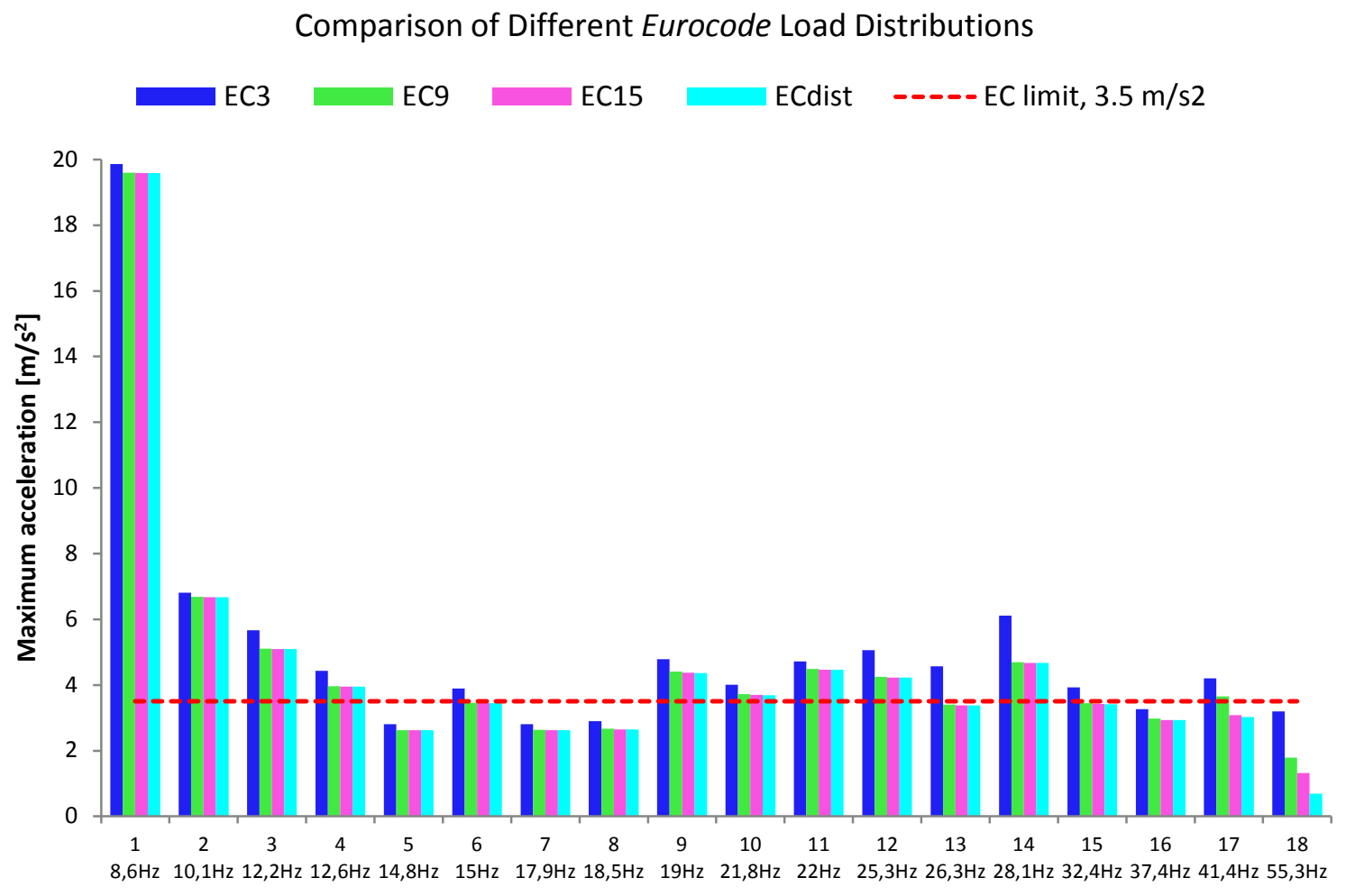

Bridge number and fundamental frequency

Figure 7.3: Maximum vertical accelerations for the 18 simply supported bridges studied when using different Eurocode load distributions. Marked in red is the Eurocode acceleration limit at $3.5 \mathrm{~m} / \mathrm{s}^{2}$. 


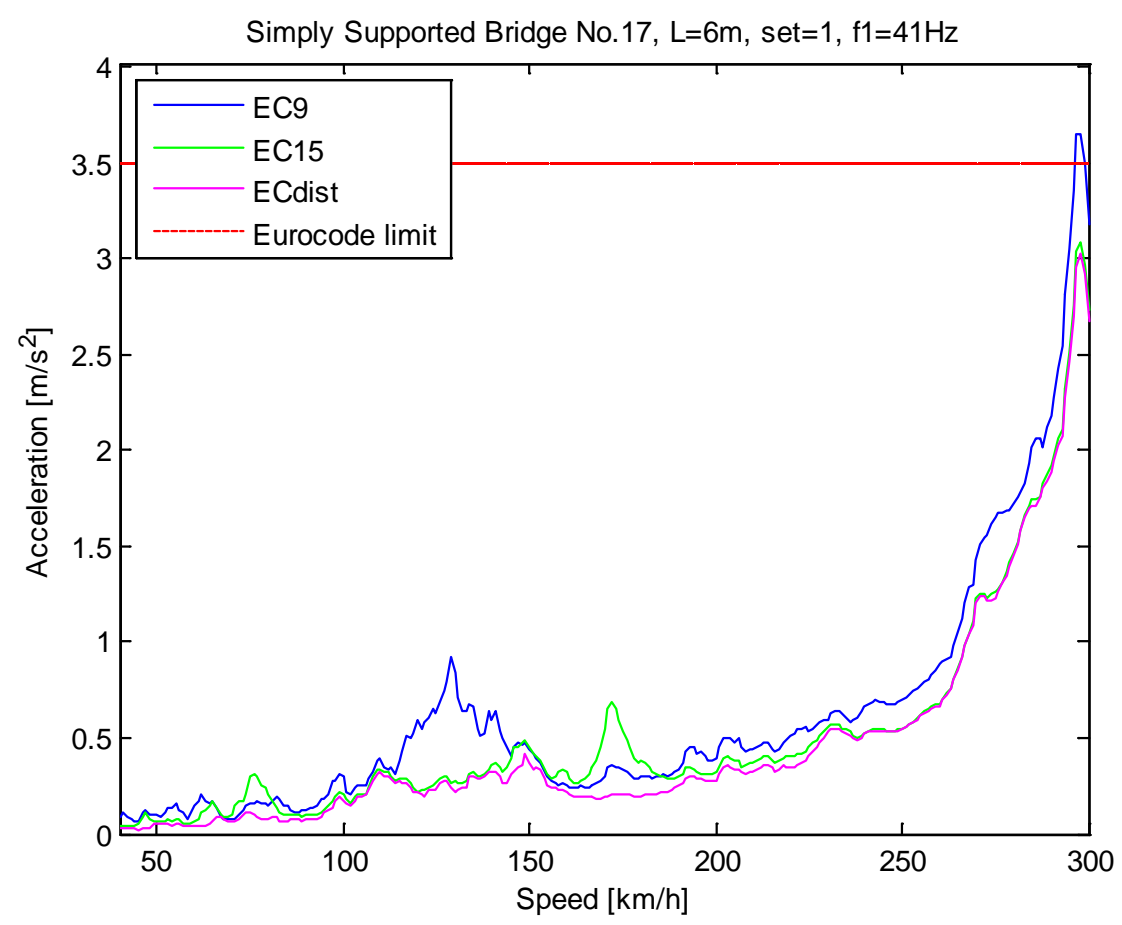

Figure 7.4: Speed-acceleration graph for bridge number 17 showing how EC9 exceeds the Eurocode limit while EC15 and ECdist pass the limit.

For the bridge with the highest fundamental frequency, bridge number 18, there is a remarkable difference in maximum acceleration between the different load distribution types and to use the distributed line load in this case, rather than point loads, gives strongly reduced accelerations. The large difference is due to spurious peaks that occur for EC9 and EC15, see figure 7.5. The point in using any other load spreading than EC3 in this case would however be none since the maximum acceleration obtained for EC3 already is lower than the Eurocode limit.

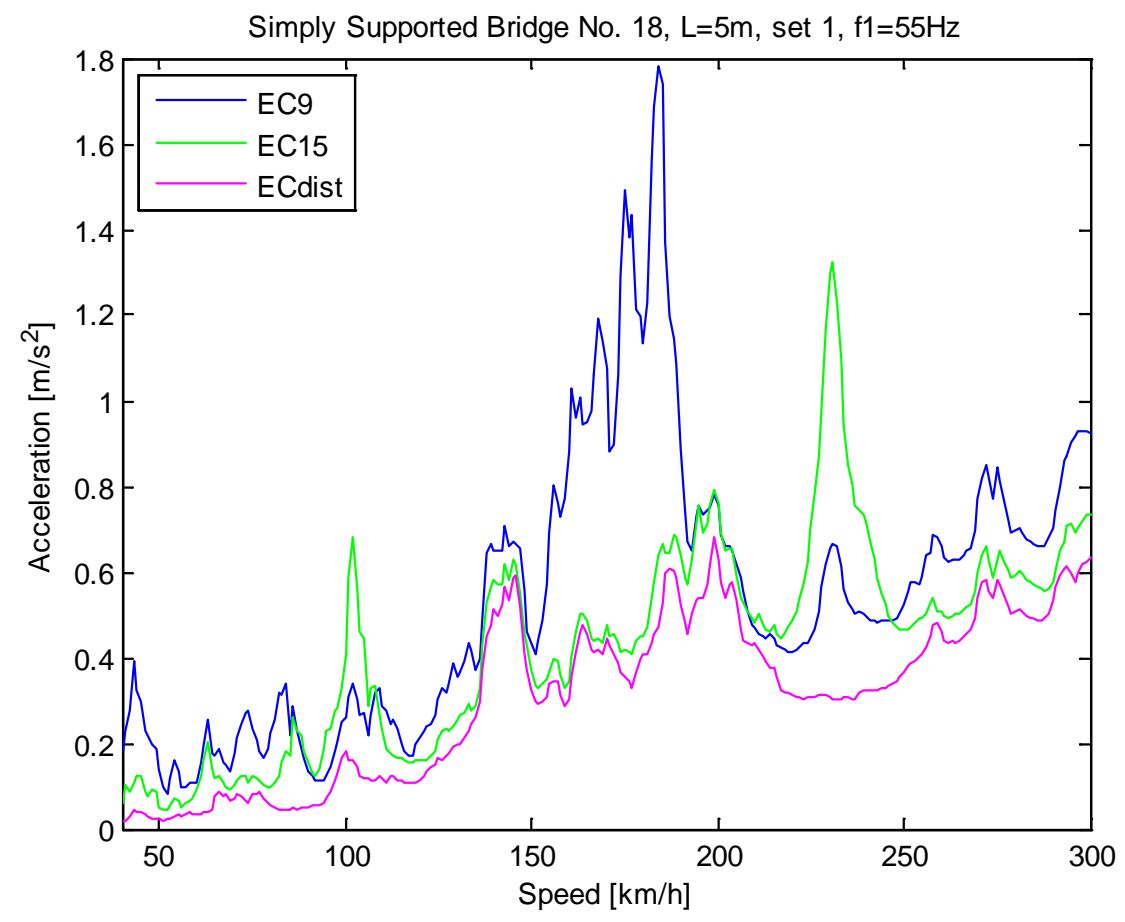

Figure 7.5: Speed-acceleration graph for bridge number 18 showing how spurious acceleration peaks occur when using EC9 and EC15. 


\section{The Triangle Load Distribution}

The results from simulations with the triangle load shapes with load distributions EC3, Tri17, Tri21 and Tridist are compiled in figure 7.6. As in the case with the Eurocode distributions, a general trend can be seen of larger acceleration reductions with higher fundamental frequencies of the bridges, when compared to EC3. However, the maximum accelerations for the different triangle load distributions follow a different pattern than for the different Eurocode load distributions. All three types of triangle loads give a significant reduction of the accelerations compared to EC3, but the more point loads the triangular load distribution is divided into, the higher become the vertical accelerations of the bridges. Bridge number 18 seems to show the opposite effect in the figure but this is found to be due to spurious peaks for Tri17 and Tri21. If these are removed, the same pattern as for the other bridges can be seen.

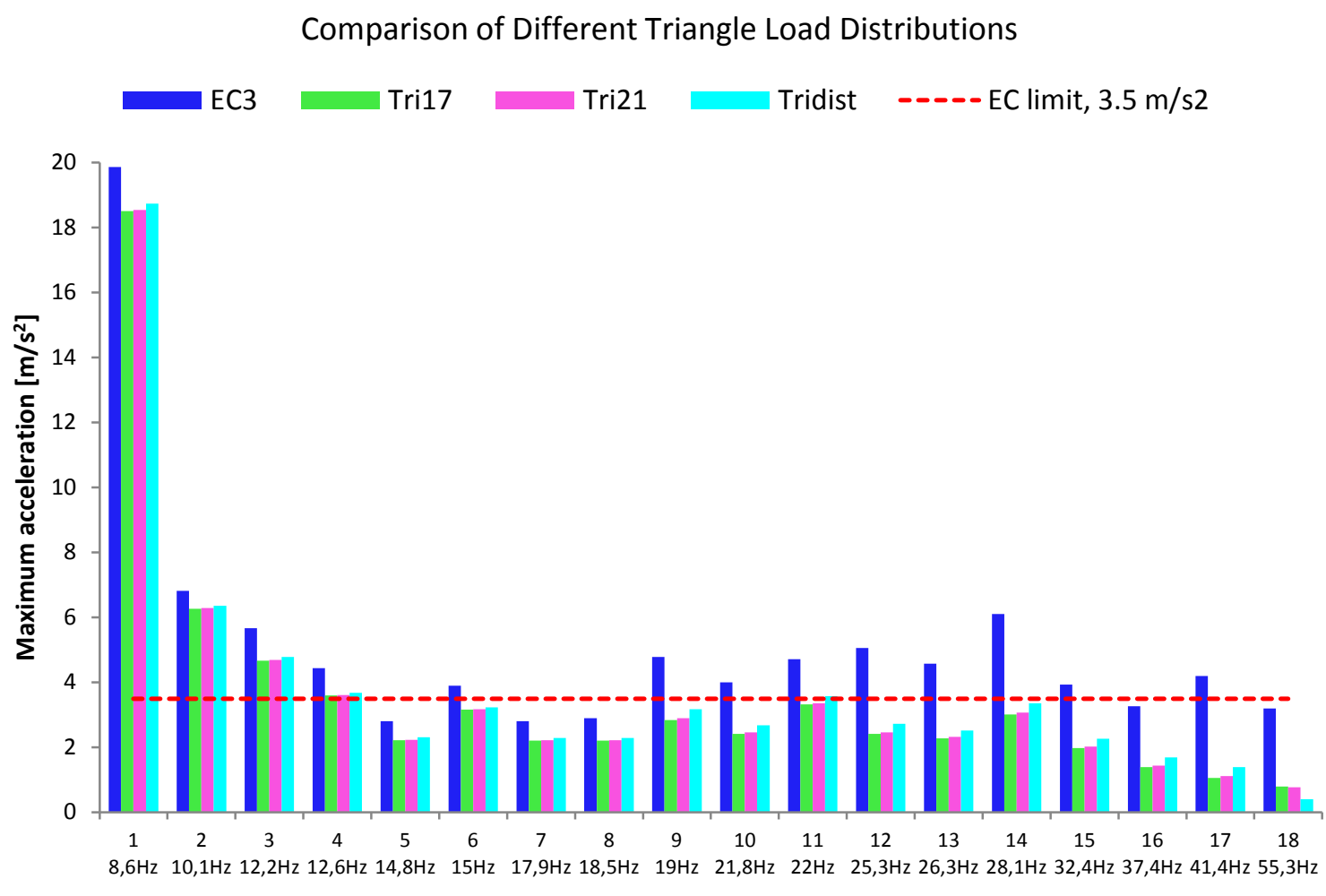

Bridge number and fundamental frequency

Figure 7.6: Maximum vertical accelerations for the 18 simply supported bridges studied when using EC3 and different triangle distributions. Marked in red is the Eurocode acceleration limit at $3.5 \mathrm{~m} / \mathrm{s}^{2}$.

As mentioned, the more point loads that are used for modeling the triangle load shape, the higher become the maximum accelerations. The opposite effect would be expected, but the pattern has been verified both by running the simulations with an increasing number of point loads and by modeling the load shapes both in Matlab and in Abaqus. The results show that the accelerations from the triangle point load distributions converge towards the accelerations obtained from the distributed line load Tridist, as shown in figure 7.7.

In the case of bridge number 11 the difference between using point loads and using the distributed line load is critical for whether the bridge will be considered to pass the Eurocode limit or not, see figure 7.8. 


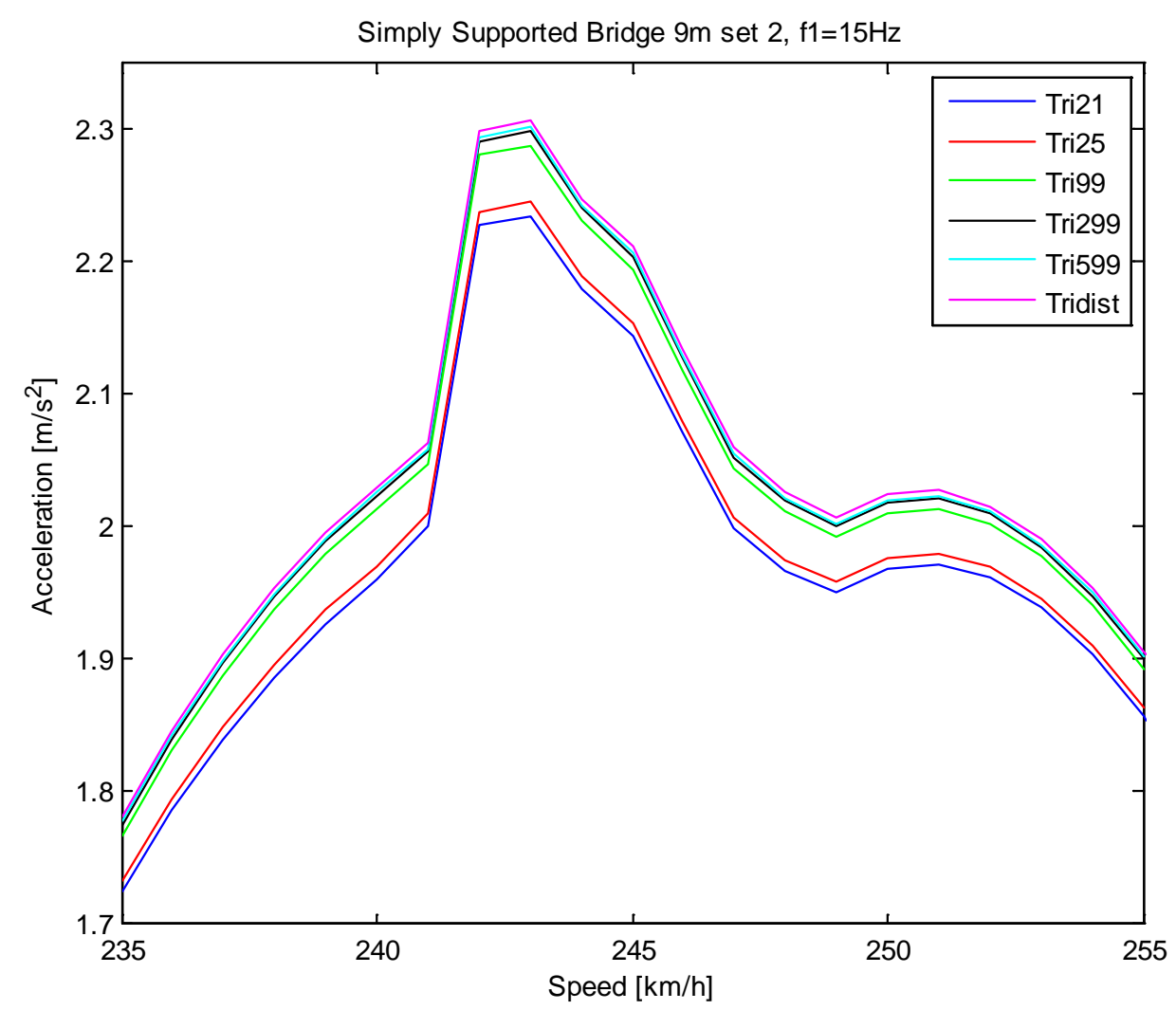

Figure 7.7: Speed-acceleration graph for a simply supported bridge showing how the accelerations become higher and approach the Tridist curve as more point loads are used to model the load distribution.

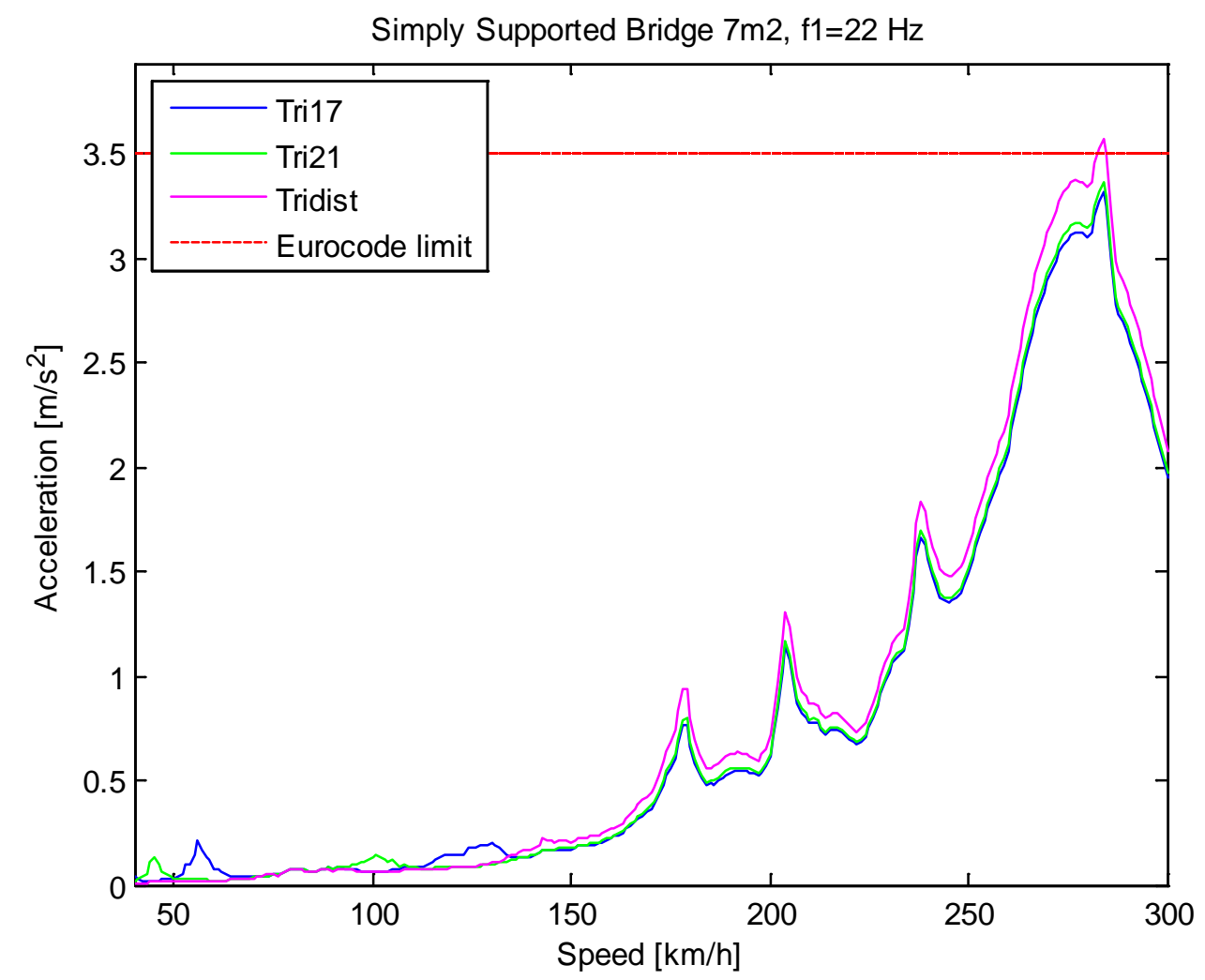

Figure 7.8: Speed-acceleration graph for bridge number 11 showing how Tridist exceeds the Eurocode limit while Tri17 and Tri21 pass the limit. 


\subsubsection{Distributed Eurocode Loads versus Distributed Triangle Loads}

A comparison between the accelerations for the Eurocode distributions EC3 and ECdist and the triangle distribution Tridist is shown in figure 7.9. From the figure it can be seen that the triangle load distribution gives the lowest maximum accelerations for all bridges. Also the Eurocode line load distribution gives significantly lower accelerations compared to EC3. For some bridges the choice of load distribution is vital for whether the Eurocode acceleration criterion is fulfilled or not. An example of such a bridge is shown in figure 7.10.

The reductions of the accelerations, $R^{\prime}$, have been calculated with equation (2.2) for all bridges and are compiled in figure 7.11. The blue curves show the reductions when using the Eurocode distributed line load and the curves in magenta show the reductions when using the triangle distributed line load. Also included is the lower bound defined by Museros et al. (2002). The lower bound was only defined for wavelengths from 2 to $10 \mathrm{~m}$. Since lower wavelengths are included in this study, an extension of the curve has been added and is represented by the dashed line. The extension is attained by using equation (2.3) with wavelengths shorter than $2 \mathrm{~m}$.

It can be seen that for wavelengths larger than $1 \mathrm{~m}$ the obtained results follow the same trend as the lower bound defined by Museros et al. However, the obtained reductions are larger for all wavelengths greater than $1 \mathrm{~m}$, which was expected since the load is spread over a greater distance than what was used by Museros et al.

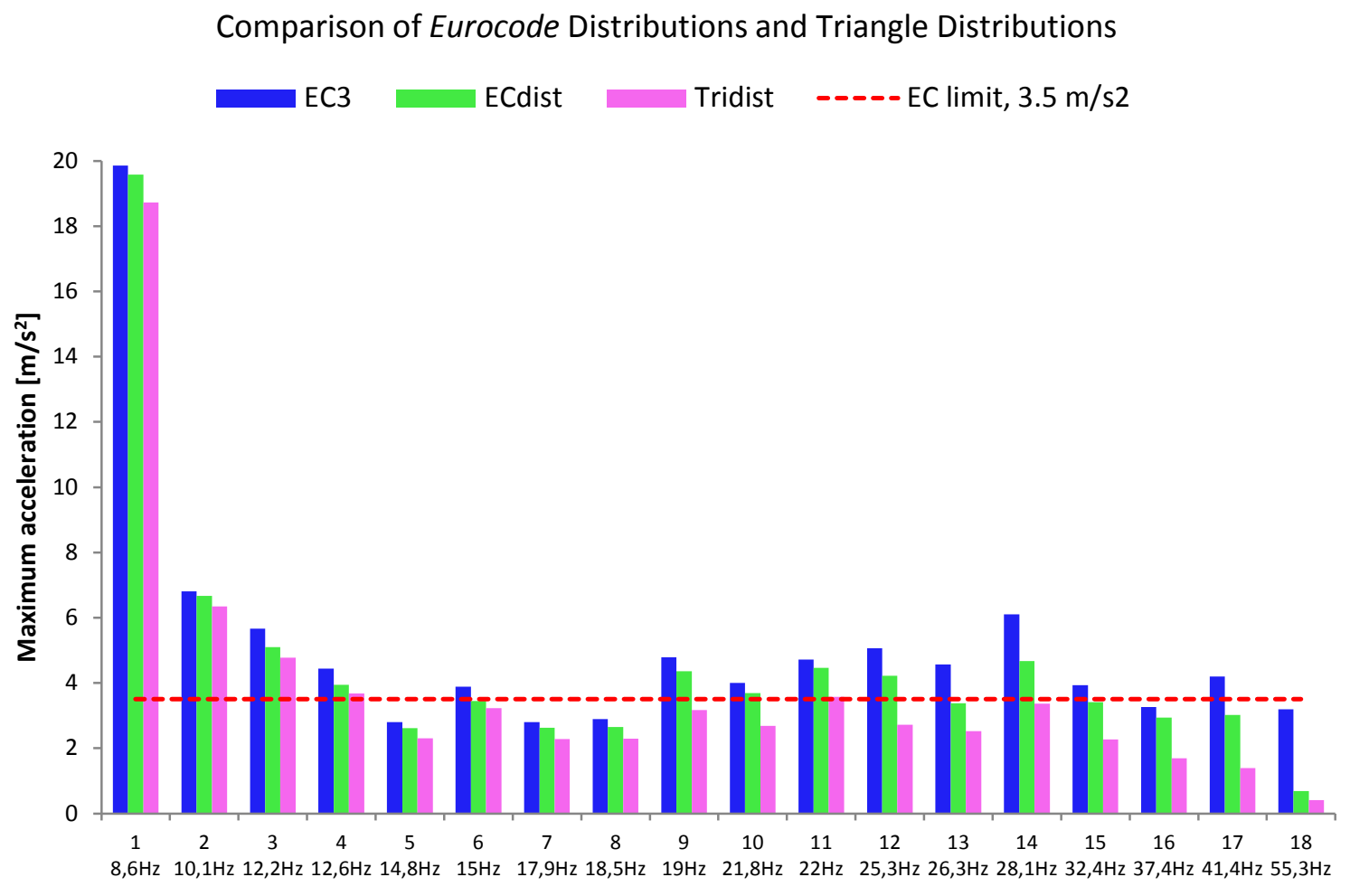

Bridge number and fundamental frequency

Figure 7.9: Maximum vertical accelerations for the 18 simply supported bridges studied when using different load distributions. Marked in red is the Eurocode acceleration limit at $3.5 \mathrm{~m} / \mathrm{s}^{2}$. 
Simply Supported Bridge $5 \mathrm{~m} 3, \mathrm{f} 1=25 \mathrm{~Hz}$

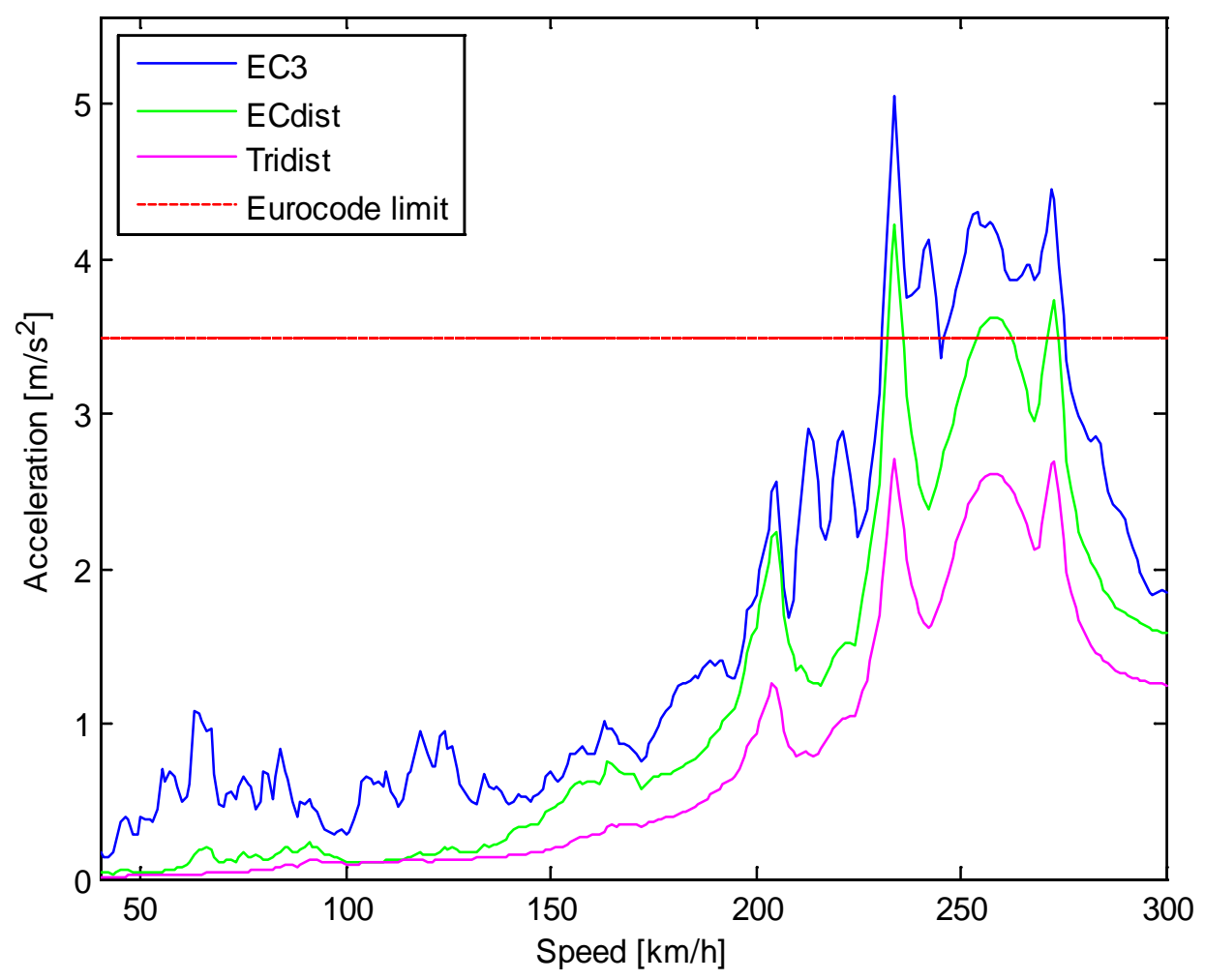

Figure 7.10: Speed-acceleration graph for bridge number 12 showing how EC3 and ECdist exceed the Eurocode limit while Tridist passes the limit.

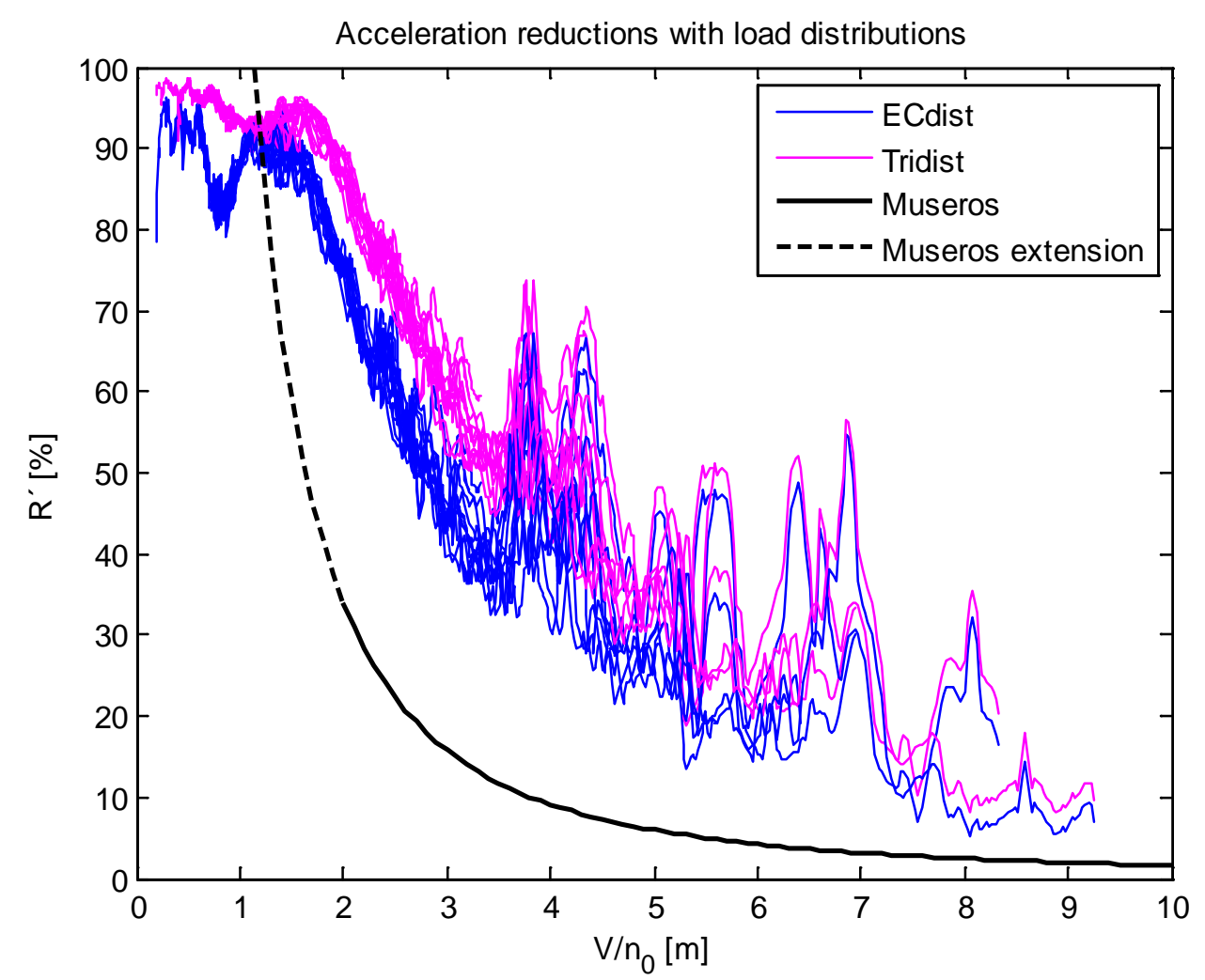

Figure 7.11: Reduction of the accelerations as a function of the wavelength. 


\subsection{Bending Moments - Simply Supported Bridges}

When calculating the maximum positive and negative bending moments, the bending moment in the bridge is first calculated for every time step. Positive bending moments are defined as the moments caused by upward curvature and negative as the moments caused by downward curvature. The maximum values in every node are then collected, forming an envelope for the specific speed, see figure 7.12a. The same procedure is repeated for all train speeds, creating a number of envelopes. A second, final envelope is created from the previous envelopes, giving the maximum bending moment in the bridge for all train passages studied, see figure 7.12b.

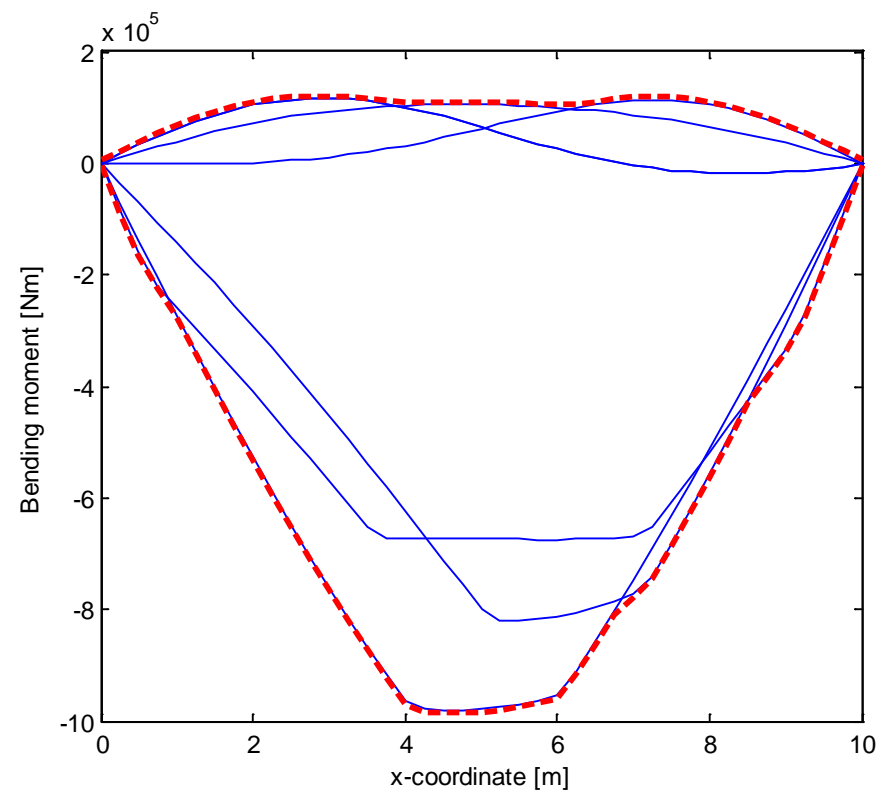

(a)

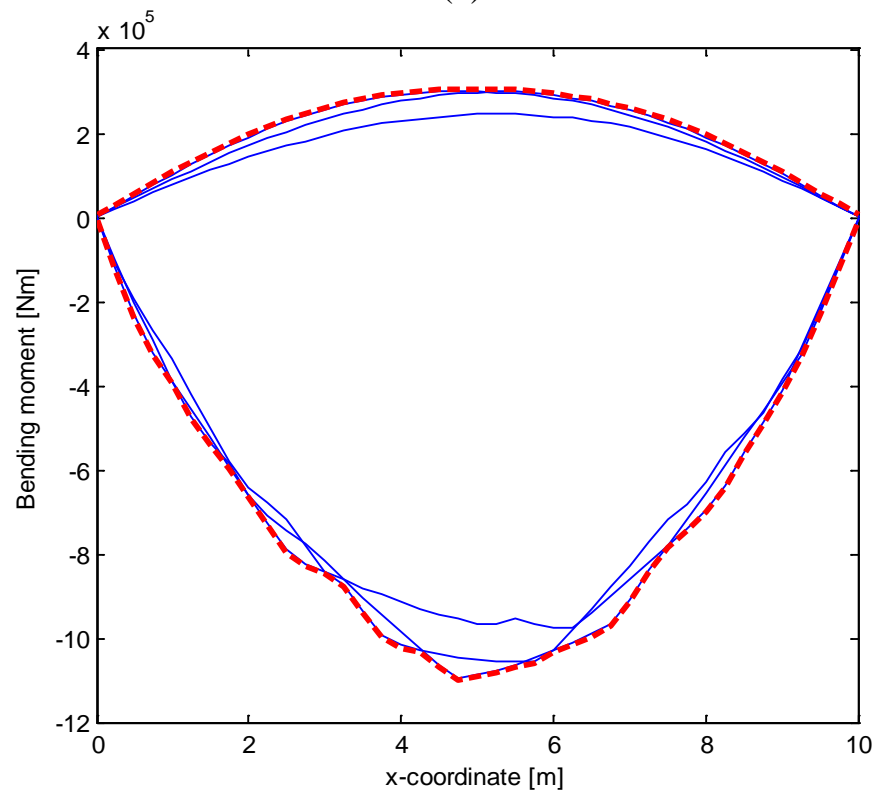

(b)

Figure 7.12: Bending moment in a bridge. (a) The blue curves represent the moment at different time steps. The dashed, red curves represent the envelopes for maximum positive and negative moments. (b) The blue curves represent the moment envelopes for different train speeds. The dashed, red curves represent the final envelopes for maximum positive and negative moments. 
The maximum bending moments have been calculated for the 18 simply supported bridges with properties according to table 4.1. The studied bridges are numbered from 1 to 18 in order of fundamental frequencies, where bridge number 1 is the bridge with the lowest fundamental frequency and bridge number 18 is the bridge with the highest. Simulations of an HSLM-A1 train passing over the bridges have been performed with speeds from $40 \mathrm{~km} / \mathrm{h}$ to $300 \mathrm{~km} / \mathrm{h}$, with a step of $1 \mathrm{~km} / \mathrm{h}$.

Comparisons between using point loads and using distributed loads for modeling the load distributions have been made and the results are presented below.

Since all bridges studied are short there are times when the train is passing although no axles are on the bridge. This is due to the fact that the distance between the front and rear bogies of the coaches is $18 \mathrm{~m}$. During the times when no axles are on the bridge, free vibrations arise resulting in upward curvature and tension in the top, see figure 7.13. For some cases the upward displacements and bending moment reach very high levels. The most extreme example is bridge number 1 , shown in figure 7.14 , a $10 \mathrm{~m}$ bridge where the maximum positive moment reaches a value of almost $4 \mathrm{MNm}$.

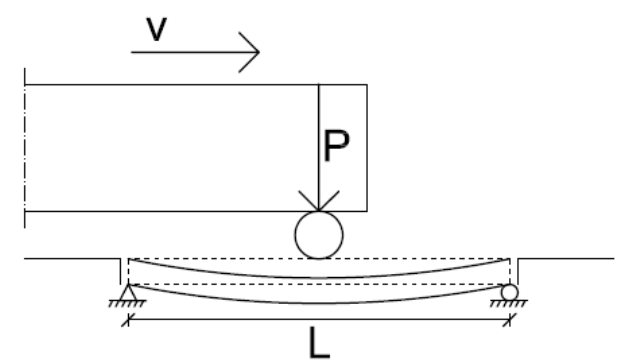

(a)

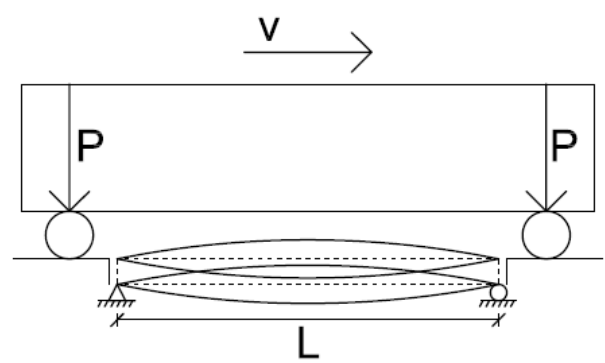

(b)

Figure 7.13: A train coach passing a bridge. (a) An axle is acting on the bridge causing downward displacements. (b) No axles are acting on the bridge giving rise to free vibrations. During this time the bridge is subjected to both upward and downward displacements.

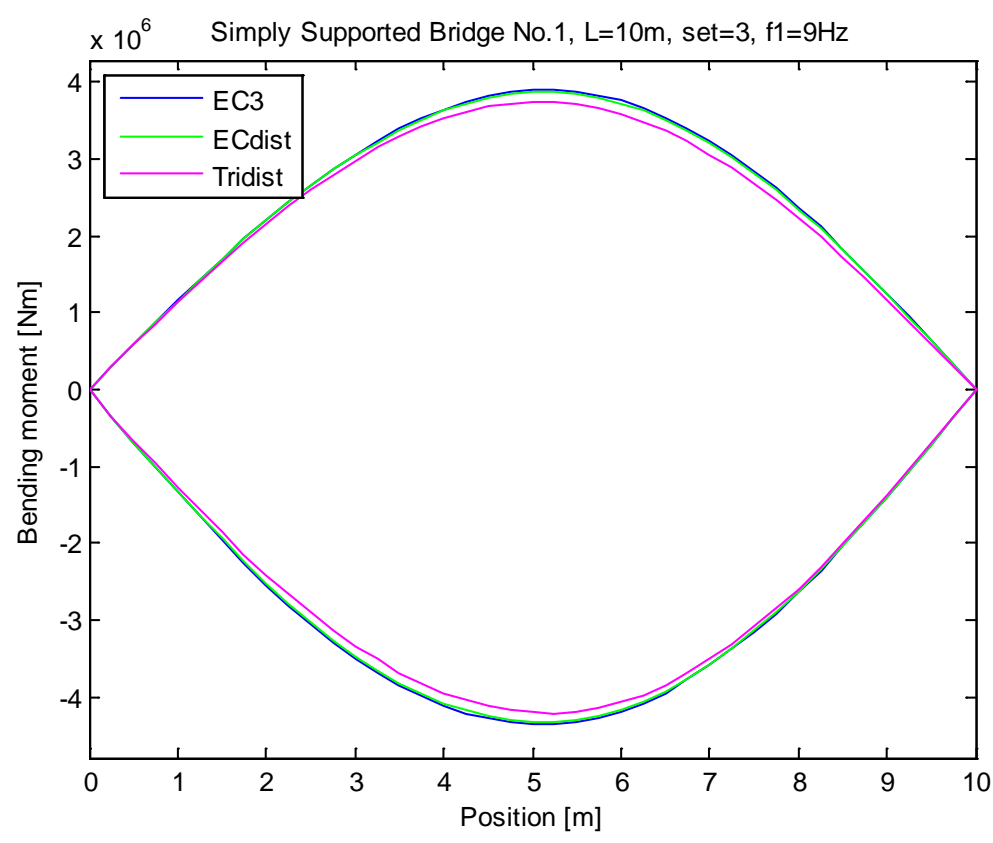

Figure 7.14: Maximum bending moments in bridge number 1 for different load distributions. 
It has been found that the maximum and minimum bending moments peak at approximately the same speeds as the maximum vertical accelerations, an example of this is shown in figure 7.15. As seen in the figure, the maximum bending moments follows the acceleration curve very well, while the curve of the minimum bending moment differs a little bit.
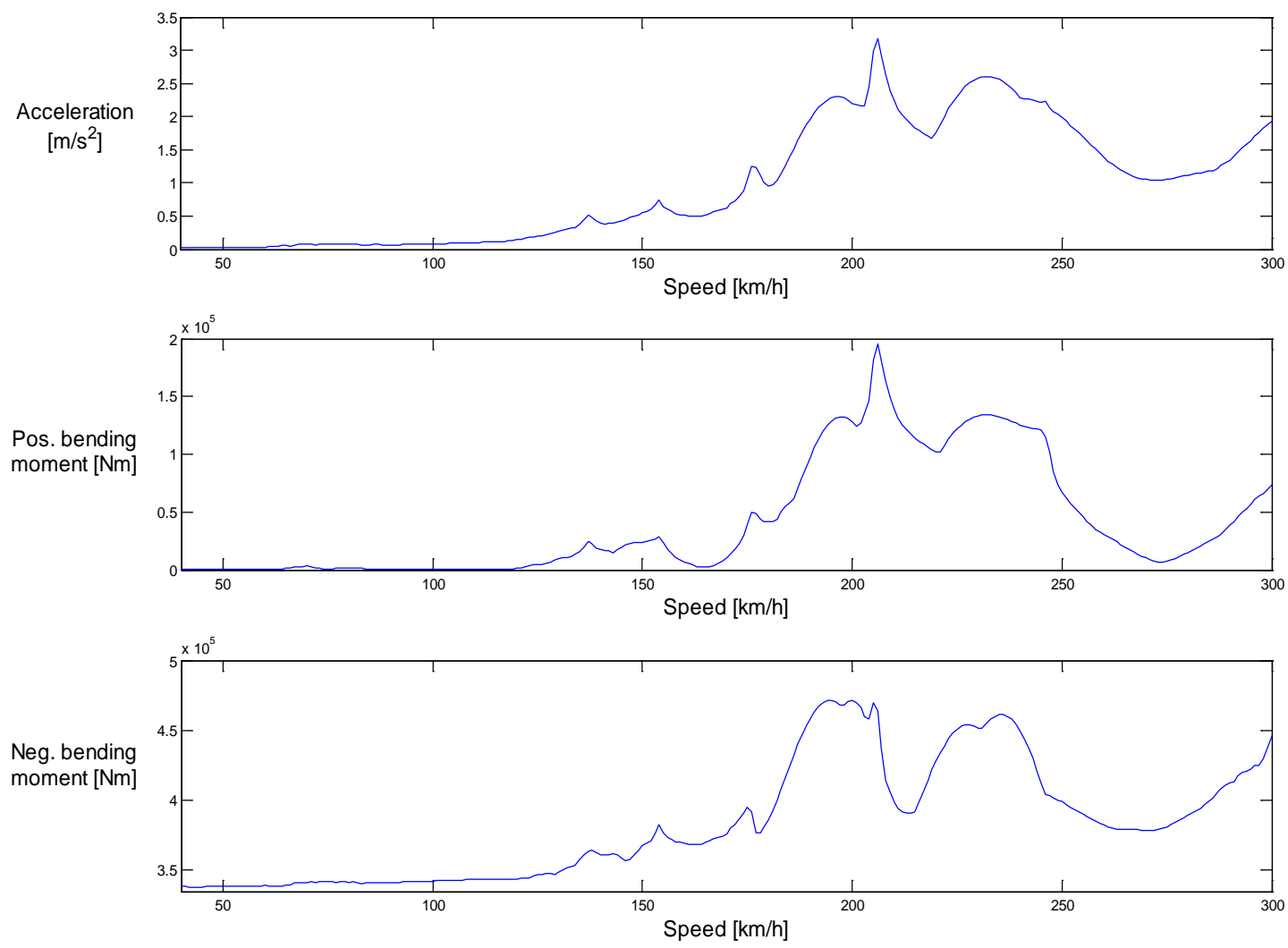

Figure 7.15: Speed-acceleration and speed-bending moment graphs for bridge number 9.

\subsubsection{Point Loads versus Distributed Line Loads}

\section{The Eurocode Load Distribution}

The obtained maximum bending moments for the studied bridges when using different Eurocode load distributions are presented in figure 7.16. From the figures it can be seen that the reduction of bending moments when modeling the Eurocode load distribution as a distributed line load instead of with point loads is negligible. The difference in bending moments between using nine or fifteen point loads is also very small.

\section{The Triangle Load Distribution}

The maximum positive and negative bending moments in the bridges when using different triangle load distributions are presented in figure 7.17. The tendencies for the moments are the same as for the maximum vertical accelerations, the more point loads used to model the load distribution, the higher the values of the bending moments. The highest values are obtained for the distributed line load. From the figure it can be seen that the difference between Tri17 and Tri21 is very small, while there is a somewhat larger difference between the point load 
distributions and Tridist. It can also be seen that the reductions of the positive bending moments are larger than the reductions of the negative moments.

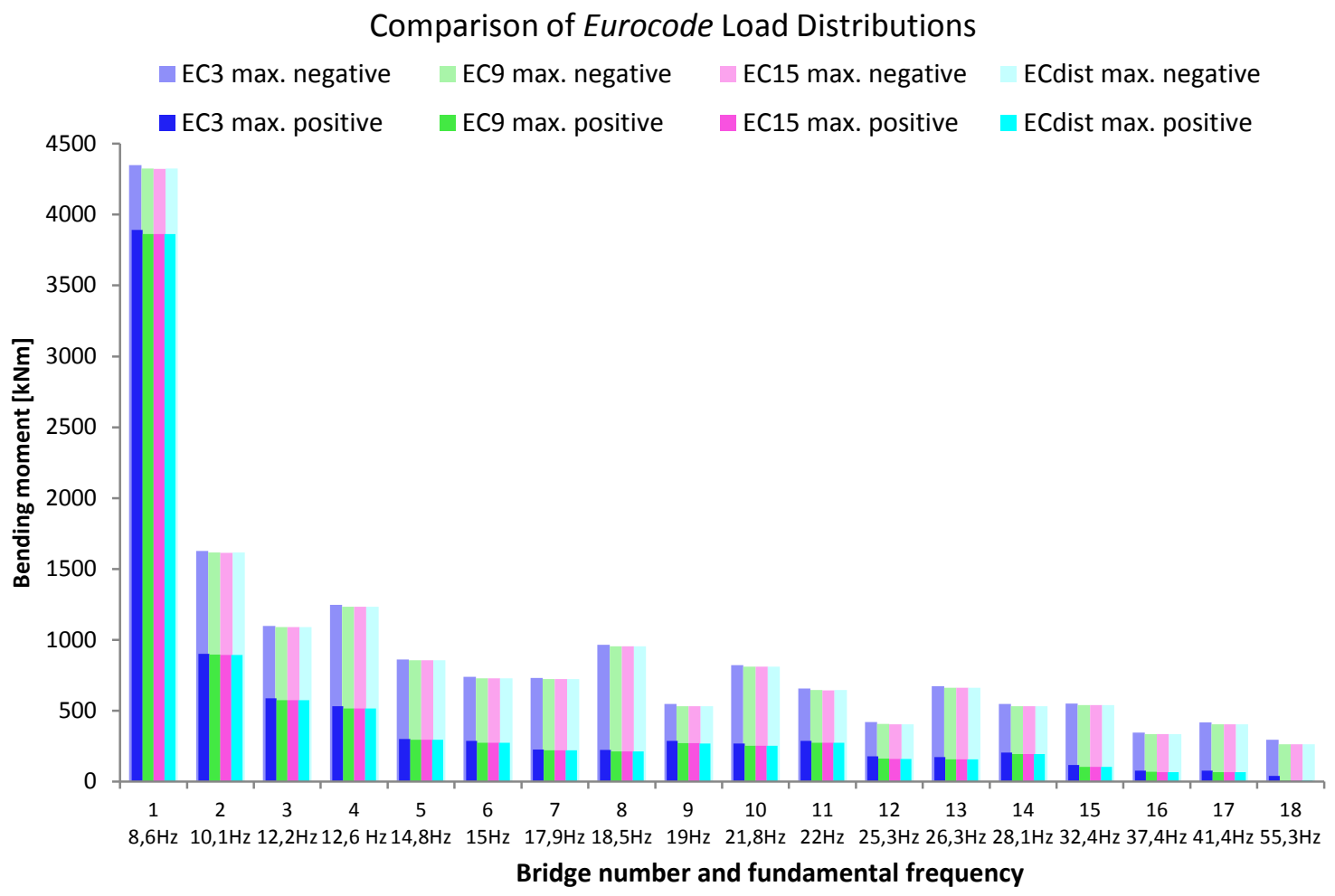

Figure 7.16: Maximum positive and negative bending moment for the 18 simply supported bridges studied when using different Eurocode load distributions.

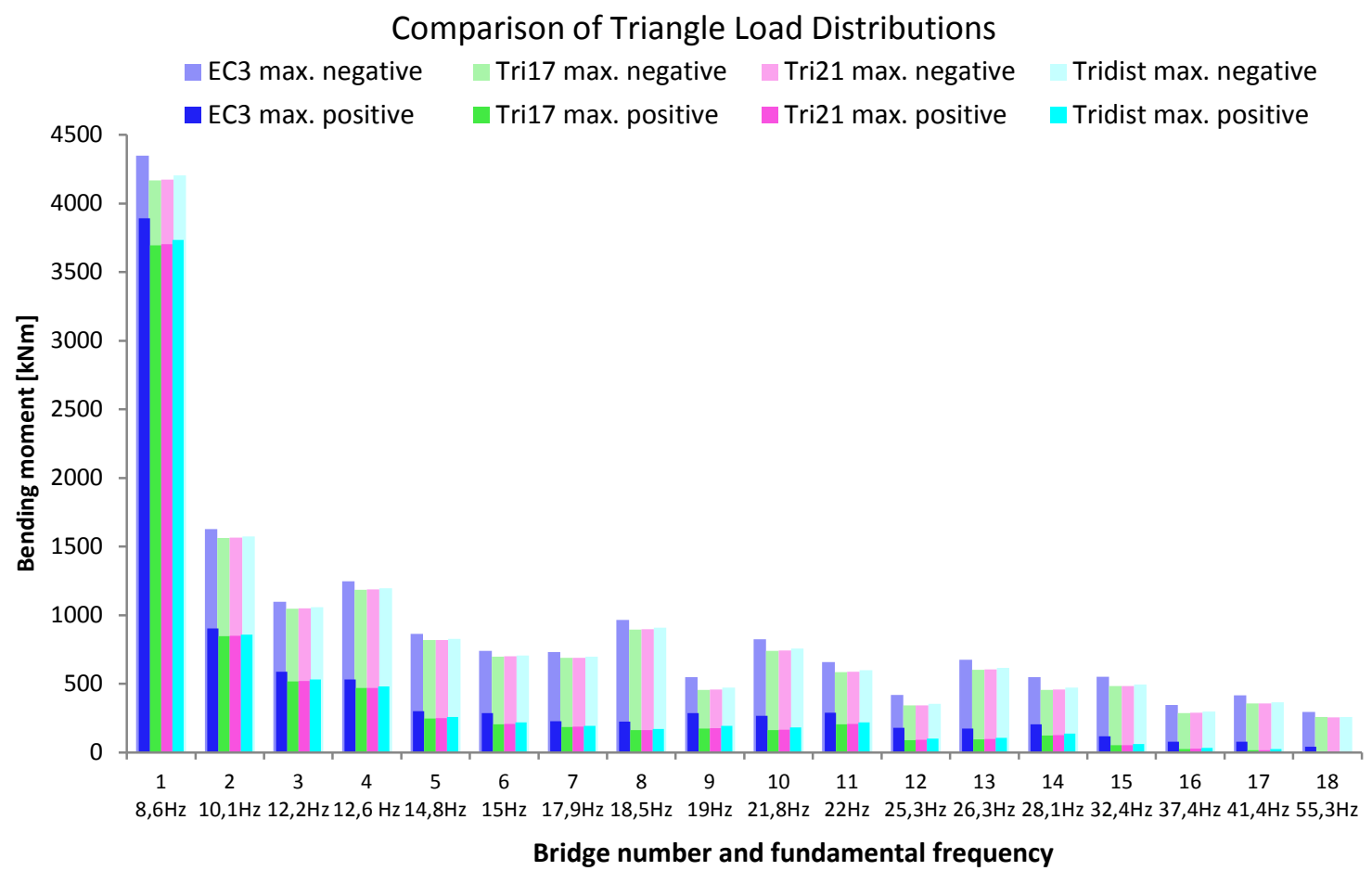

Figure 7.17: Maximum positive and negative bending moment for the 18 simply supported bridges studied when using different triangle load distributions. 


\subsubsection{Distributed Eurocode Loads versus Distributed Triangle Loads}

Comparisons between the Eurocode line load distribution and the triangle line load distribution for the maximum positive and negative bending moments are shown in figure 7.18. The triangle distributed line load gives the lowest values of the bending moments for all bridges, and is therefore the most advantageous load distribution to use.

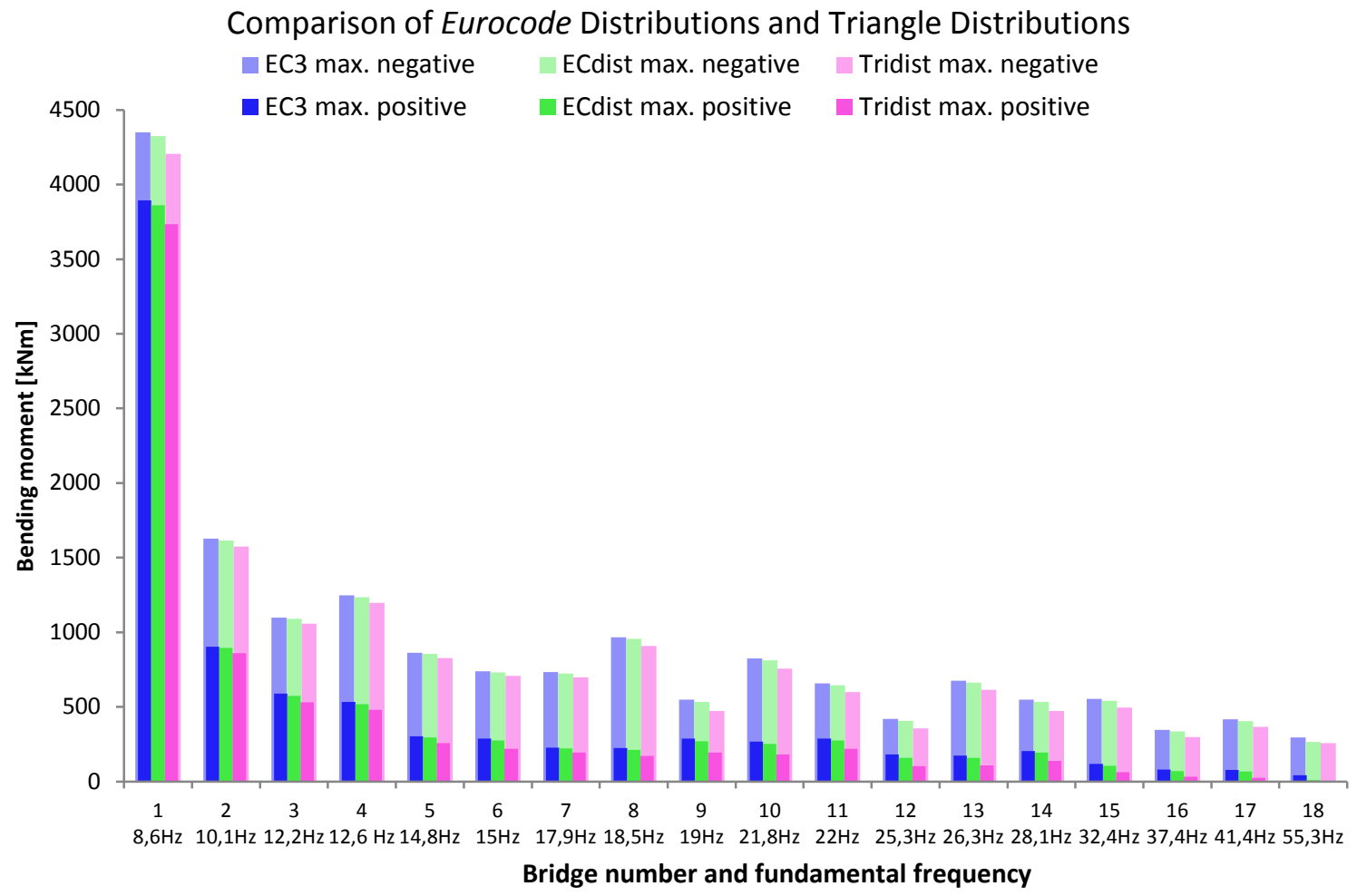

Figure 7.18: Maximum positive and negative bending moment for the 18 simply supported bridges studied when using different load distributions. 


\subsection{Accelerations - Bridges with Integrated Backwalls}

The maximum vertical accelerations of four bridges with integrated backwalls and properties according to table 4.2 have been calculated. Simulations of an HSLM-A1 train passing over the bridges have been performed with speeds from $40 \mathrm{~km} / \mathrm{h}$ to $300 \mathrm{~km} / \mathrm{h}$, with a step of 1 $\mathrm{km} / \mathrm{h}$.

\subsubsection{Point Loads versus Distributed Line Loads}

Comparisons between using point loads and using distributed loads for modeling the load distributions have been made and the results are presented below.

\section{The Eurocode Load Distribution}

The maximum accelerations obtained for the different Eurocode load distributions are shown in figures 7.19-7.22.

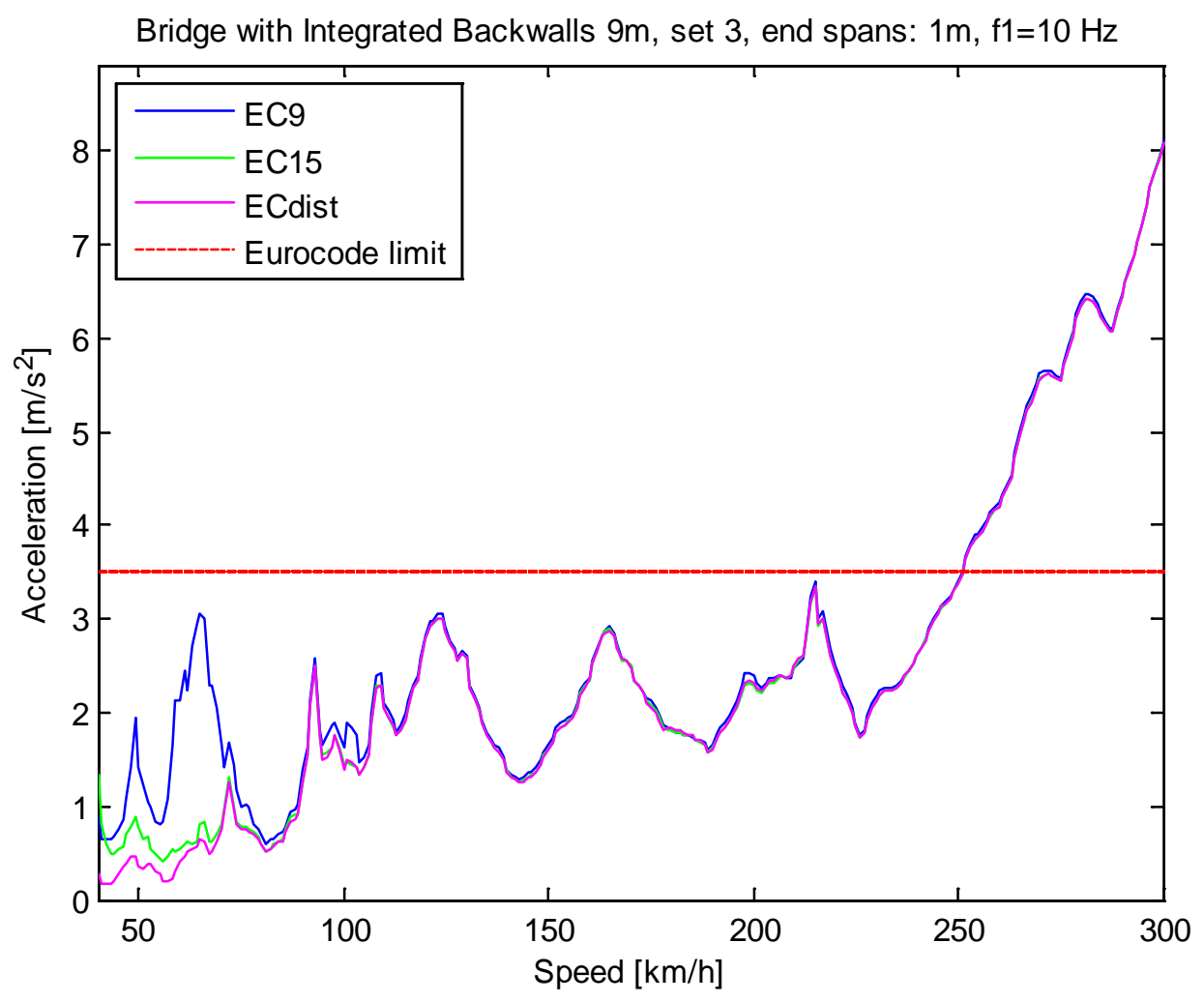

Figure 7.19: Speed-acceleration graph of a bridge with integrated backwalls when using different Eurocode load distributions. 
Bridge with Integrated Backwalls $7 \mathrm{~m}$, set 3 , end spans: $1 \mathrm{~m}, \mathrm{f} 1=15 \mathrm{~Hz}$

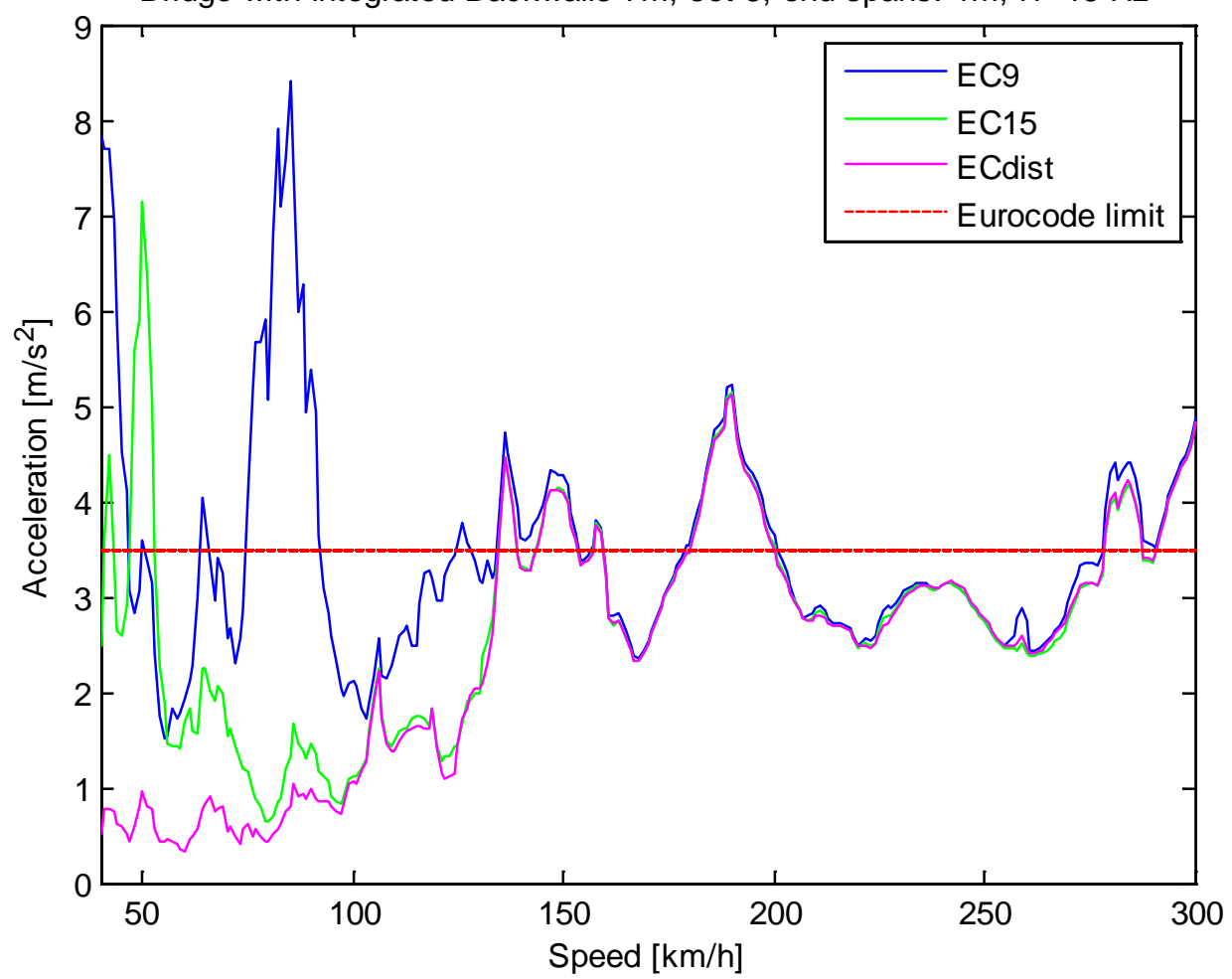

Figure 7.20: Speed-acceleration graph of a bridge with integrated backwalls when using different Eurocode load distributions.

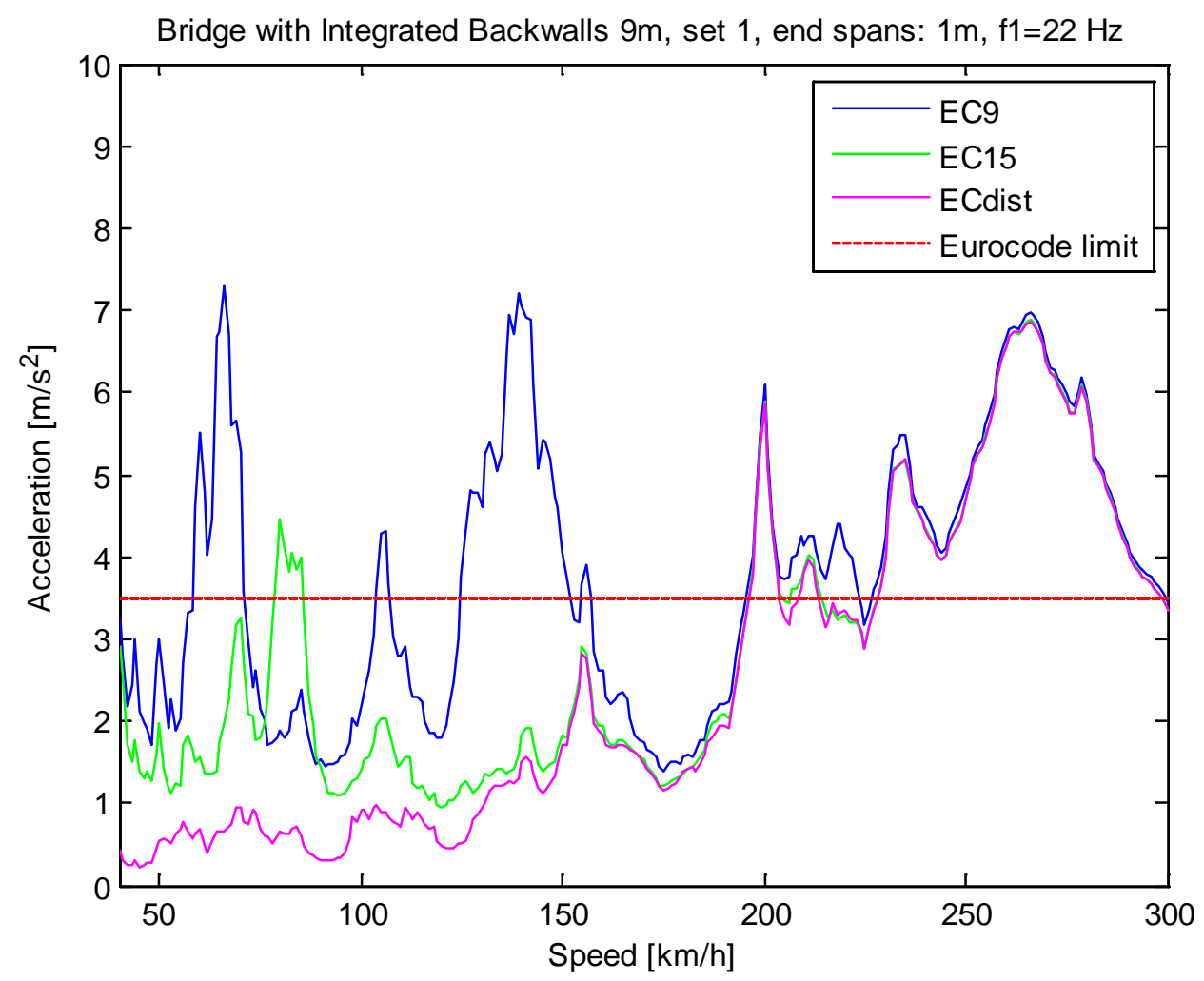

Figure 7.21: Speed-acceleration graph of a bridge with integrated backwalls when using different Eurocode load distributions. 
Bridge with Integrated Backwalls 7m, set 1 , end spans: $1 \mathrm{~m}$, f1=32 Hz

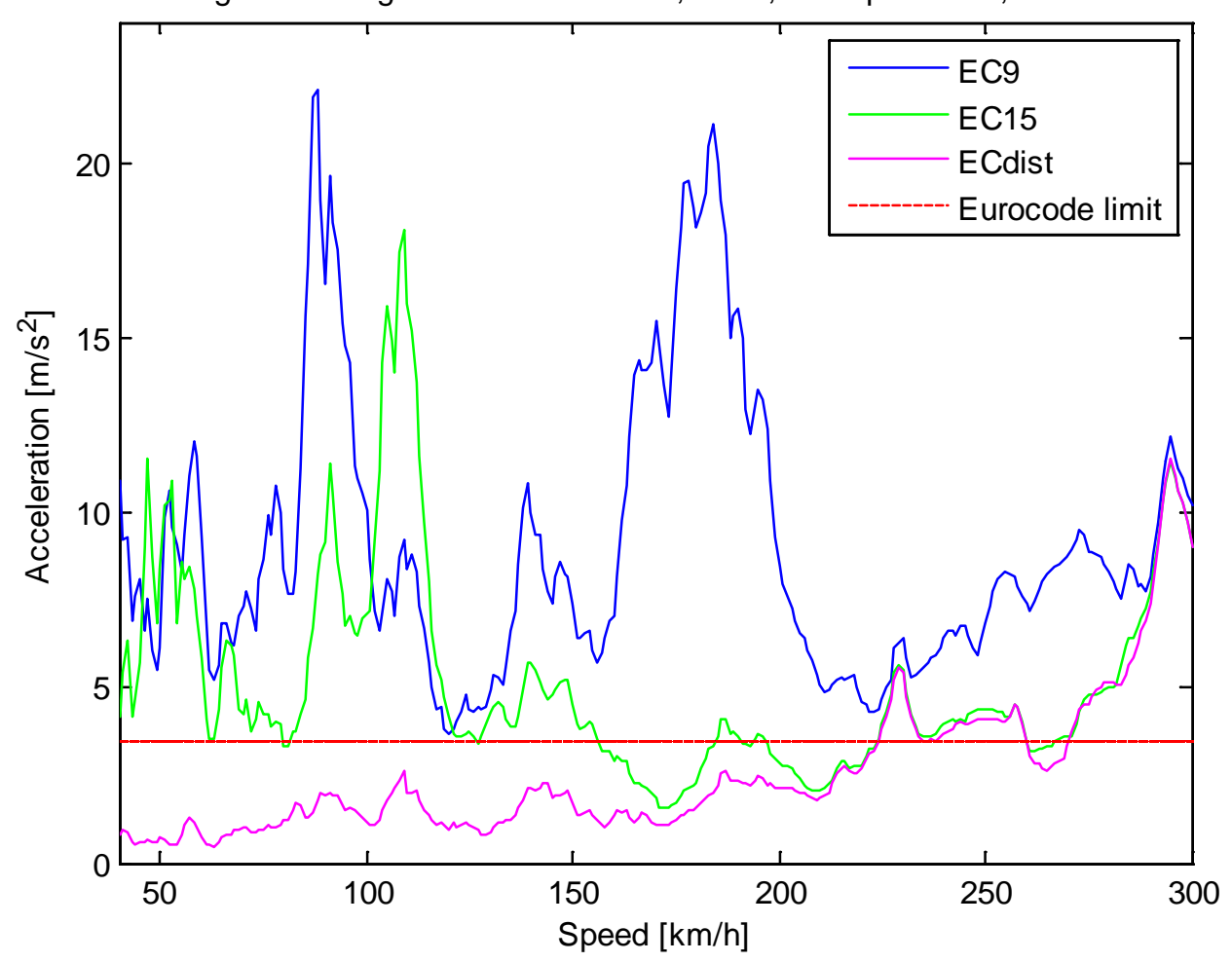

Figure 7.22: Speed-acceleration graph of a bridge with integrated backwalls when using different Eurocode load distributions.

From the graphs it can be seen how high spurious peaks occur for the point load distributions due to the distance between the point loads, as described in section 7.1. These spurious peaks give the maximum accelerations for all bridges except the bridge with the lowest fundamental frequency. The spurious peaks occur for both EC9 and EC15. If these peaks are not taken into account, it can be seen that the difference between using Eurocode point loads and distributed line loads is very small, as for the simply supported bridges.

\section{The Triangle Load Distribution}

High spurious peaks are found also for the triangle point load distributions. The speedacceleration graphs for the four bridges are presented in figures 7.23-7.26.

As in the case with the Eurocode load distributions, the highest accelerations of the bridges are obtained from the spurious peaks except for the bridge with lowest fundamental frequency where the spurious peaks are smaller. When not taking the spurious peaks into account, small differences can be seen between using point loads and using the distributed line load. The tendency is the same as in the case with the simply supported bridges; the more point loads used to model the triangle load shape, the higher become the maximum accelerations. The highest accelerations are obtained for the distributed line load Tridist. 
Bridge with Integrated Backwalls $9 \mathrm{~m}$, set 3 , end spans: $1 \mathrm{~m}, \mathrm{f} 1=10 \mathrm{~Hz}$

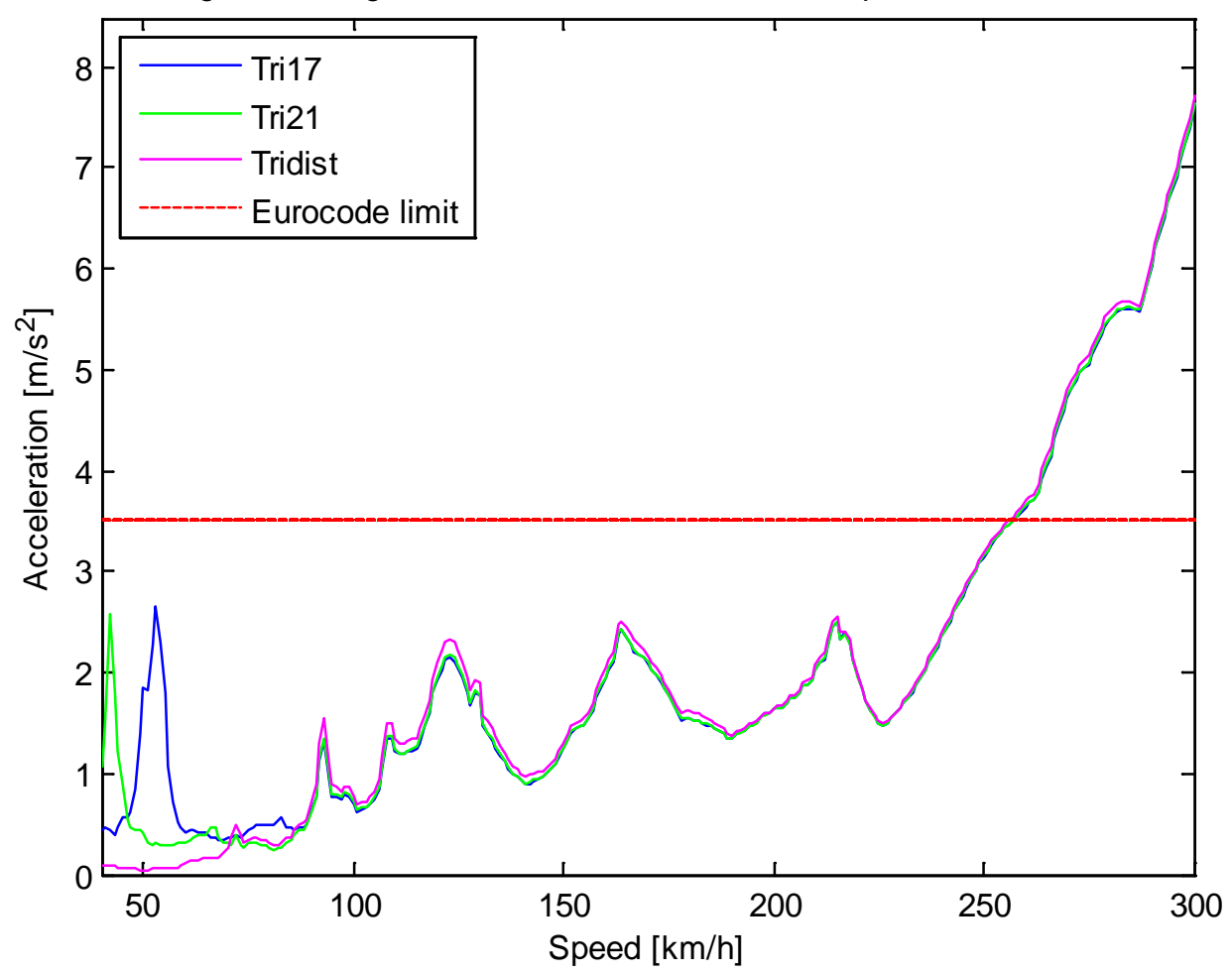

Figure 7.23: Speed-acceleration graph of a bridge with integrated backwalls when using different triangle load distributions.

Bridge with Integrated Backwalls $7 \mathrm{~m}$, set 3 , end spans: $1 \mathrm{~m}, \mathrm{f} 1=15 \mathrm{~Hz}$

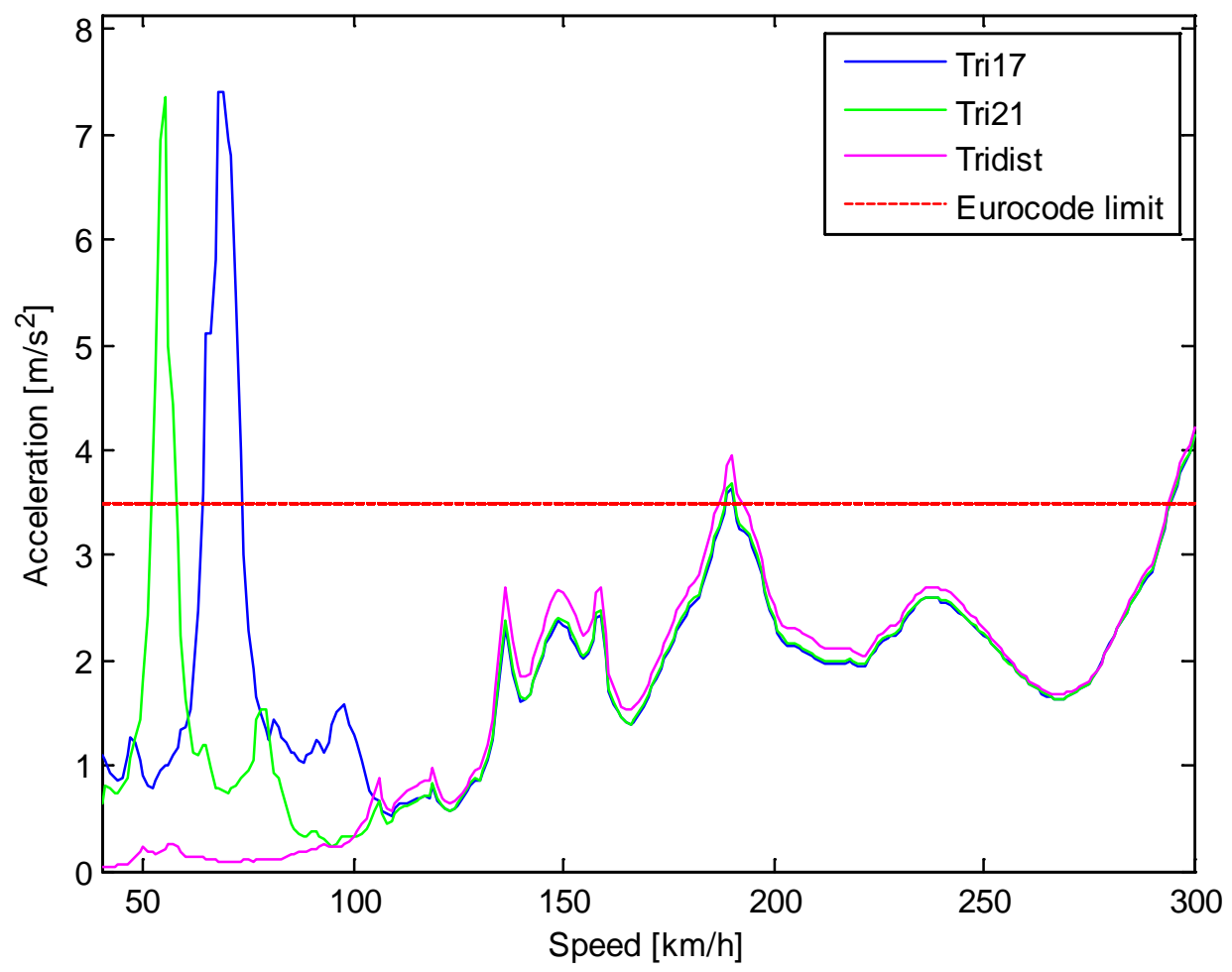

Figure 7.24: Speed-acceleration graph of a bridge with integrated backwalls when using different triangle load distributions. 
Bridge with Integrated Backwalls 9m, set 1 , end spans: $1 \mathrm{~m}, \mathrm{f} 1=22 \mathrm{~Hz}$

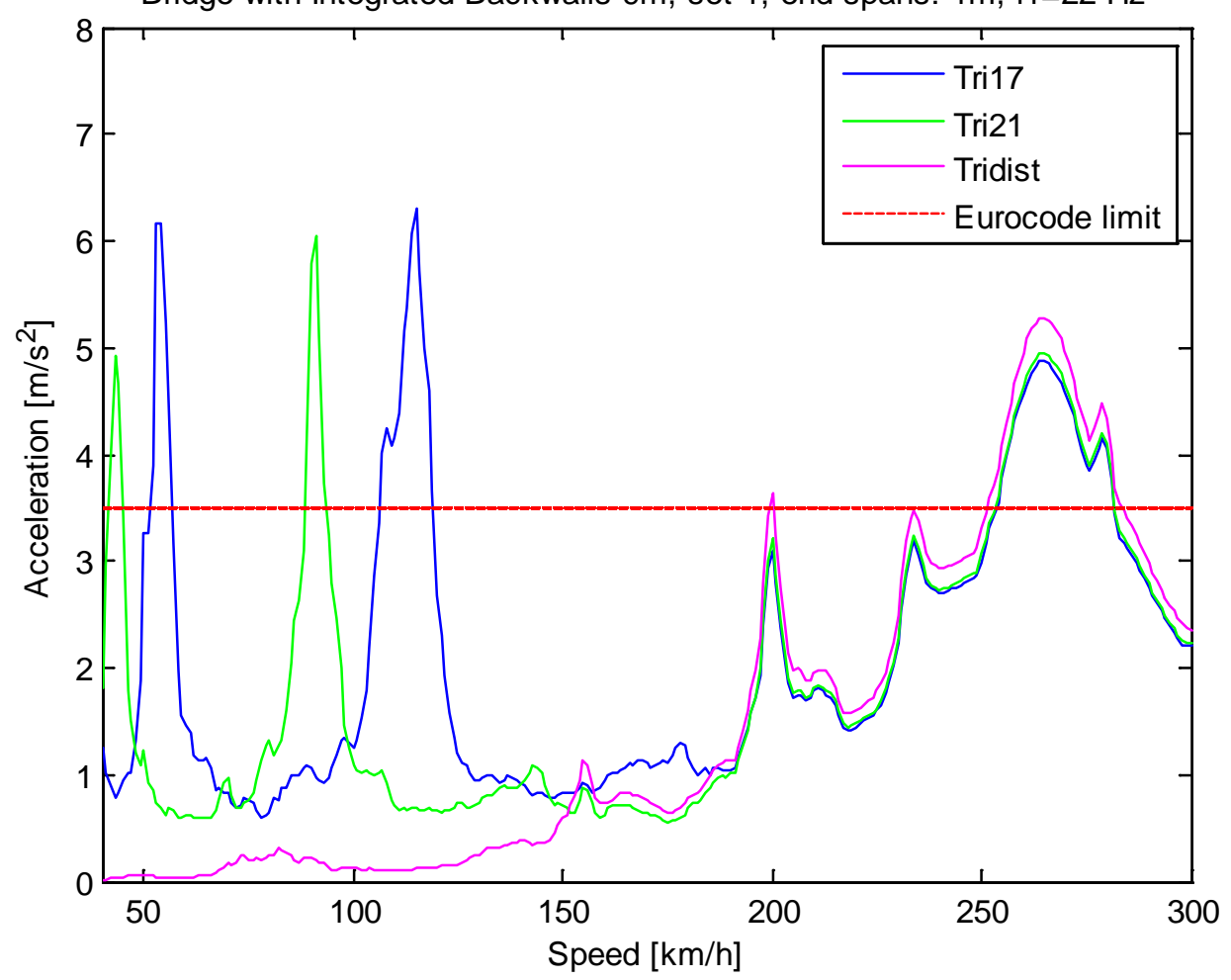

Figure 7.25: Speed-acceleration graph of a bridge with integrated backwalls when using different triangle load distributions.

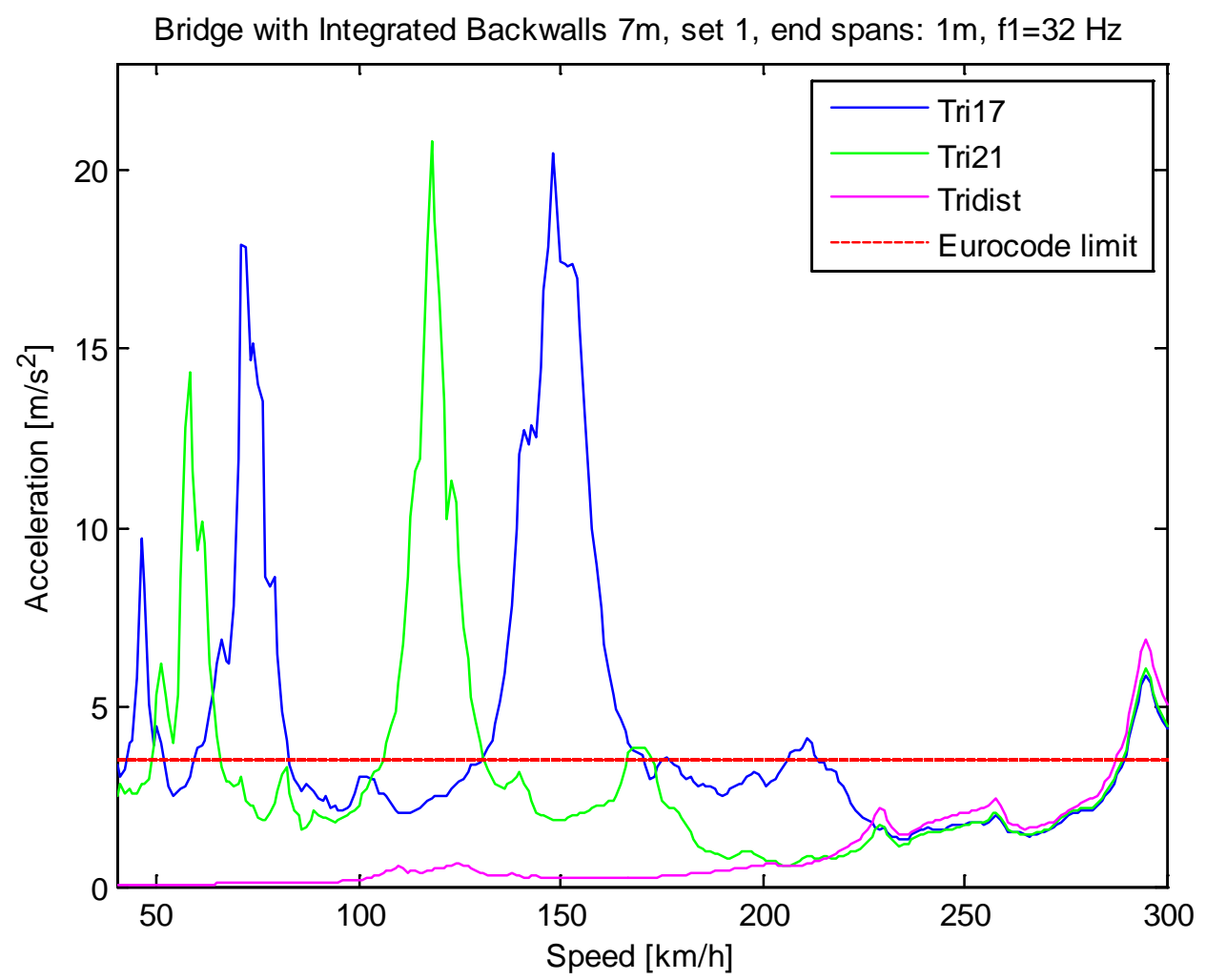

Figure 7.26: Speed-acceleration graph of a bridge with integrated backwalls when using different triangle load distributions. 


\subsubsection{Distributed Eurocode Loads versus Distributed Triangle Loads}

Maximum accelerations for the four bridges when using Eurocode line load distribution and triangular line load distribution compared to when using EC3 are compiled in figures 7.277.30. A big difference can be observed between the obtained maximum accelerations for EC3 and the maximum accelerations for ECdist, where the second are much lower. It can also be seen that the triangle distributed line load gives the lowest accelerations for all bridges. However the Eurocode acceleration criterion is not satisfied for any bridge, even when using the triangle load distribution.

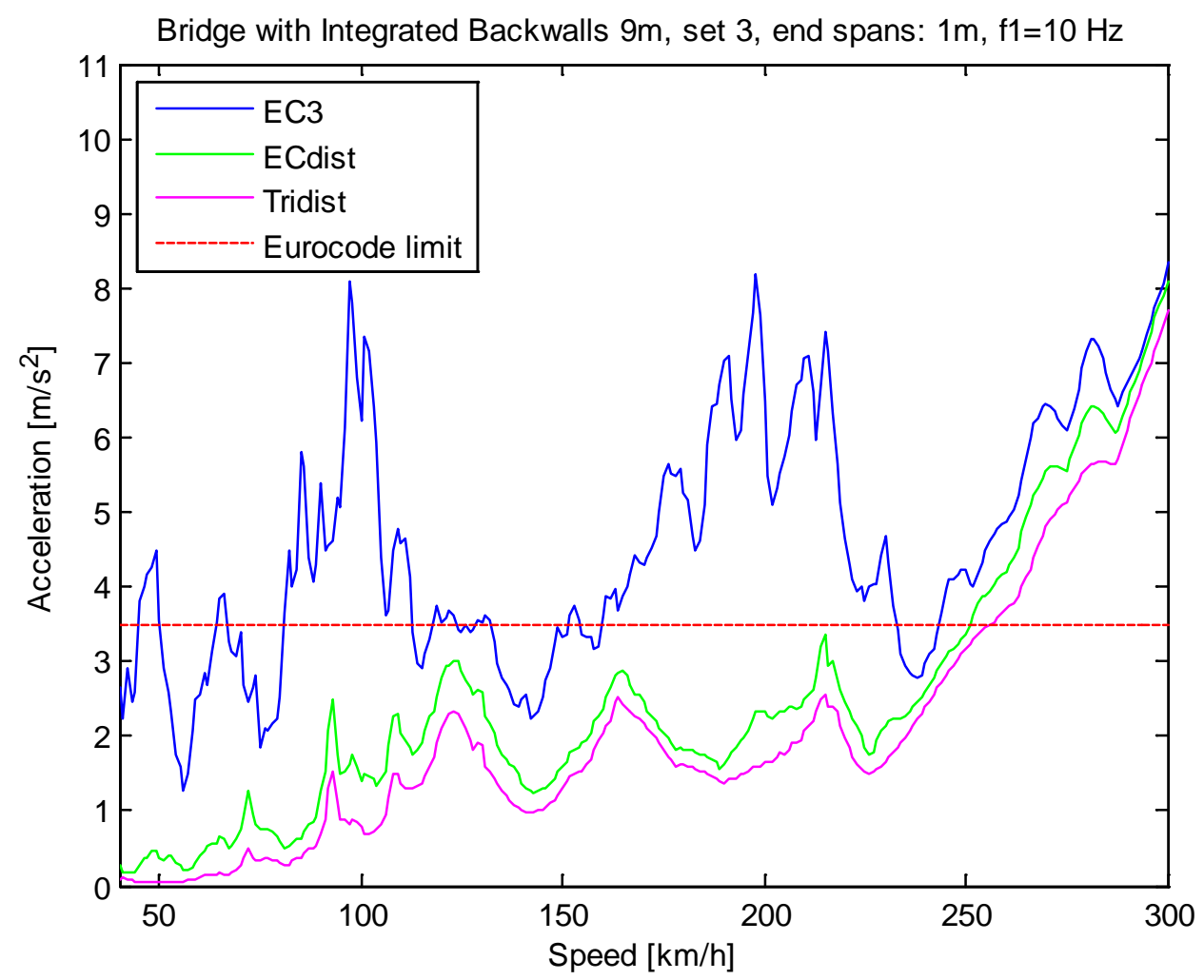

Figure 7.27: Speed-acceleration graph of a bridge with integrated backwalls when using different load distributions. 
Bridge with Integrated Backwalls $7 \mathrm{~m}$, set 3 , end spans: $1 \mathrm{~m}, \mathrm{f} 1=15 \mathrm{~Hz}$

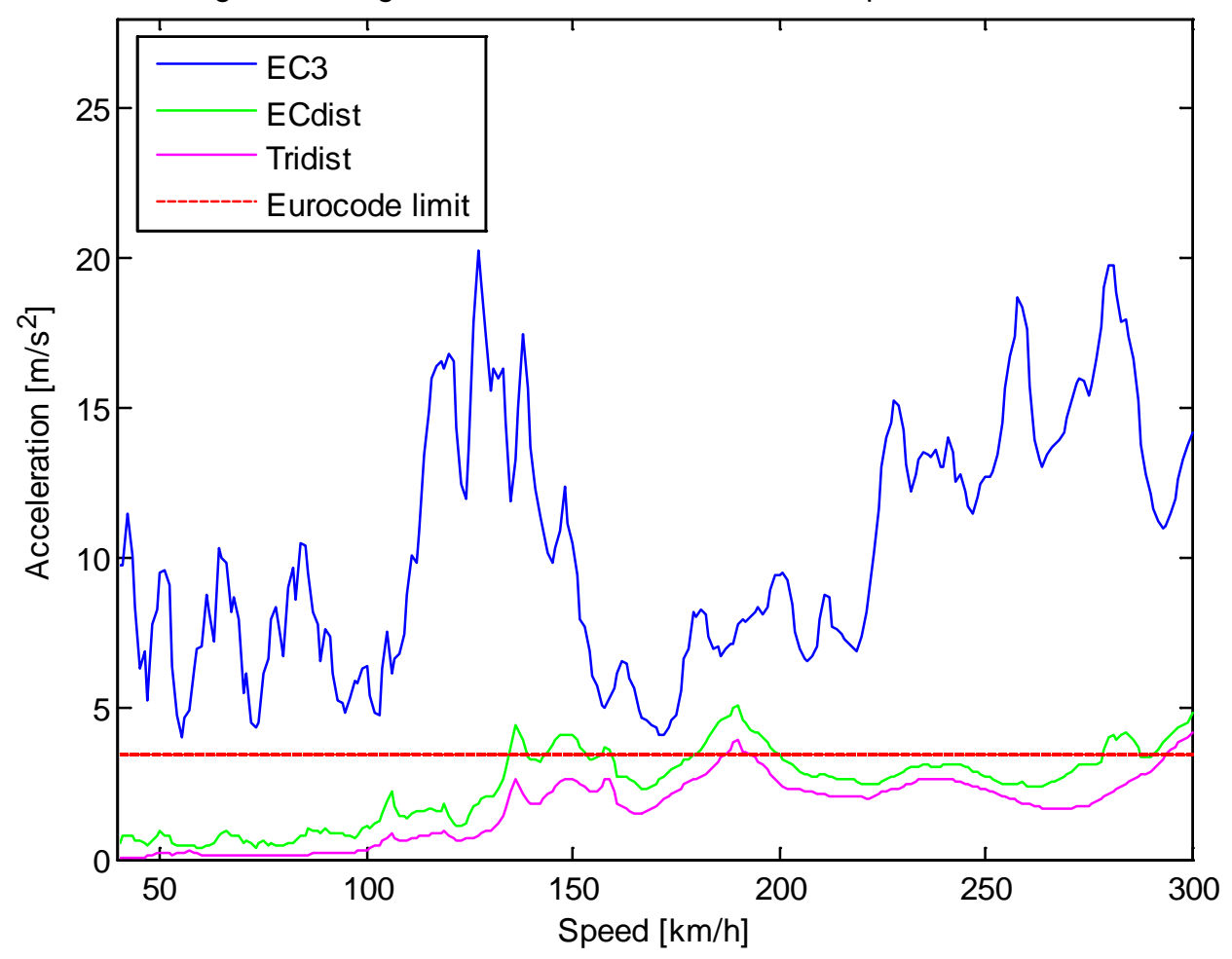

Figure 7.28: Speed-acceleration graph of a bridge with integrated backwalls when using different load distributions.

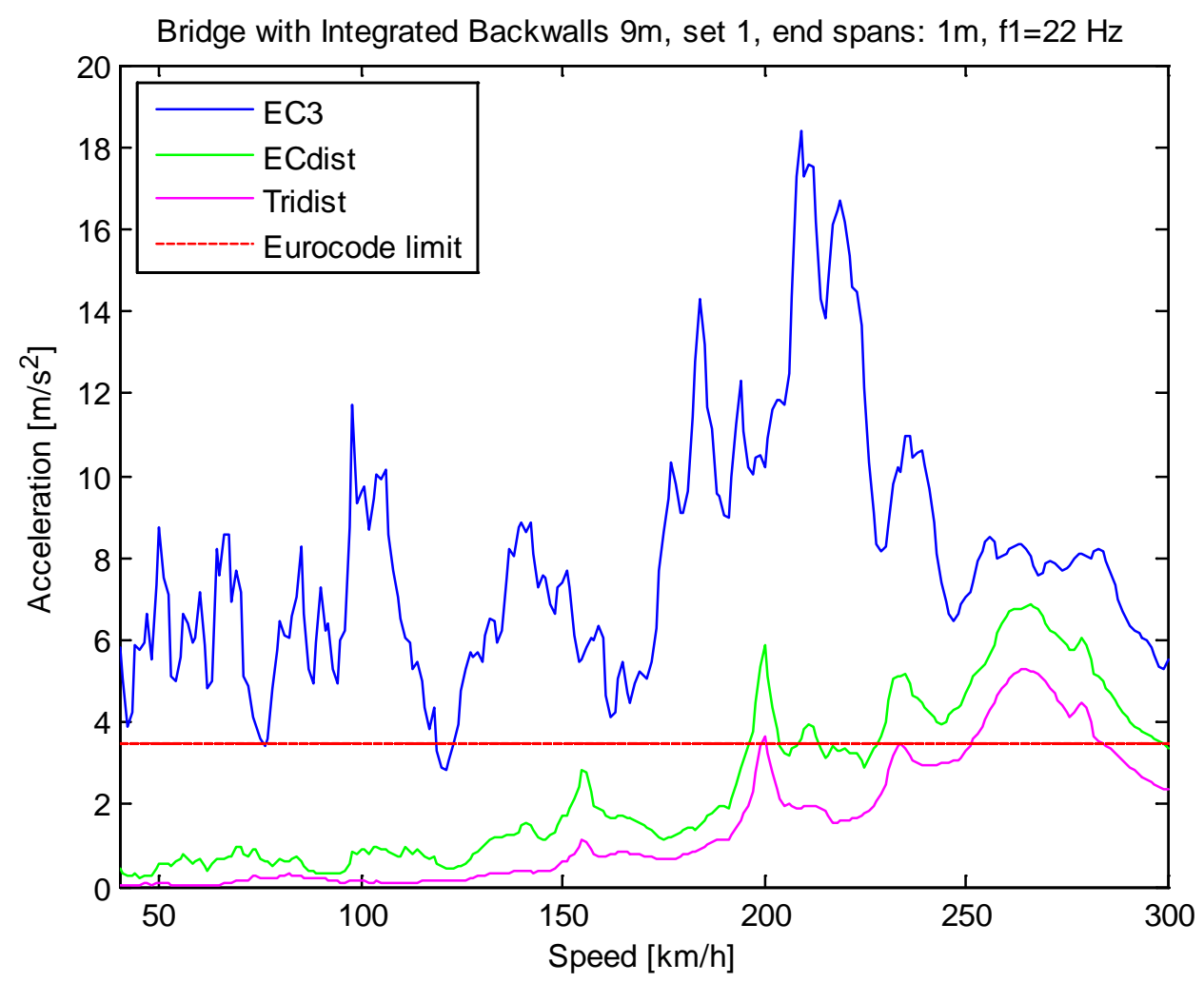

Figure 7.29: Speed-acceleration graph of a bridge with integrated backwalls when using different load distributions. 


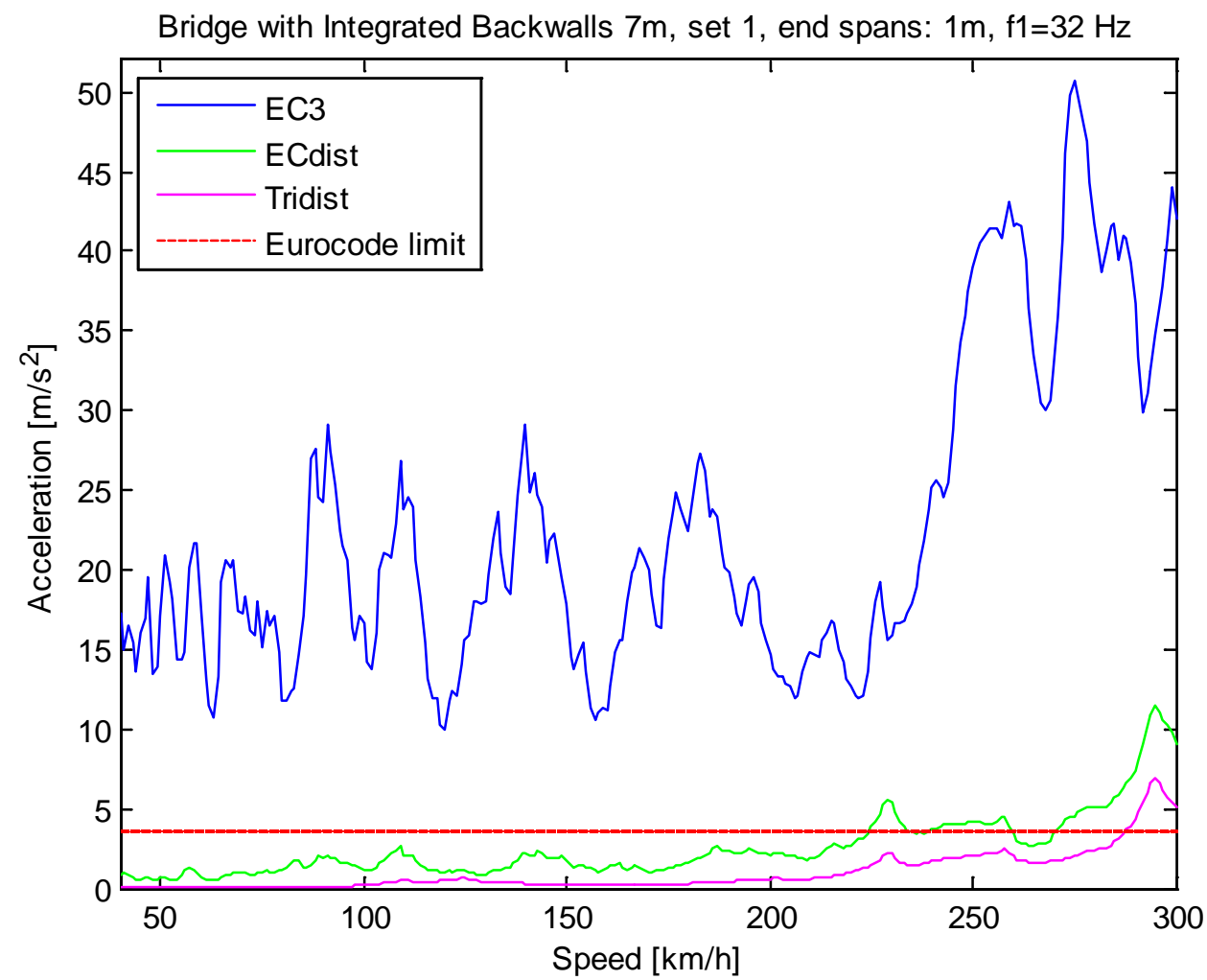

Figure 7.30: Speed-acceleration graph of a bridge with integrated backwalls when using different load distributions.

\subsection{Bending Moments - Bridges with Integrated Backwalls}

When calculating the bending moments for the bridges with integrated backwalls the same procedure as for the simply supported bridges have been used, see section 7.3.

The maximum positive and negative bending moments have been calculated for the four bridges with integrated backwalls with properties according to table 4.2. The studied bridges are numbered from 1 to 4 in order of fundamental frequencies, where bridge number 1 is the bridge with the lowest fundamental frequency and bridge number 4 is the bridge with the highest. Simulations of an HSLM-A1 train passing over the bridges have been performed with speeds from $40 \mathrm{~km} / \mathrm{h}$ to $300 \mathrm{~km} / \mathrm{h}$, with a step of $1 \mathrm{~km} / \mathrm{h}$.

Comparisons between using point loads and using distributed loads for modeling the load distributions have been made and the results are presented below. 


\subsubsection{Point Loads versus Distributed Line Loads}

\section{The Eurocode Load Distribution}

The obtained maximum bending moments for the studied bridges when using different Eurocode load distributions are presented in figure 7.31. From the figure it can be seen that the difference in bending moments between using nine or fifteen point loads to model the load distribution is small. The difference is also small between using nine or fifteen point loads and using the distributed line load. It can be seen that larger reductions are obtained for higher fundamental frequencies when the ballast distribution is considered.

\section{The Triangle Load Distribution}

The obtained maximum bending moments for the studied bridges when using different triangle load distributions are presented in figure 7.32. It can be seen from the figure that there is a small difference between the different load distributions, most evidently for bridge number 4 . The highest values of the bending moments for the triangle loads are, as for the maximum vertical accelerations, obtained when using the distributed line load Tridist.

The point load models do not seem to have the same spurious effects on the bending moments as they have on the accelerations. Figure 7.33 shows an example of bending moment results obtained for a bridge with integrated backwalls with graphs presenting the maximum vertical accelerations and the maximum positive and negative bending moments both for Tri17 and Tridist. From the figure it can be seen that the spurious peaks in the acceleration graph have practically no effect on the bending moment results, only one of the peaks (at about $60 \mathrm{~km} / \mathrm{h}$ ) can be seen in the bending moment results and it is much lower than for accelerations. The results show the same behavior for both for the Eurocode and the triangle point load distributions.

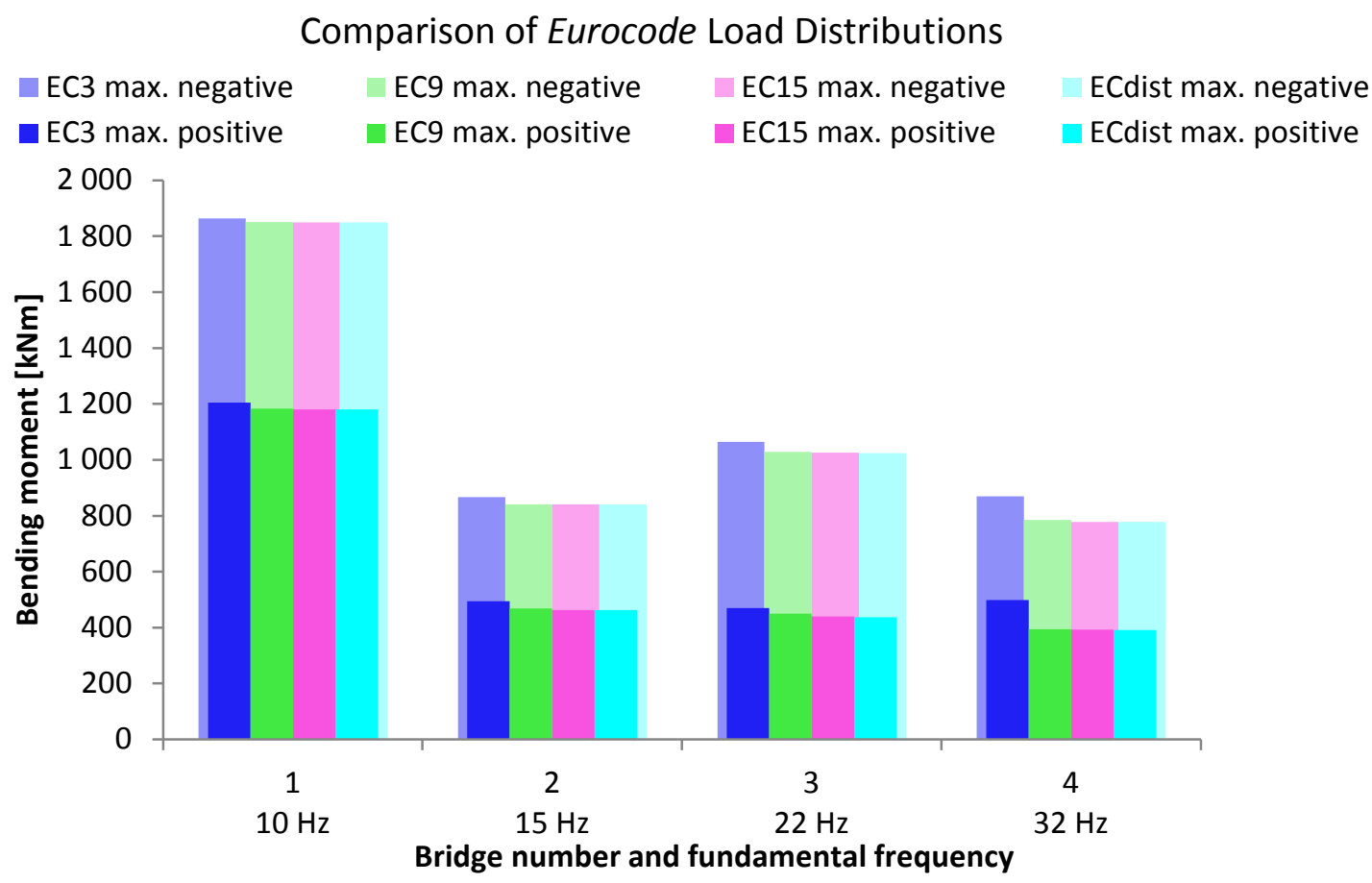

Figure 7.31: Maximum positive and negative bending moment for the four studied bridges with integrated backwalls when using different Eurocode load distributions. 


\section{Comparison of Triangle Load Distributions}

$\begin{array}{lll}\text { EC3 max. negative } \quad \text { Tri17 max. negative } \quad \text { Tri21 max. negative } & \text { Tridist max. negative } \\ \text { EC3 max. positive } & \text { Tri17 max. positive } \quad \text { Tri21 max. positive } \quad \text { Tridist max. positive }\end{array}$

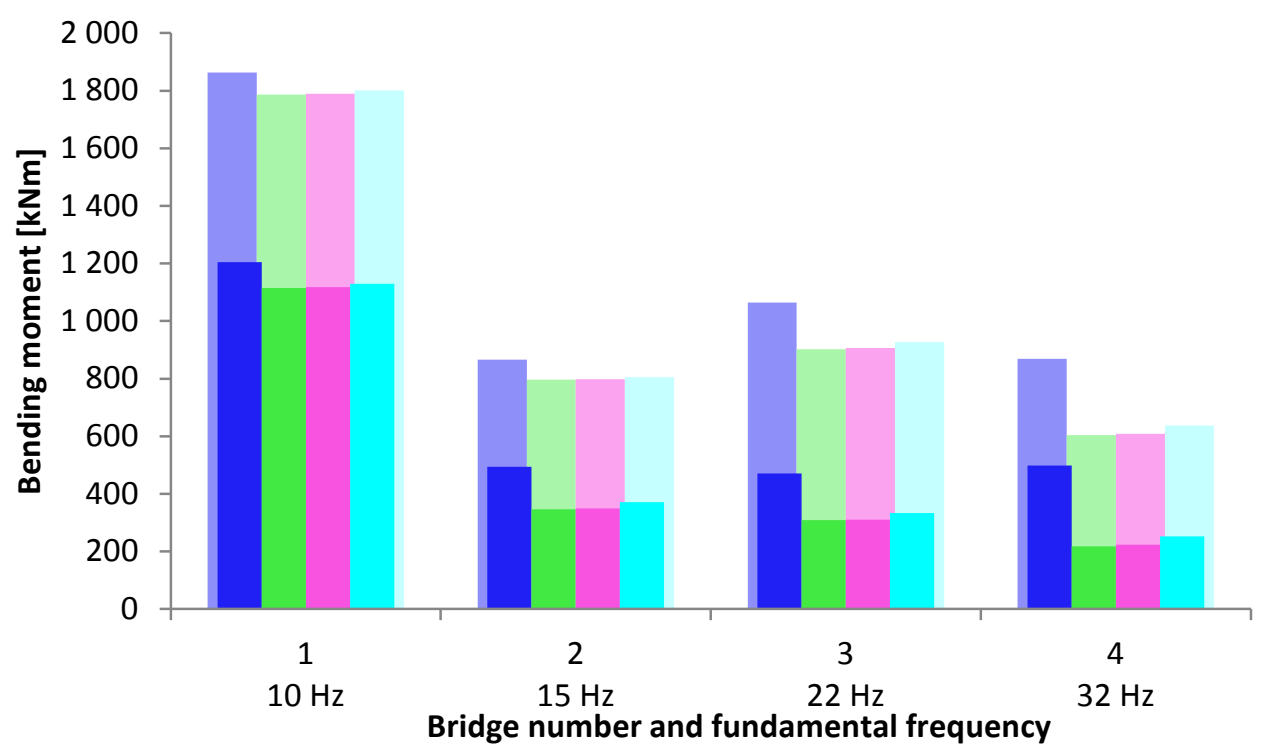

Figure 7.32: Maximum positive and negative bending moment for the four studied bridges with integrated backwalls when using different triangle load distributions.

Bridge with Integrated Backwalls $9 \mathrm{~m}$, set 1 , end spans: $1 \mathrm{~m}, \mathrm{f} 1=22 \mathrm{~Hz}$
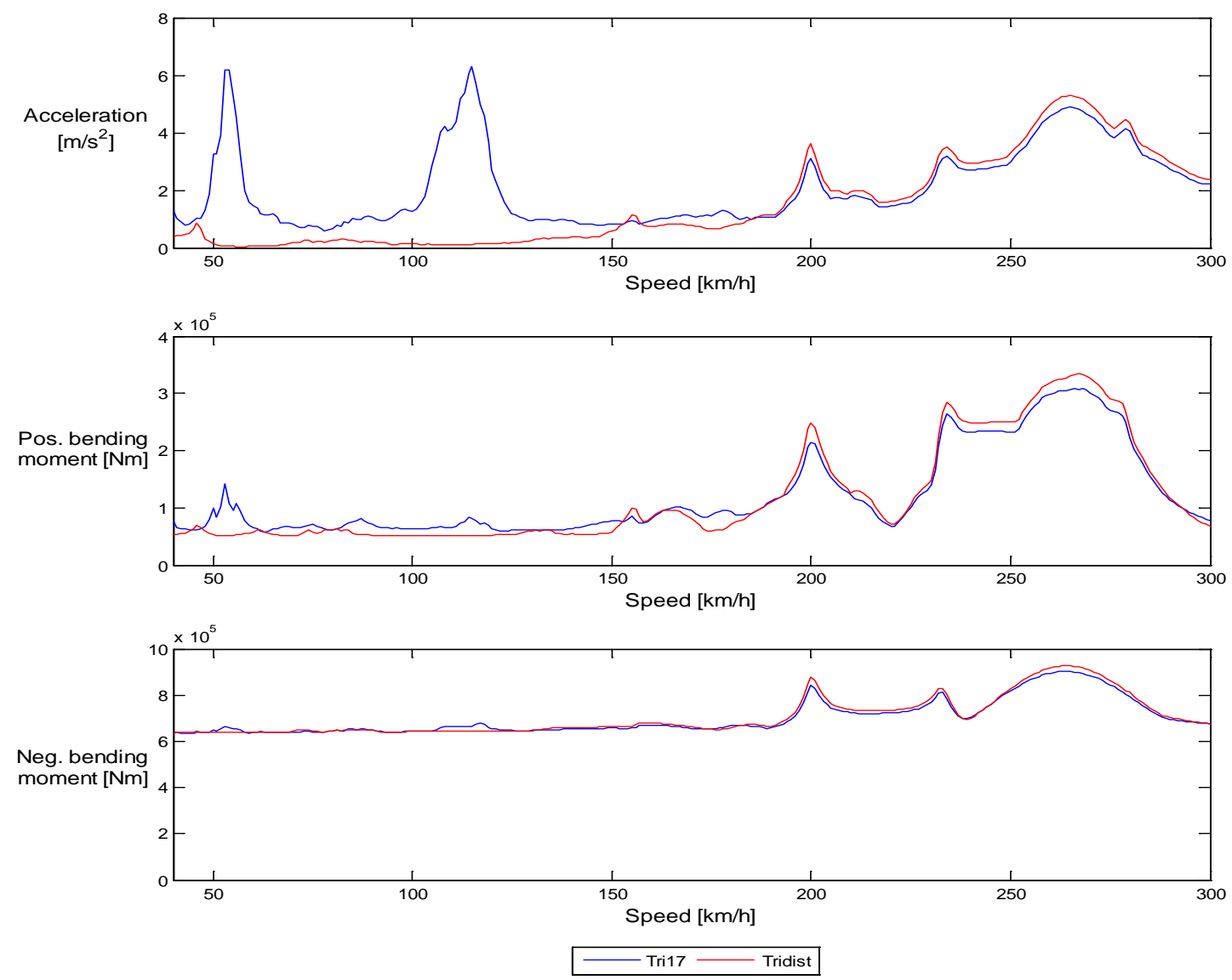

Figure 7.33: Maximum positive and negative bending moment for a bridge with integrated backwalls when using the triangle load distribution Tri17 and the distributed line load Tridist. 


\subsubsection{Distributed Eurocode Loads versus Distributed Triangle Loads}

Comparisons between the Eurocode line load distribution and the triangle line load distribution for the maximum positive and negative bending moments are shown in figure 7.34. As can be seen in the figure, the triangle distributed line load gives the lowest values of the bending moments for all bridges, and is therefore the most advantageous load distribution to use.

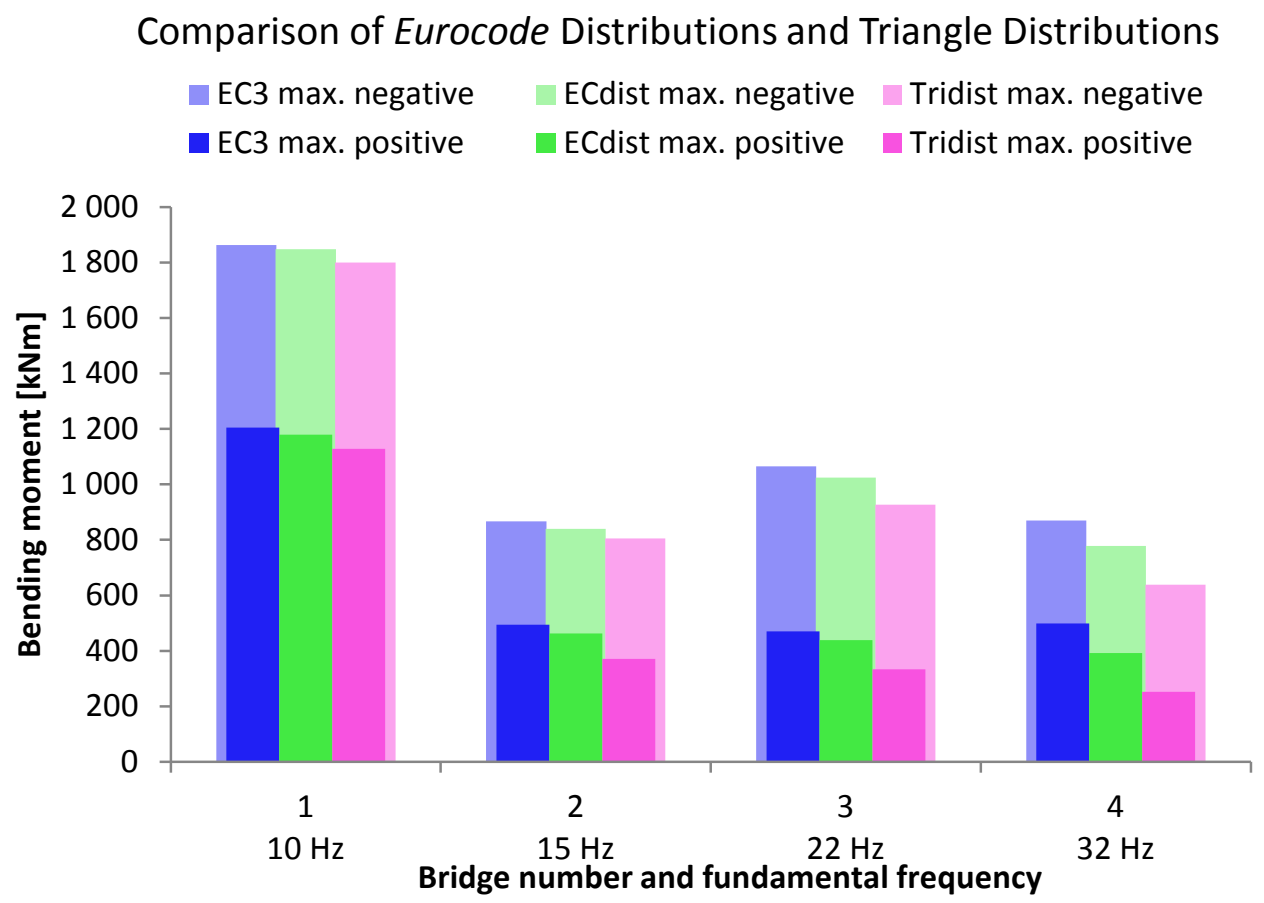

Figure 7.34: Maximum positive and negative bending moment for the four studied bridges with integrated backwalls when using different load distributions.

\subsection{Bridges with Integrated Backwalls with Spring Supports}

The four studied bridges with integrated backwalls have all been modeled with spring supports with varying spring stiffness, see section 4.2.2. Simulations were run for the triangle distributed line load Tridist only.

\subsubsection{Accelerations}

The acceleration results for the first bridge studied are presented in figures 7.36-7.37. For this bridge, values from $0.5 \mathrm{GN} / \mathrm{m}$ to $20 \mathrm{GN} / \mathrm{m}$ were used for the spring stiffness. From the figures it can be seen that different spring stiffness values give large differences in the response of the bridge. For a spring stiffness of $0.5 \mathrm{GN} / \mathrm{m}$, the accelerations are much higher than for the other simulations. By running a modal analysis it is found that the second mode shape is 
strongly excited and thereby the reason to these large values. The first three mode shapes of the bridge are depicted in figure 7.35. As seen in figure 7.35b, the second mode shape is a rigid body mode that causes no bending of the bridge but only displacements in the springs.

By increasing the stiffness from $0.5 \mathrm{GN} / \mathrm{m}$ the accelerations first decrease before increasing again and approaching the results for the fixed supports, which are infinitely stiff. For a spring stiffness of $2 \mathrm{GN} / \mathrm{m}$, the requirement in Eurocode is fulfilled.

For the other three bridges with integrated backwalls, spring stiffness values from $0.5 \mathrm{GN} / \mathrm{m}$ to $5 \mathrm{GN} / \mathrm{m}$ were used and the acceleration results are presented in figures $7.38-40$. From the figures it can be seen that the acceleration curves are displaced to the left and that the peaks in most cases are lowered when the stiffness is decreased. When the stiffness has been decreased to a certain value, the pattern is broken and the accelerations increase due to the emergence and excitation of rigid body modes.

For the bridge with a fundamental frequency of $22 \mathrm{~Hz}$, figure 7.38, using both a stiffness of 2 $\mathrm{GN} / \mathrm{m}$ and $3 \mathrm{GN} / \mathrm{m}$ makes the bridge fulfill the Eurocode acceleration criterion. For the two bridges with fundamental frequencies of 10 and $15 \mathrm{~Hz}$, figures 7.39-7.40, the maximum accelerations become higher than when using fixed supports. This seems to be due to that peaks for higher velocities are displaced when using springs to occur for speeds in the studied speed interval.

For the cases where the lowest response is obtained, the displacements have been studied to ensure that they attain realistic values. The two cases studied are the bridges in figures 7.35 and 7.38, both with a spring stiffness of $2 \mathrm{GN} / \mathrm{m}$. None of the bridges were displaced more than $0.7 \mathrm{~mm}$ which is well below the Eurocode criterion for vertical deformation of the deck, seen below

$$
u_{\max }=\frac{L}{600}
$$

Figure 7.41 shows a time-acceleration plot for the bridge with a fundamental frequency of 22 Hz. The three curves are obtained for the three acceleration peaks around $240-270 \mathrm{~km} / \mathrm{h}$ when using fixed supports and spring stiffness values of 3 and $5 \mathrm{GN} / \mathrm{m}$. Each curve shows the acceleration data in the node where the maximum acceleration occurs, which are nodes around the midpoint of the bridge. From the figure it can be seen that the accelerations in the bridge are decreased when using spring supports. The largest reductions are obtained when the train enters and exits the bridge. A possible explanation is that the springs allow for a certain flexibility which decreases the effect of the sudden application and removal of loads at the bridge ends. The three curves are obtained for different train speeds, which means that the train exits the bridge at different times.

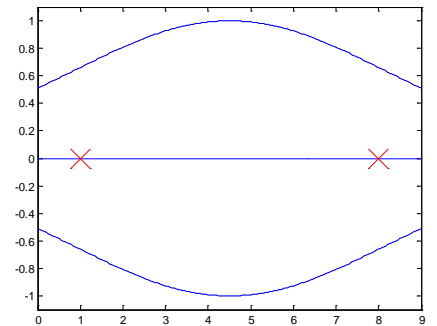

(a)

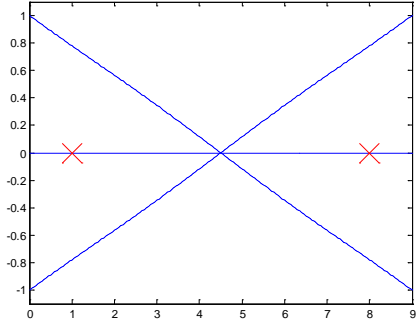

(b)

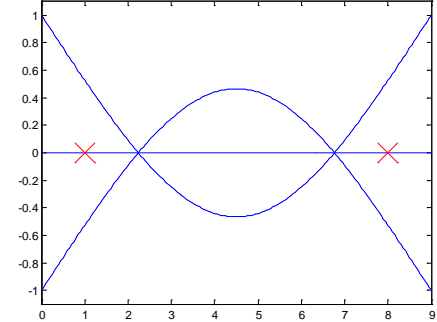

(c)

Figure 7.35: First three mode shapes of the bridge with integrated backwalls with spring supports. 
Bridge with Integrated Backwalls $7 \mathrm{~m}$, set 1 , end spans: $1 \mathrm{~m}, \mathrm{f} 1=32 \mathrm{~Hz}$

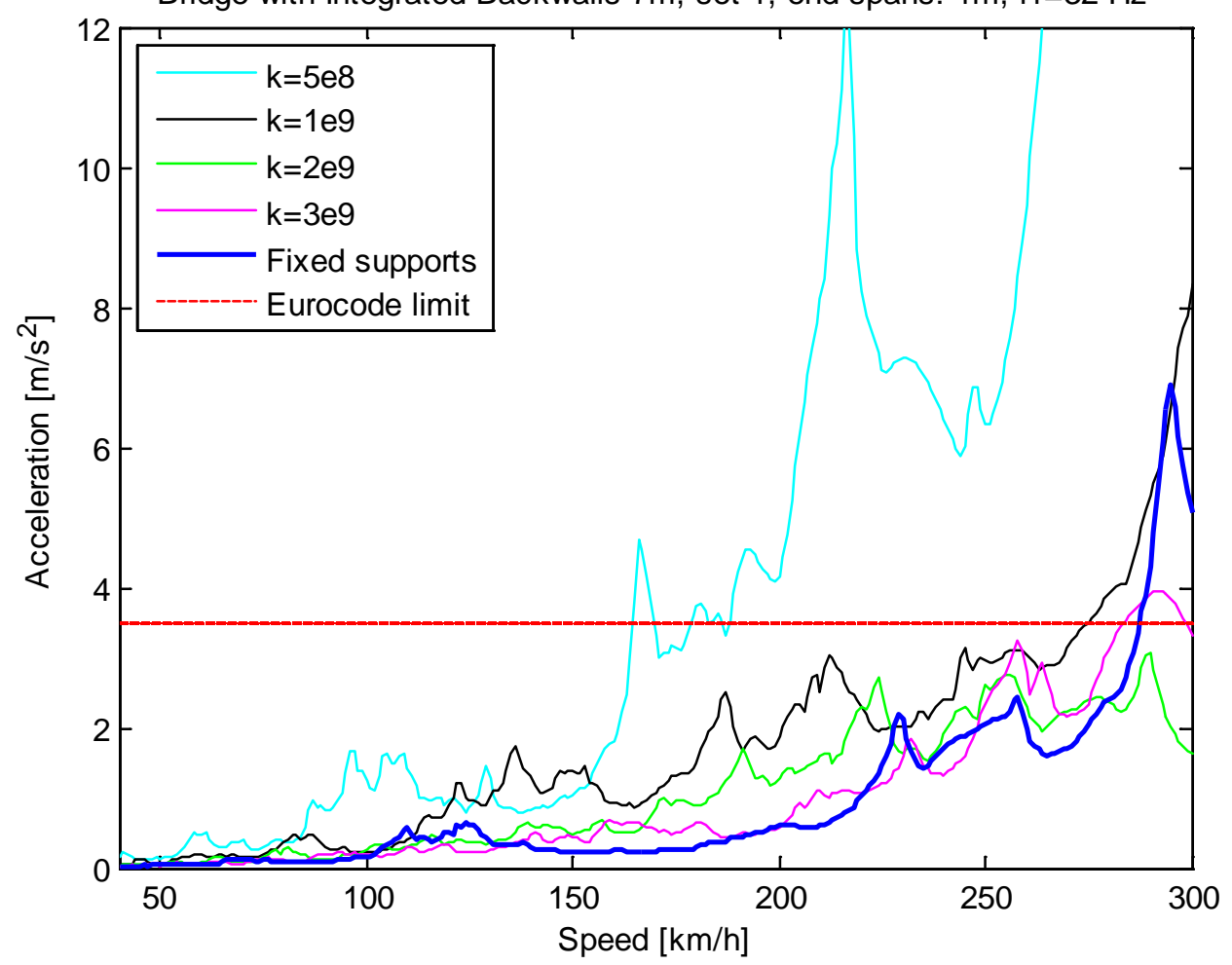

Figure 7.36: Speed-acceleration graph for a bridge with integrated backwalls with varying spring stiffness from $0.5 \mathrm{GN} / \mathrm{m}$ to $5 \mathrm{GN} / \mathrm{m}$.

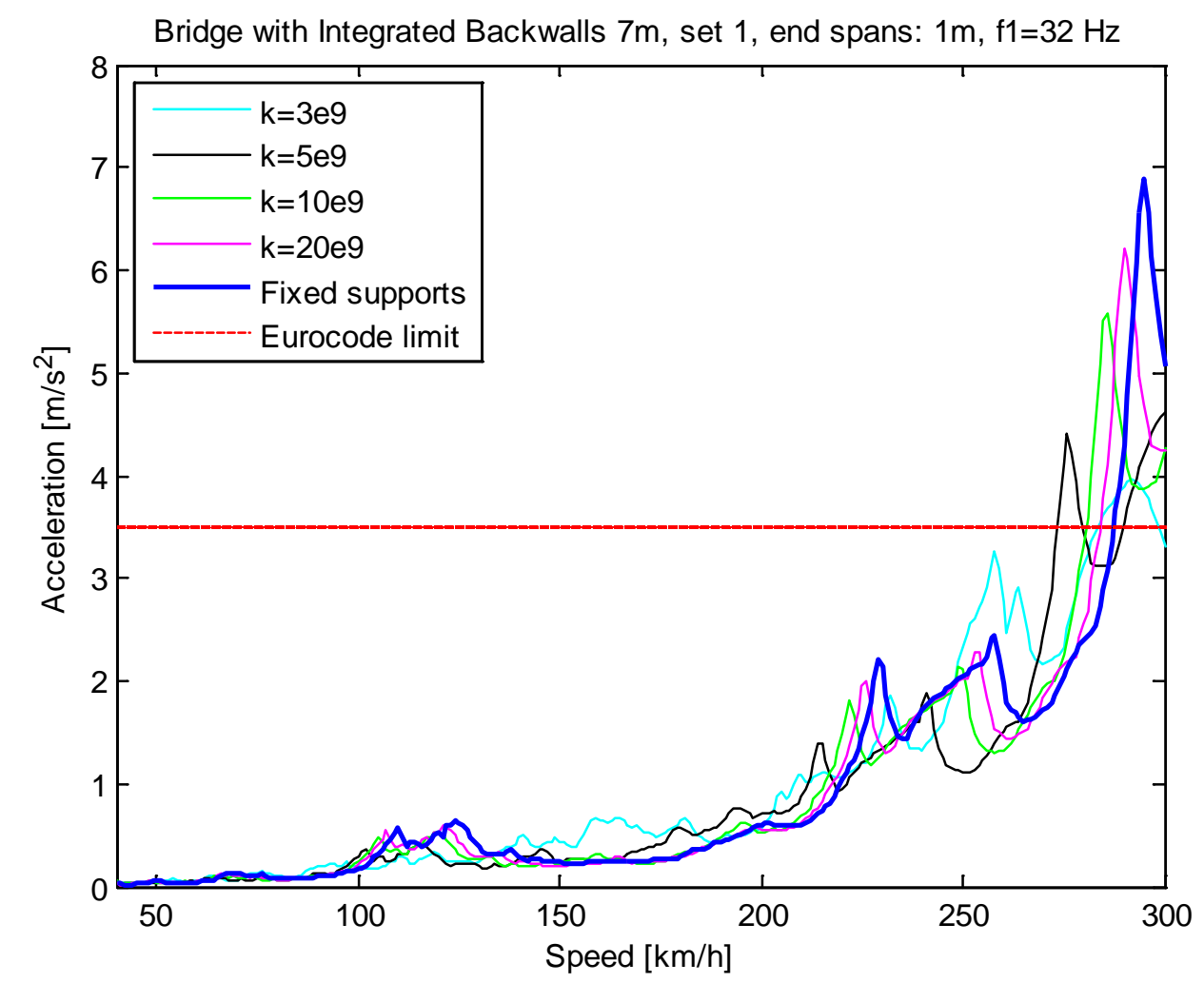

Figure 7.37: Speed-acceleration graph for a bridge with integrated backwalls with varying spring stiffness from $3 \mathrm{GN} / \mathrm{m}$ to $20 \mathrm{GN} / \mathrm{m}$. 


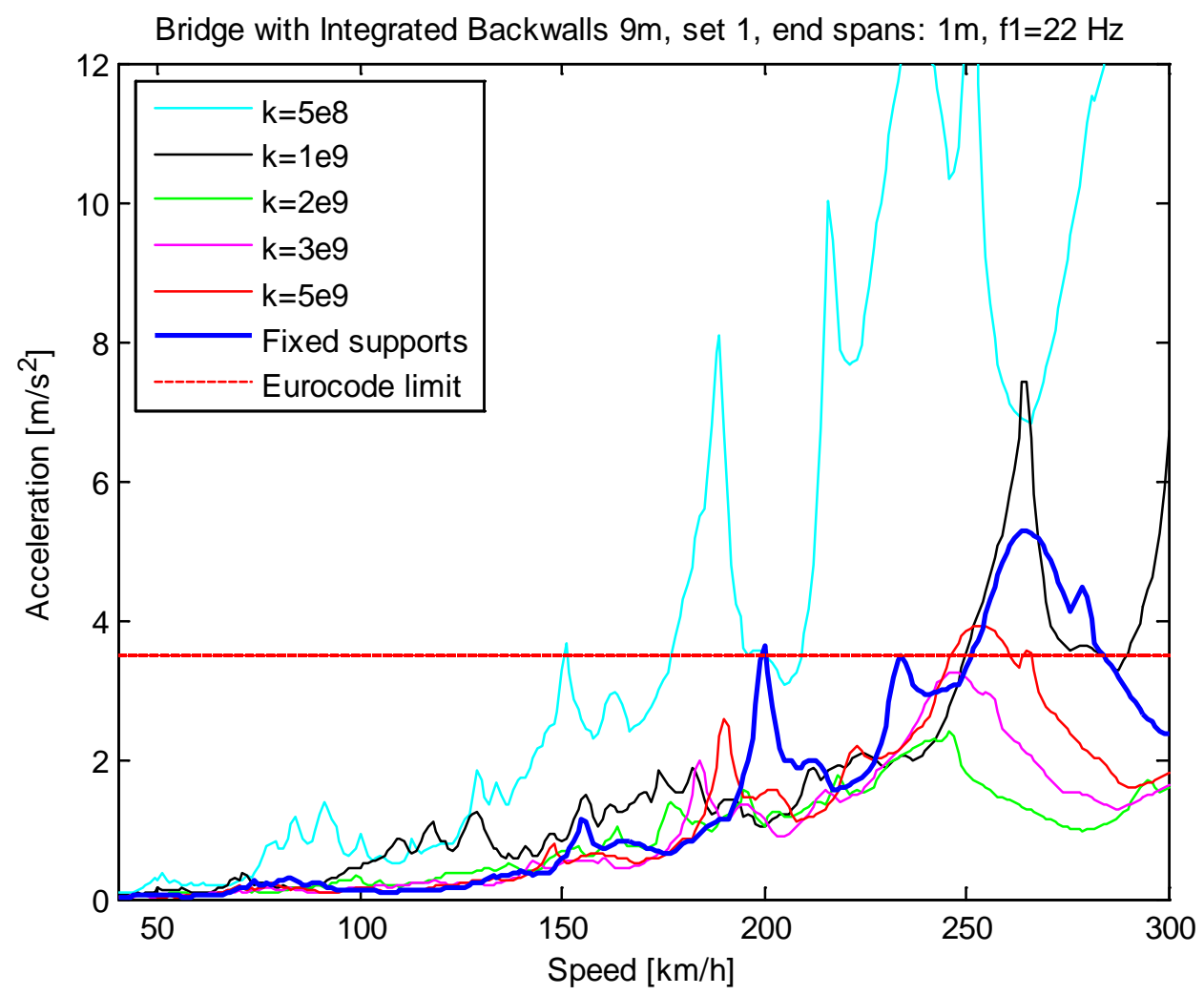

Figure 7.38: Speed-acceleration graph for a bridge with integrated backwalls with varying spring stiffness from $0.5 \mathrm{GN} / \mathrm{m}$ to $5 \mathrm{GN} / \mathrm{m}$.

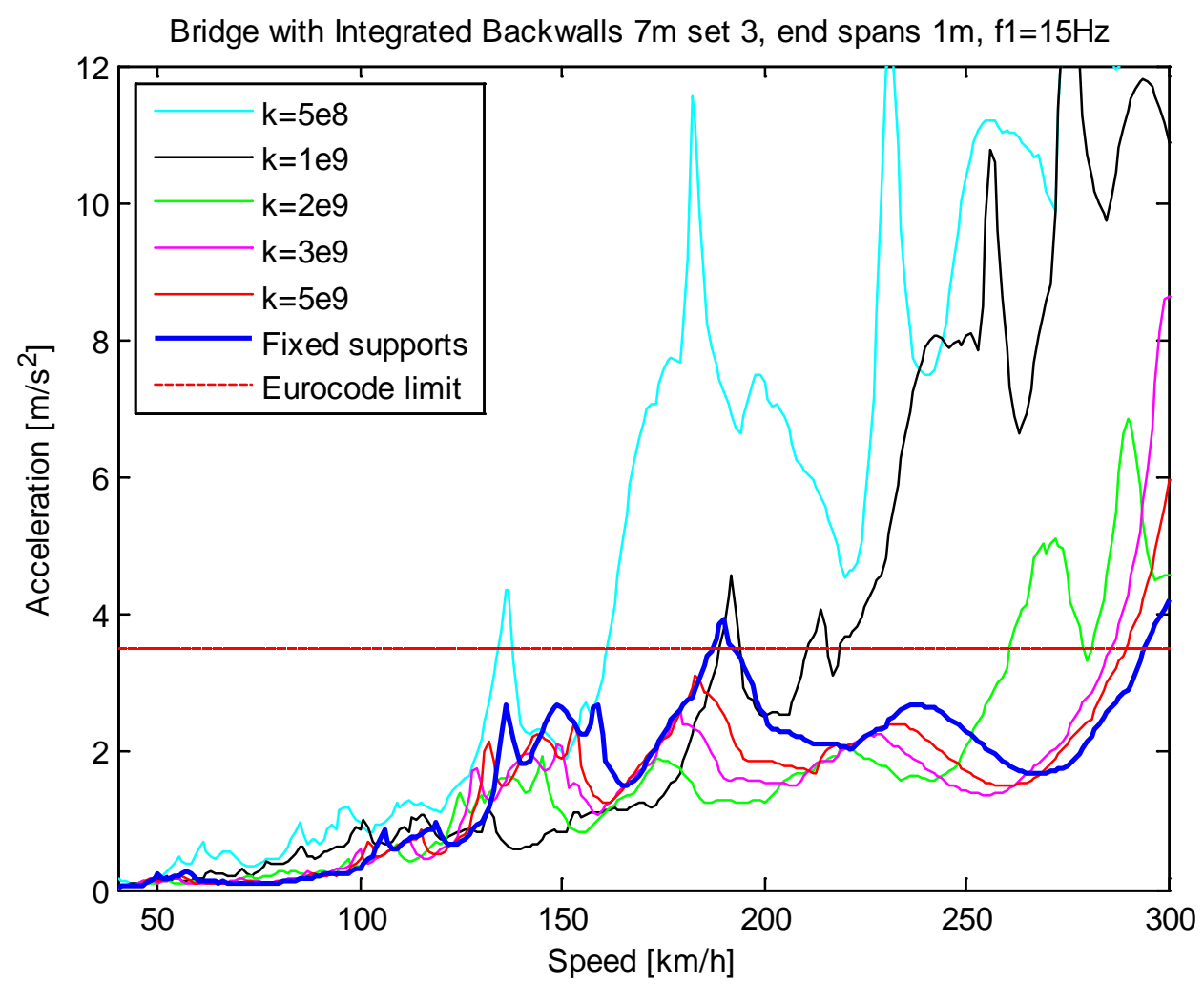

Figure 7.39: Speed-acceleration graph for a bridge with integrated backwalls with varying spring stiffness from $0.5 \mathrm{GN} / \mathrm{m}$ to $5 \mathrm{GN} / \mathrm{m}$. 


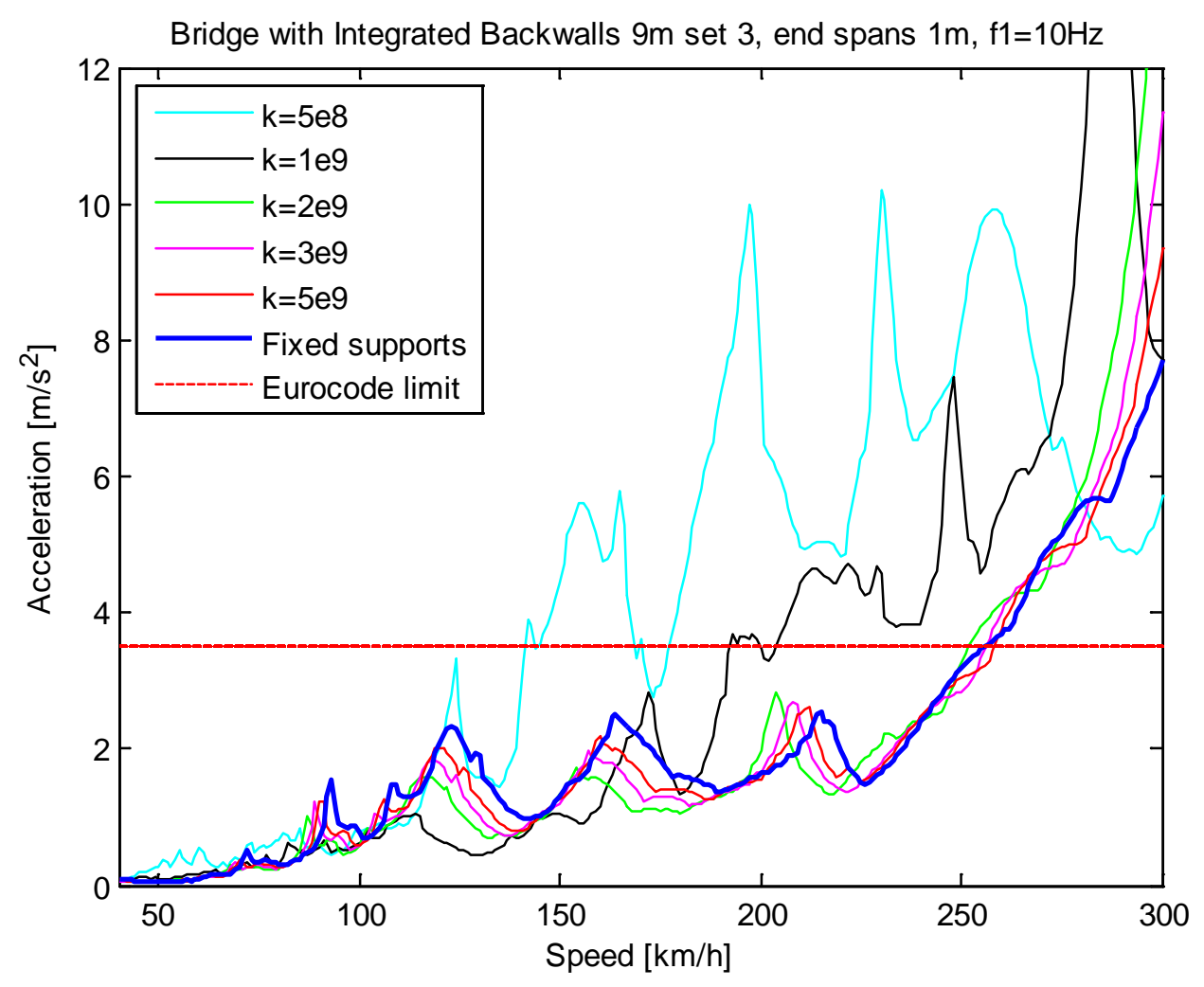

Figure 7.40: Speed-acceleration graph for a bridge with integrated backwalls with varying spring stiffness from $0.5 \mathrm{GN} / \mathrm{m}$ to $5 \mathrm{GN} / \mathrm{m}$.

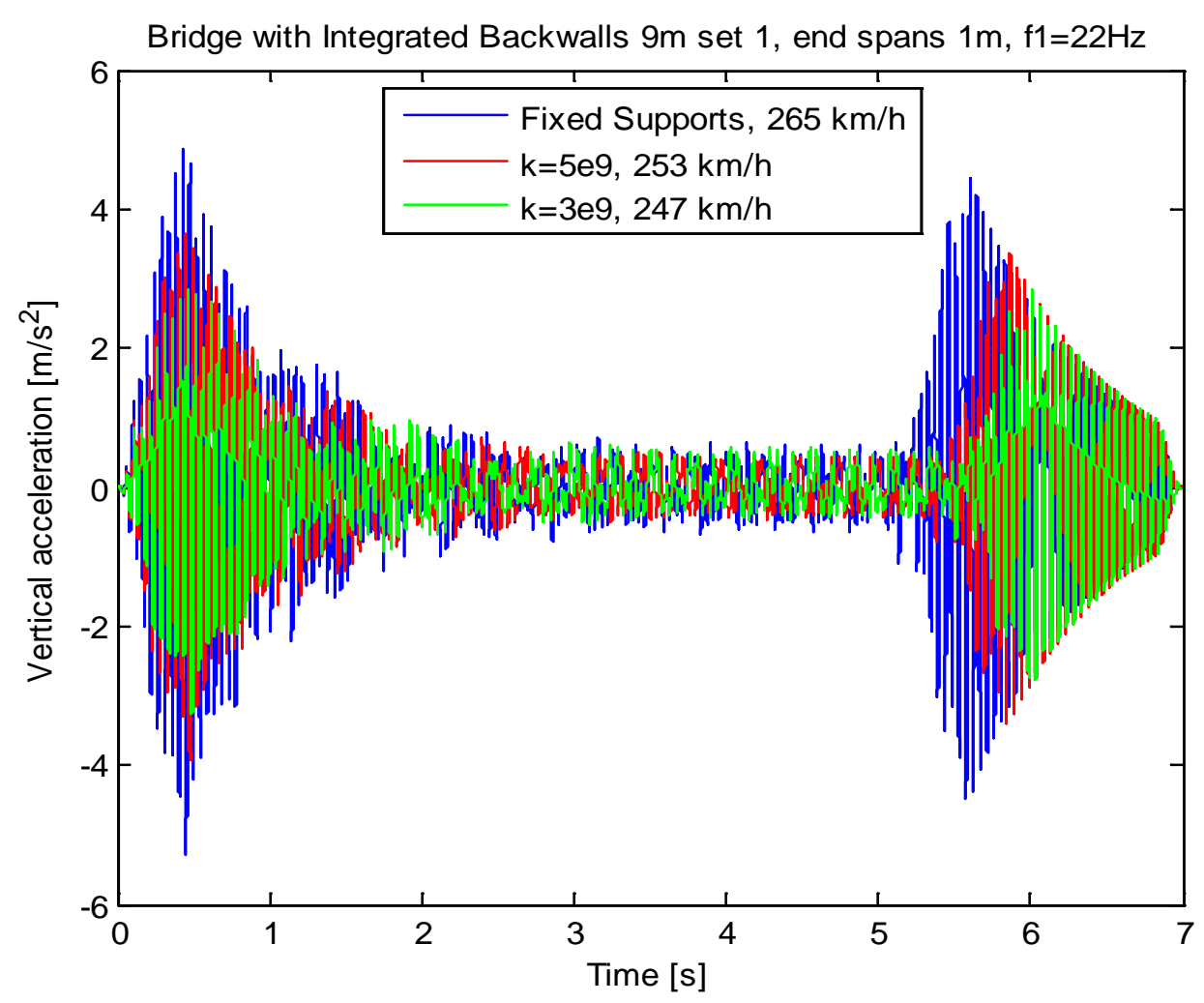

Figure 7.41: Time-acceleration graph for a train passage over a bridge with integrated backwalls. 


\subsubsection{Bending Moments}

The obtained maximum positive and negative bending moments for the studied bridges when using the Tridist load distribution and different support stiffness are presented in figures 7.427.45 .

From the results it can be seen that the bending moments do not necessarily have their maximum values for the same values of the spring stiffness as the accelerations. This is due to the fact that there are rigid body modes, or close to rigid body modes, that when excited cause high accelerations but not as high bending moments since there is almost no bending of the bridge for these modes. An example of this can be seen if the bridge of length $9 \mathrm{~m}$ and property set 1 is studied. In figure 7.37 it is seen that the second highest maximum accelerations are obtained for the spring stiffness $1 \mathrm{GN} / \mathrm{m}$ with a peak at $265 \mathrm{~km} / \mathrm{h}$, only the stiffness $0.5 \mathrm{GN} / \mathrm{m}$ give higher maximum accelerations. However, when looking at the bending moment results for the same bridge, in figure 7.42, it is seen that the spring stiffness $1 \mathrm{GN} / \mathrm{m}$ gives the lowest bending moments of all spring stiffness, although it causes such high accelerations. The reason for this is that the mode that gives the acceleration peak is a rotational rigid body mode where little bending occurs.

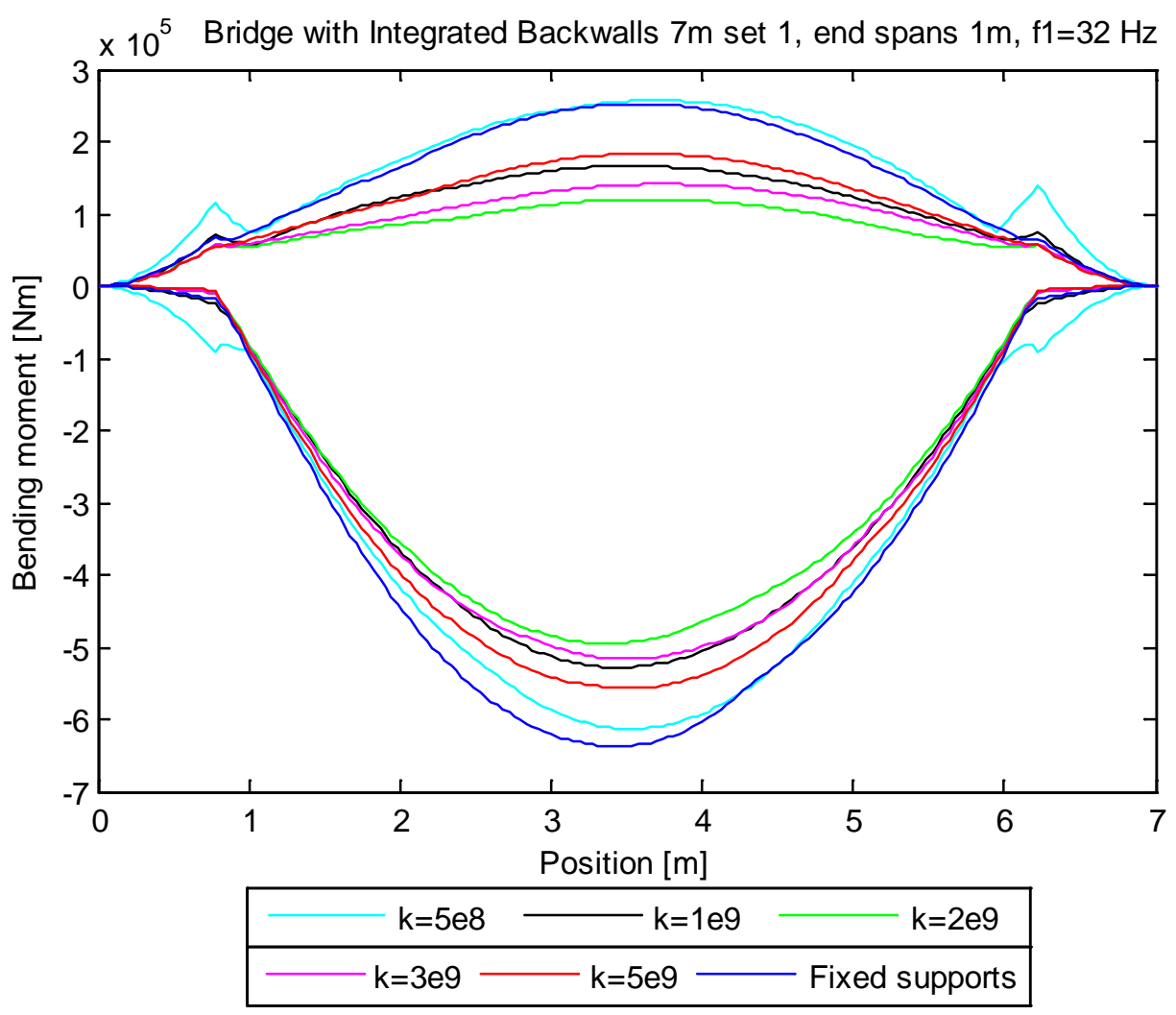

Figure 7.42: Moment diagram for a bridge with integrated backwalls for varying support stiffness from $0.5 \mathrm{GN} / \mathrm{m}$ to $5 \mathrm{GN} / \mathrm{m}$. 


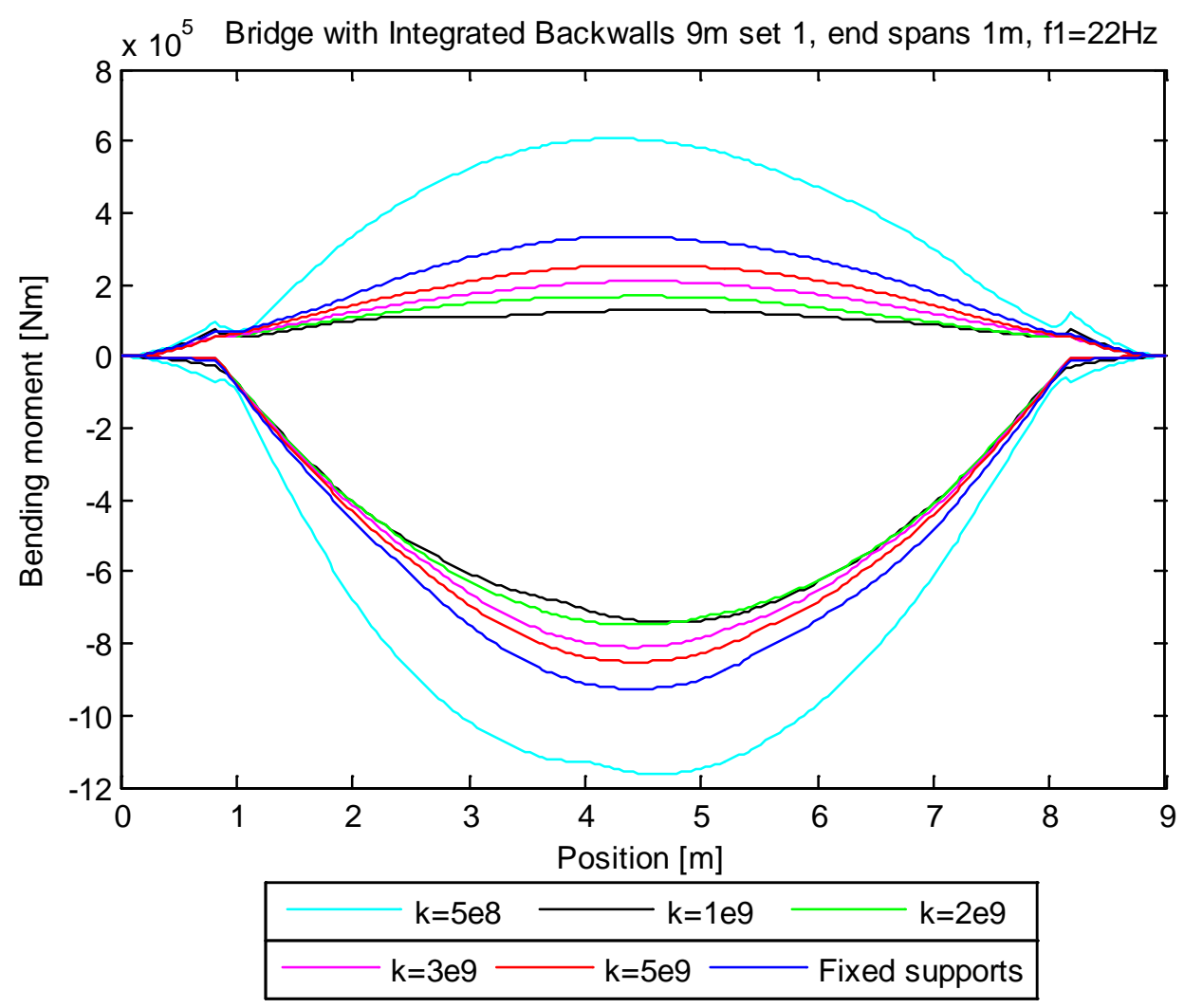

Figure 7.43: Moment diagram for a bridge with integrated backwalls for varying support stiffness from $0.5 \mathrm{GN} / \mathrm{m}$ to $5 \mathrm{GN} / \mathrm{m}$.

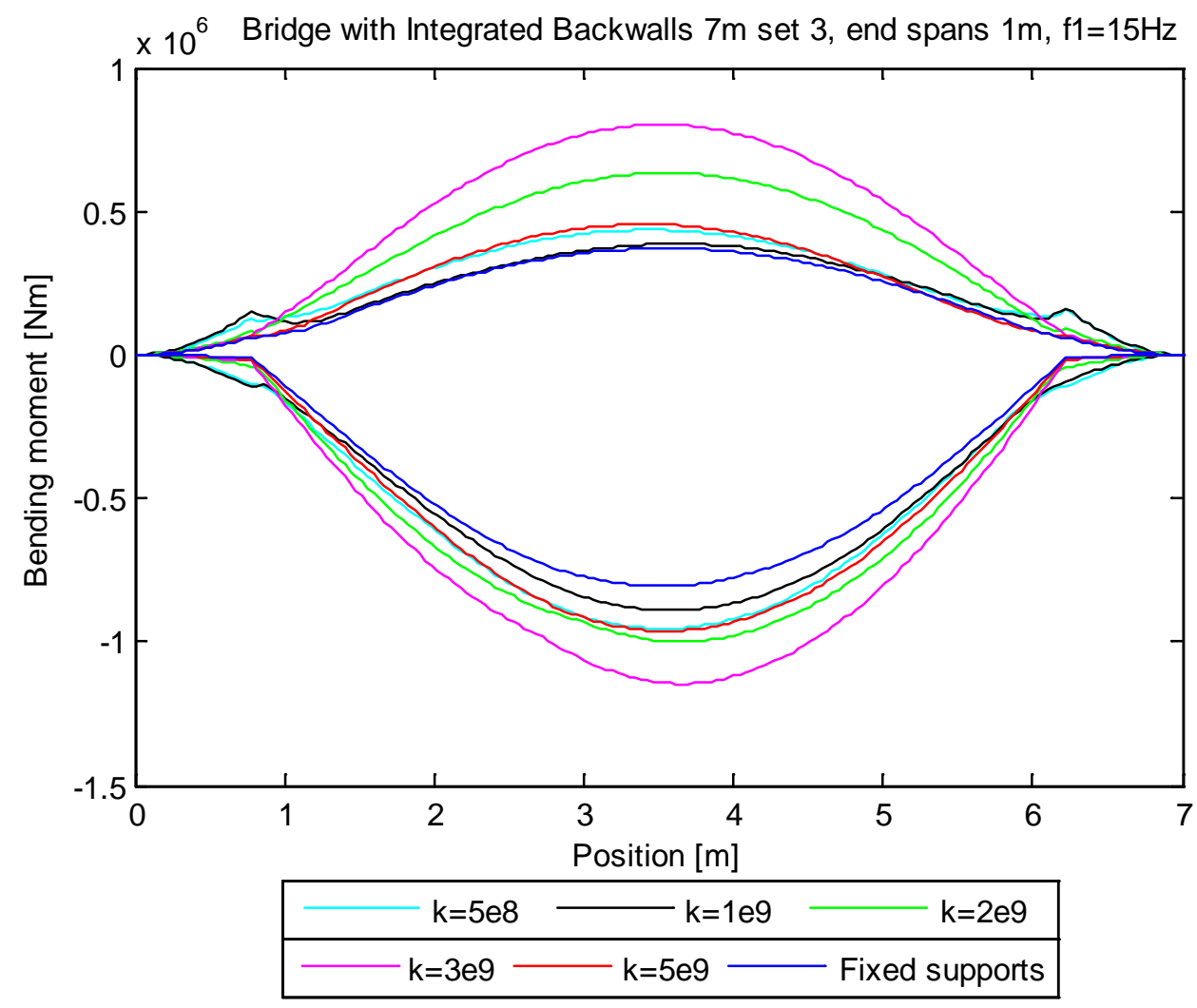

Figure 7.44: Moment diagram for a bridge with integrated backwalls for varying support stiffness from $0.5 \mathrm{GN} / \mathrm{m}$ to $5 \mathrm{GN} / \mathrm{m}$. 


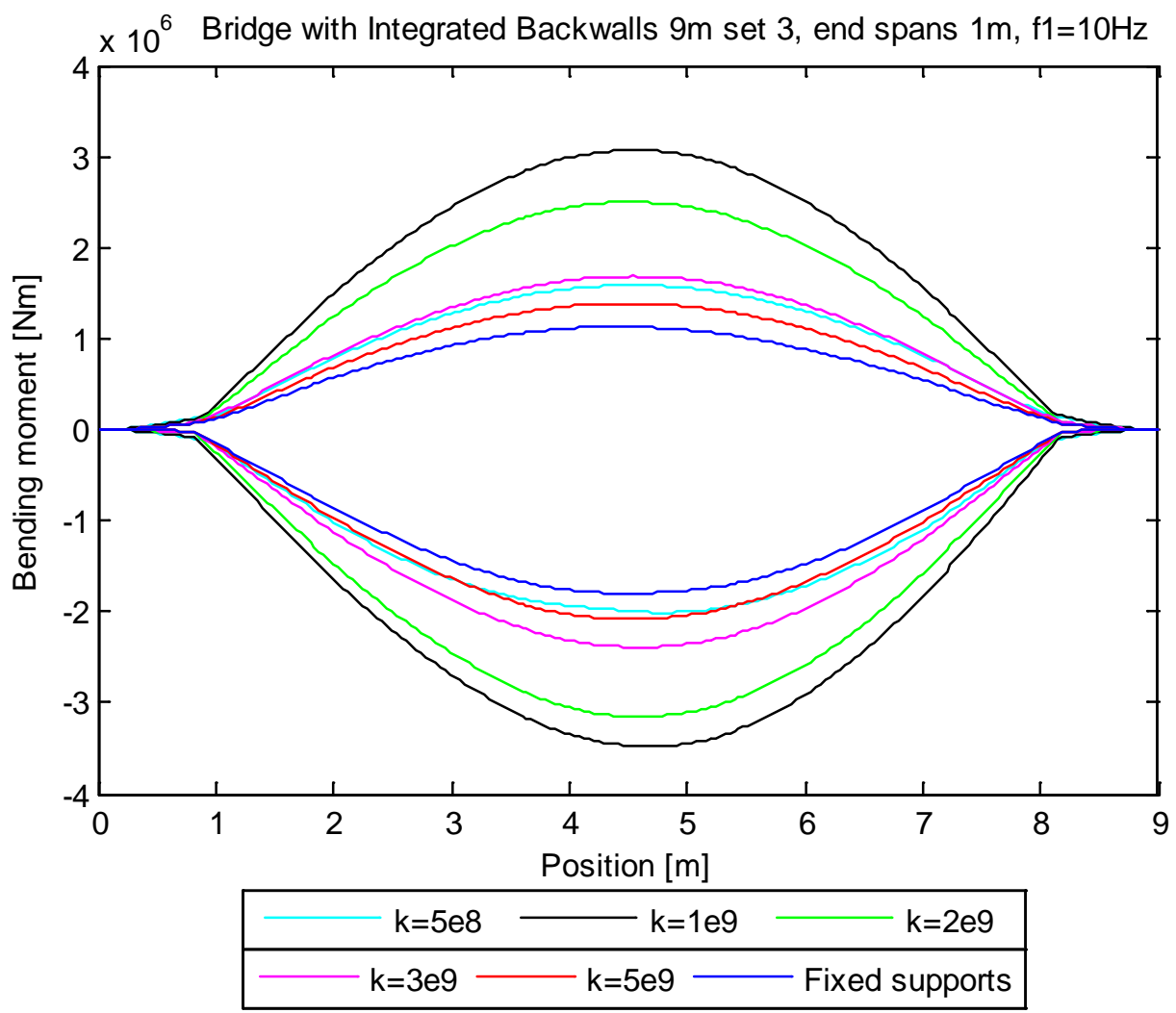

Figure 7.45: Moment diagram for a bridge with integrated backwalls for varying support stiffness from $0.5 \mathrm{GN} / \mathrm{m}$ to $5 \mathrm{GN} / \mathrm{m}$. 


\section{Chapter 8}

\section{Conclusions and Further Research}

\subsection{Conclusions}

The aim of this thesis was to study the load spreading effect on short span railway bridges. Two load shapes have been studied; the shape prescribed in Eurocode and a triangular load shape. These load shapes have been modeled both with a number of point loads and as distributed line loads.

The bridges studied were simply supported bridges and bridges with integrated backwalls. For the bridges with integrated backwalls, the effect of different support stiffness has been analyzed. The response of the bridges was measured in terms of vertical acceleration and bending moment.

\subsubsection{Accelerations}

The results from simulations run with Eurocode load distributions showed that:

For simply supported bridges:

- When considering the spreading effect in the ballast, the responses of the bridges were reduced significantly. For the bridge with the highest fundamental frequency, a reduction of almost $80 \%$ was obtained, although in most cases values around $10 \%$ were achieved compared to EC3.

- The gain in using more than nine point loads to model each axle was negligible for bridges with fundamental frequencies up to about $40 \mathrm{~Hz}$. For higher frequencies, a larger effect of going from EC9 to EC15 can be seen.

- Spurious acceleration peaks occurred for the Eurocode point load distributions but it was only for bridges with higher fundamental frequencies that the peaks arose at higher speeds and caused the maximum accelerations. To avoid this problem, each axle has either to be divided into a higher number of point loads or to be modeled as a distributed line load. However, the spurious peaks did not exceed the Eurocode acceleration limit and were therefore not a problem for the simply supported bridges under study. 
For bridges with integrated backwalls:

- As in the case with simply supported bridges, the responses of the bridges were reduced significantly when considering the spreading effect in the ballast. For the bridge with the lowest fundamental frequency $(10 \mathrm{~Hz})$ the reduction was less than $3 \%$ compared to EC3. For the other bridges the reductions were much larger with values between 60 and $77 \%$.

- The spurious peaks were higher than for the simply supported bridges and were critical even for lower fundamental frequencies.

The results from simulations run with triangle load distributions showed that:

For simply supported bridges:

- Using a triangular load shape reduced the response of the bridges significantly compared to EC3. Moreover, in all studied cases the triangle load distributions gave lower accelerations than the Eurocode distributions. The reduction increased steadily with higher fundamental frequencies with a reduction of $87 \%$ for the bridge with highest fundamental frequency.

- When using point loads to model the triangle load distribution, higher accelerations were obtained with increasing number of point loads. The highest accelerations were obtained for the distributed line load. Caution should therefore be taken when using point loads to model the triangular load shape, as there were cases when the Eurocode criterion was satisfied for the point load shapes but not for the distributed line load.

- As for the Eurocode point load distributions spurious peaks occured when using triangular point load distributions. However, it only became critical for the bridge with the highest fundamental frequency.

For bridges with integrated backwalls:

- As for the simply supported bridges, the reduction was larger for the triangular load distributions than for the Eurocode distributions in all cases. The highest obtained reduction was $86 \%$.

- The spurious peaks were higher than for the simply supported bridges and were critical even for lower fundamental frequencies.

\subsubsection{Bending Moments}

When running the simulations, positive displacements were found to occur due to the fact that the distances between the train axles were greater than the length of the bridges. The bridges then vibrate freely when in between two train axles. The positive displacements cause tension in the top of the bridge structures, something that needs to be considered when designing short span bridges.

For all simulations the reductions of the positive bending moment were larger than the reduction of the negative bending moment. This is explained by the fact that the positive 
bending moments occur only due to free vibrations. By using load distributions the accelerations are decreased, leading to reduced free vibrations and thereby reduced positive bending moments. For the negative bending moments there is always a static contribution and the dynamic contribution is only a part of the total moment. The static contribution is not affected as much by the load spreading as the dynamic contribution, and therefore the reductions are not as large for the negative bending moments as for the positive bending moments.

The maximum bending moments followed the same pattern as the maximum accelerations for the different load distributions. For the Eurocode load distributions the bending moments were lower the more point loads that were used and the line load distribution gave the lowest values. For the triangular load shapes the effect was the opposite and the highest values were obtained for the line load distribution. The triangle load distributions gave the lowest bending moments in all cases studied.

\subsubsection{Bridges with Integrated Backwalls with Spring Supports}

The bridges with integrated backwalls were modeled with spring supports of varying stiffness. The choice of support stiffness was found to have a significant influence on the dynamic response of the bridges.

- For low spring stiffness, rigid body modes were excited, resulting in strongly increased accelerations compared to when fixed supports were used.

- Significant reductions can be obtained for optimal values of the spring stiffness for bridges with higher fundamental frequencies.

- The largest reductions were obtained as the train entered and exited the bridges since the flexibility of the supports reduced the impact.

\subsection{Further Research}

In this thesis no comparisons have been made with measured values from existing bridges. A suggestion for future studies is to measure accelerations on existing railway bridges and evaluate what load distribution corresponds best to the measured values.

All simulations in this thesis are run with 2D beam elements. To capture transversal effects of the bridges, 3D-modeling would be necessary and could be an area of further investigation. The study can also be extended to include other types of bridges.

To further investigate the influence of the support conditions for bridges with integrated backwalls, more detailed analyses would be needed on a greater number of bridges. An interesting aspect would be to investigate how the optimal stiffness of the supports can be calculated. 



\section{References}

Agilent Technologies, 2000. The fundamentals of signal analysis.

CEN, 2002. Eurocode: Basis of structural design. EN 1990:2002. Brussels: CEN.

CEN/TC 250, 2002. Eurocode 1: Actions on structures - Part 2: Traffic loads on bridges. EN 1991-2. Brussels: CEN.

Chopra, A. K., 2012. Dynamics of Structures. 4th ed. Boston, MA: Pearson Education, Inc.

Cook, R. D., Malkus, D. S., Plesha, M. E. \& Witt, R. J., 2001. Concepts and Applications of Finite Element Analysis. 4th ed. Hoboken, NJ: John Wiley \& Sons, Inc.

Dassault Systèmes Simulia Corp., 2011a. Abaqus 6.11 Theory Manual. Providence, RI.

Dassault Systèmes Simulia Corp., 2011b. Abaqus 6.11 Analysis User's Manual, Volume V. Providence, RI.

Frýba, L., 1996. Dynamics of Railway Bridges. London, UK: Thomas Telford.

Gazetas, G., 1991. Foundation Vibrations. In H-Y. Fang (Ed.), Foundation Engineering Handbook (2nd ed., pp. 553-593). Norwell, MA: Van Nostrand Reinhold.

Johansson, C., Arvidsson, T., Martino, D., Yavari, M. S., Andersson, A., Pacoste, C. \& Karoumi, R., 2011. Höghastighetsprojekt bro - inventering av järnvägsbroar för ökad hastighet på befintliga banor. Stockholm: KTH, Division of Structural Design and Bridges.

Kylén, J., 2010. 2D-model of a portal frame railway bridge for dynamic analysis. Stockholm: $\mathrm{KTH}$, Division of Structural Design and Bridges.

Martínez-Rodrigo, M.D., Lavado, J. \& Museros, P., 2009, Dynamic performance of existing high-speed railway bridges under resonant conditions retrofitted with fluid viscous dampers. Engineering Structures, 32, 808-828.

Museros, P., Romero, M.L., Poy, A. \& Alarcón, E., 2002, Advances in the analysis of short span railway bridges for high-speed lines. Computers and Structures, 80, 2121-2132

Rehnström, R. \& Widén, D., 2012. The influence of ballast on the vibrations of railway bridges. Stockholm: KTH, Division of Structural Design and Bridges.

The MathWorks, Inc., 2012. Signal Processing Toolbox ${ }^{\mathrm{TM}}$ User's Guide. Natick, MA. 



\section{Appendix A}

\section{Matlab Code}

In this appendix all Matlab codes that have been used are attached. Most of the codes are further developments of codes written by Rehnström and Widén (2012). A list containing name and description is presented below:

bridge_script

bridge_script_spring_supports

ray_damp

HSLM_A1

spread_ec

spread_ec_dist

spread_tri

spread_tri_dist

force_matrix_timo

force_matrix_eul_dist

fast_fourier_transform
Main code generating the bridges and simulating train passages of various speeds. Maximum vertical accelerations and bending moments are calculated and saved to file.

Same as above but with the supports modeled as springs with various stiffness.

Function calculating Rayleigh damping matrix.

Function giving the positions and magnitudes of the axle loads of an HSLM-A1 train.

Function generating the Eurocode load shape with point loads, further described in section 5.3.1.

Function generating the Eurocode load shape with a distributed line load, further described in section 5.3.2.

Function generating the triangle load shape with point loads, further described in section 5.3.3.

Function generating the triangle load shape with a distributed line load, further described in section 5.3.4.

Function generating the force matrix using Timoshenko shape functions.

Function generating the force matrix using Euler-Bernoulli shape functions.

Script performing Fast Fourier Transform (FFT) on acceleration data. 


\section{A.1 Bridge Models}

\section{bridge_script}

\% Script generating a simply supported bridge with or without end spans $\%$ and calculating maximum vertical acceleration and bending moments from $\%$ a train passage at different velocities.

clear all, close all, clc

global edof ne nd nn Le $x y$

$\%$ Stiffness properties [ $\left.\mathrm{Nm}^{\wedge} 2\right]$

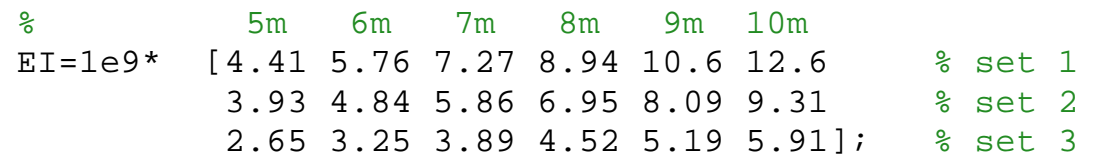

$\%$ Mass properties $[\mathrm{kg} / \mathrm{m}]$

\begin{tabular}{|c|c|c|c|c|c|c|c|}
\hline \multirow{4}{*}{$\begin{array}{l}\% \\
\text { Mass= }\end{array}$} & $5 m$ & $6 m$ & $7 \mathrm{~m}$ & $8 m$ & $9 m$ & $10 \mathrm{~m}$ & \\
\hline & {$[5700$} & 6400 & 7100 & 7800 & 8400 & 9100 & $\%$ set \\
\hline & 11100 & 11700 & 12400 & 13100 & 13800 & 14500 & $\%$ set \\
\hline & 16400 & 17100 & 17800 & 18400 & 19100 & $19800]$; & $\%$ set \\
\hline
\end{tabular}

$\mathrm{Np}=17 ; \%$ - number of point loads to divide the load shapes into (for $\%$ Eurocode distribution $\mathrm{Np}$ is the number of point loads beneath $\%$ each sleeper)

$\mathrm{dx}=0.05 ; \quad \%$ - interval size to divide distributed loads into [m]

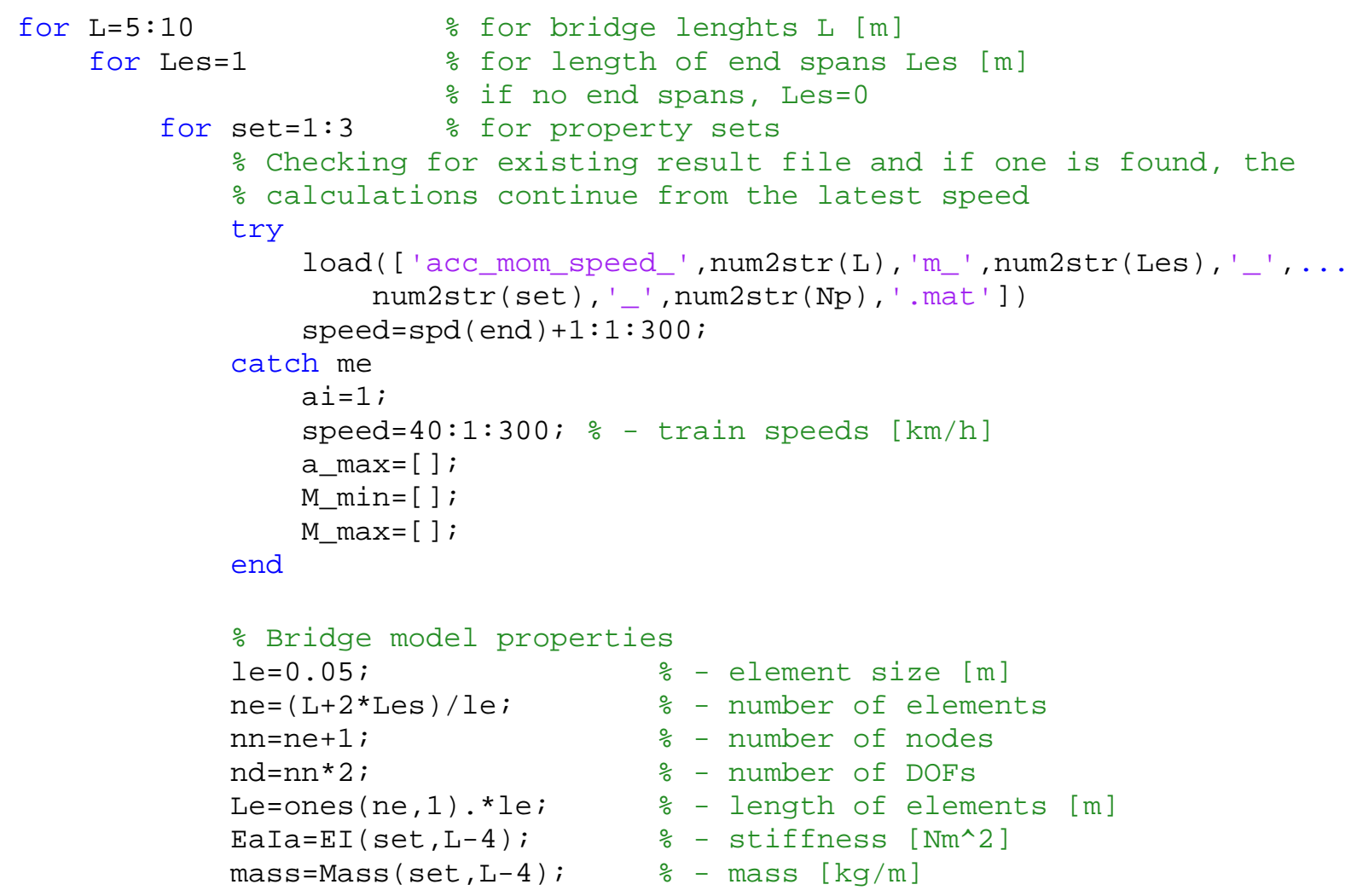




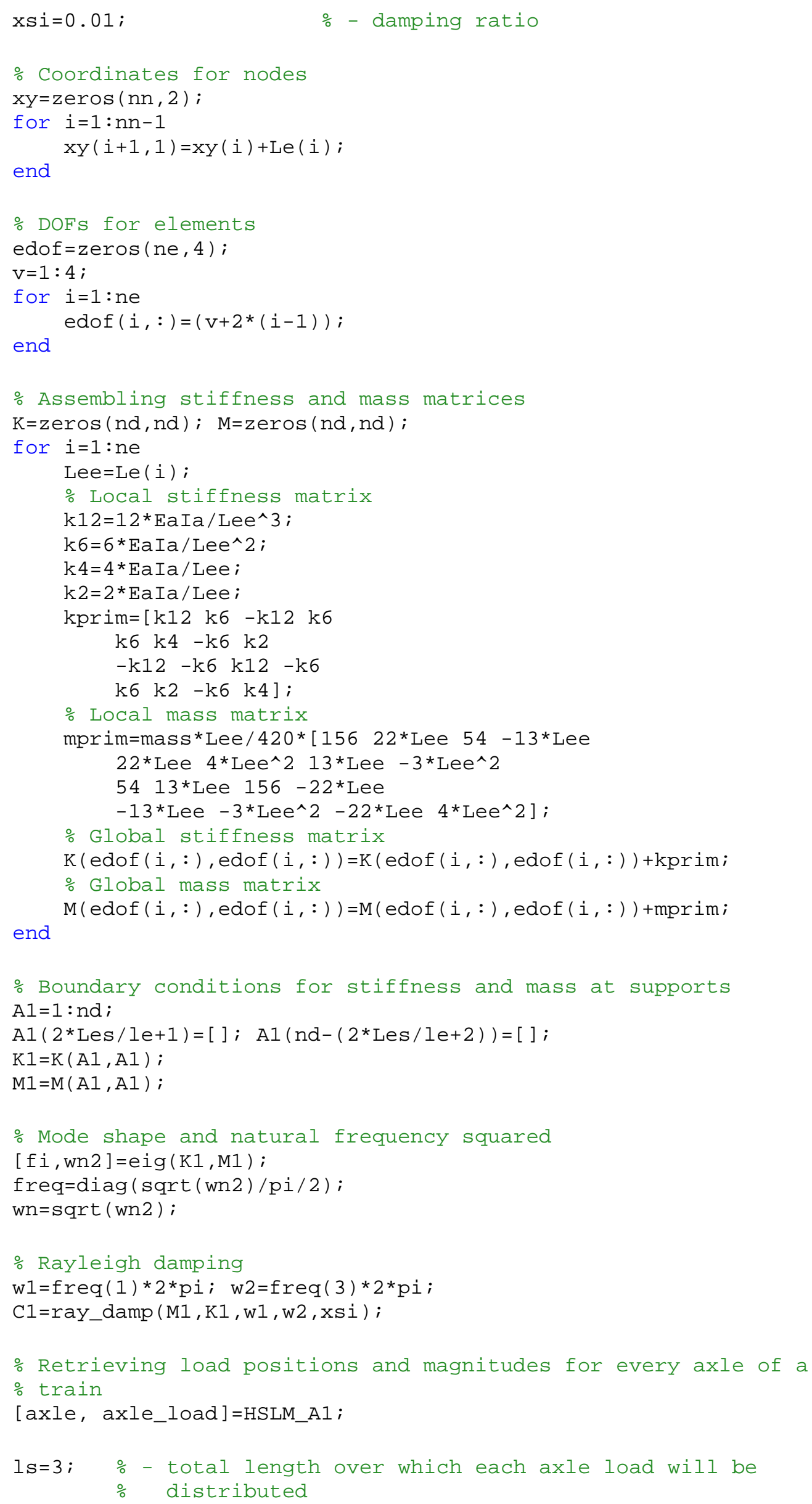




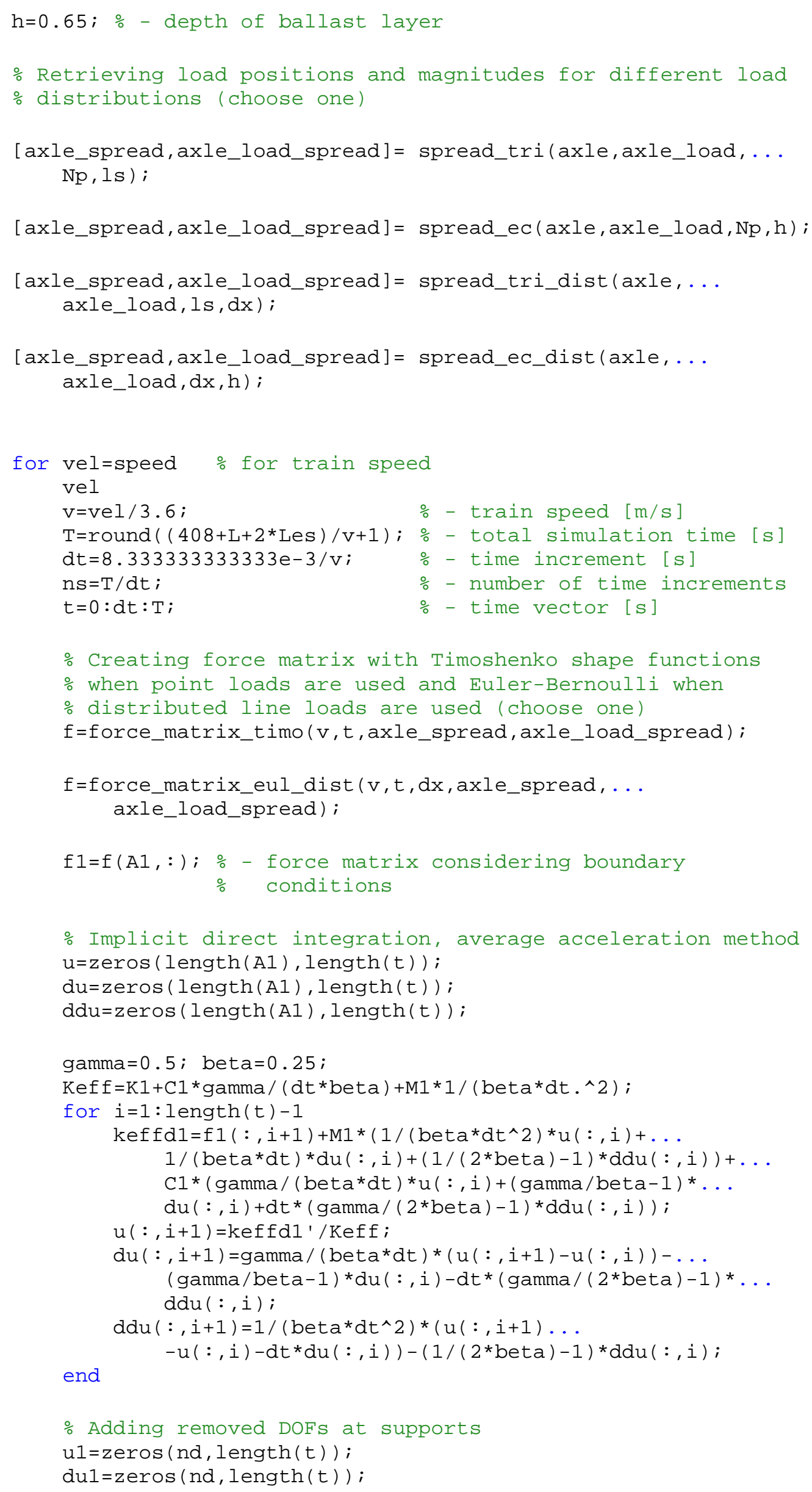




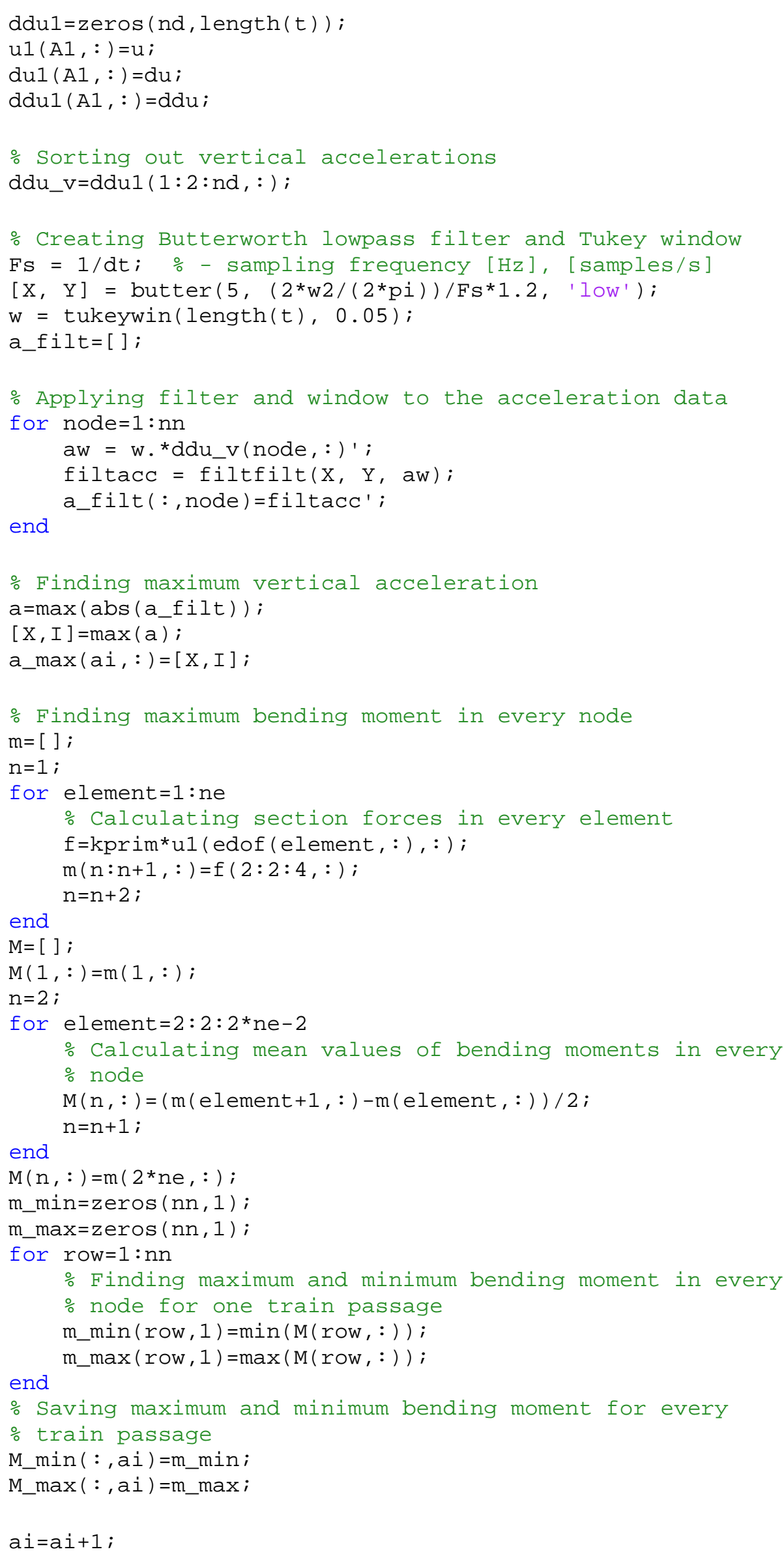


$\operatorname{spd}=\operatorname{speed}(1): 1: \mathrm{vel} ;$

$x=(0:(L+2 *$ Les $) /$ ne: $L+2 *$ Les $) '$;

save( ['acc_mom_speed_', num2str(L), 'm_', num2str(Les), ... '_', num2str( set), '-', num2str(Np), '. mat' '], ..

end 'a_max', 'spd', 'M_min', 'M_max', 'x', 'ai')

end

end

end

\section{brigde_script_spring_supports}

\% Script generating a simply supported bridge with or without end spans $\%$ and calculating maximum vertical acceleration and bending moments from $\%$ a train passage at different velocities. The supports are modeled as \% springs which can be given a chosen stiffness.

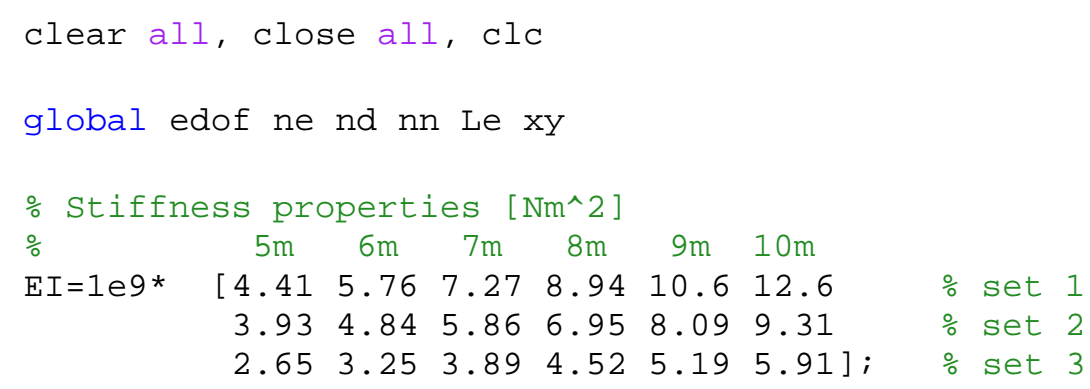




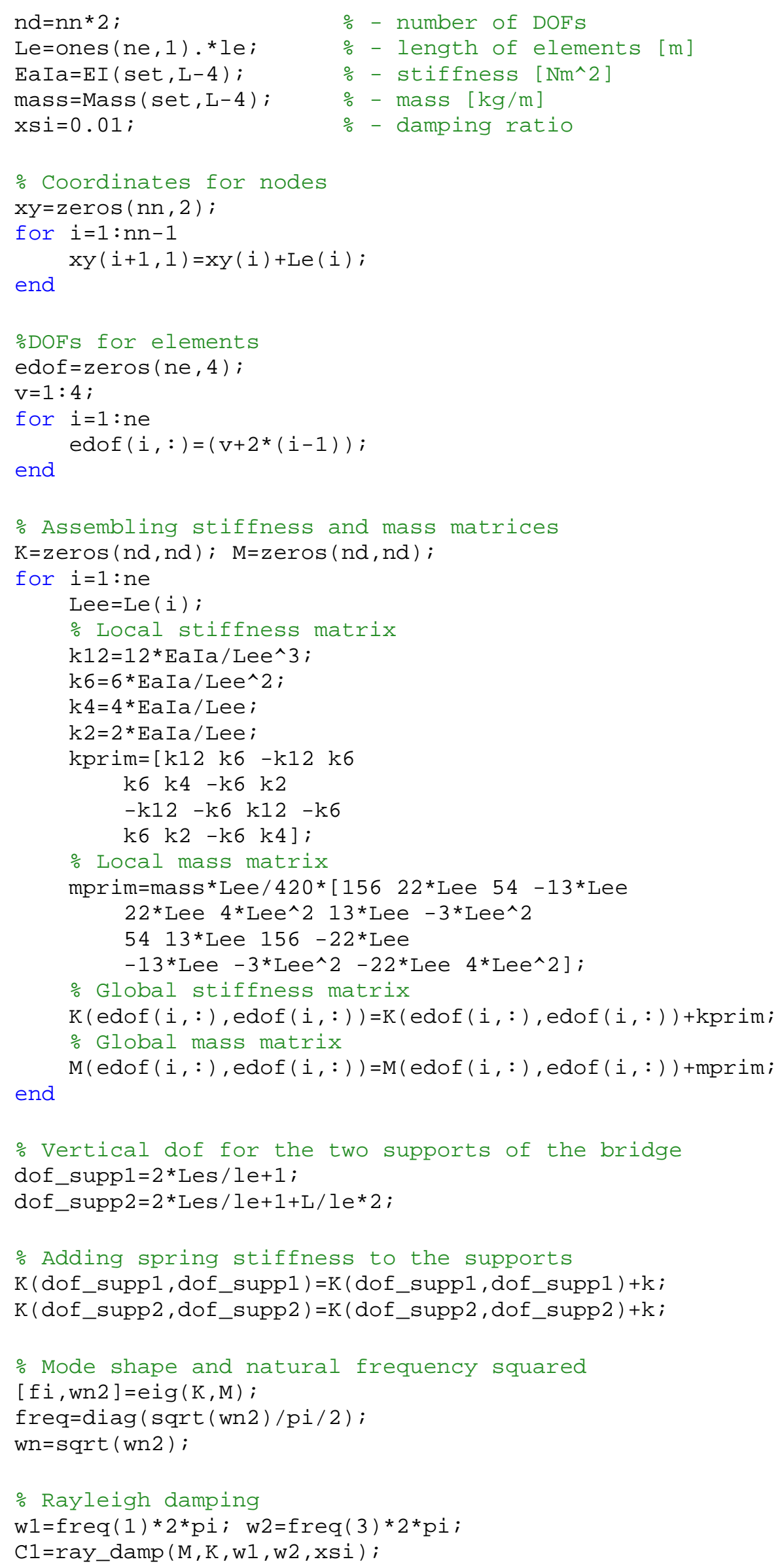


\% Retrieving load positions and magnitudes for every axle of a $\%$ train

[axle, axle_load]=HSLM_A1;

ls=3; \% - total length over which each axle load will be $\%$ distributed

\% Retrieving load positions and magnitudes for triangle load $\%$ distribution

[axle_spread,axle_load_spread] = spread_tri_dist $($ axle, . . . axle_load, ls, $\mathrm{dx}$ );

for vel=speed \% for train speed

vel

$\mathrm{v}=\mathrm{vel} / 3.6 ; \quad \%$ - train speed $[\mathrm{m} / \mathrm{s}]$

$\mathrm{T}=\operatorname{round}((408+\mathrm{L}+2 *$ Les $) / \mathrm{v}+1) ; \%$ - total simulation time [s]

$\mathrm{dt}=8.333333333333 \mathrm{e}-3 / \mathrm{v} ; \quad \%$ - time increment [s]

$\mathrm{ns}=\mathrm{T} / \mathrm{dt} ; \quad \%$ - number of time increments

$\mathrm{t}=0: \mathrm{dt}: \mathrm{T}$;

$\%$ - time vector [s]

\% creating force matrix with Timoshenko shape functions

$f=$ force_matrix_eul_dist $(v, t, d x$, axle_spread, ... axle_load_spread);

\% Implicit direct integration, average acceleration method $\mathrm{u}=$ zeros ( nd, length $(\mathrm{t}))$;

$\mathrm{du}=$ zeros ( nd, length $(\mathrm{t}))$;

ddu=zeros ( nd, length $(\mathrm{t}))$;

gamma $=0.5 ;$ beta $=0.25$;

Keff $=\mathrm{K}+\mathrm{C} 1^{*}$ gamma $/\left(\mathrm{dt}{ }^{*}\right.$ beta $)+\mathrm{M} * 1 /($ beta* $\mathrm{dt} . \wedge 2)$;

for $i=1:$ length $(t)-1$

keffd1 $1=f(:, i+1)+M *(1 /($ beta* $d t \wedge 2) * u(:, i)+\ldots$

$1 /($ beta*dt $) * d u(:, i)+(1 /(2 *$ beta $)-1) * d d u(:, i))+\ldots$

$\mathrm{C} 1{ }^{*}($ gamma $/($ beta*dt)*u( $\mathrm{u}, \mathrm{i})+($ gamma/beta -1$) * \ldots$

$\mathrm{du}(:, \mathrm{i})+\mathrm{dt}{ }^{*}($ gamma $/(2 *$ beta $\left.)-1){ }^{*} \mathrm{ddu}(:, \mathrm{i})\right)$;

$\mathrm{u}(:, \mathrm{i}+1)=\mathrm{keffd1}$ '/Keff ;

$\operatorname{du}(:, i+1)=$ gamma $/($ beta*dt $) *(u(:, i+1)-u(:, i))-\ldots$

$($ gamma/beta -1$){ }^{*} \mathrm{du}(:, i)-d t^{*}($ gamma $/(2 *$ beta $)-1){ }^{*} \ldots$ ddu $(:, i)$;

$\operatorname{ddu}(:, i+1)=1 /($ beta*dt^2)* $(u(:, i+1) \ldots$

end $\left.-u(:, i)-d t^{*} d u(:, i)\right)-(1 /(2 *$ beta $)-1) * d d u(:, i)$;

$\%$ Sorting out vertical accelerations

ddu_v=ddu $(1: 2:$ nd, : ) ;

\% Creating Butterworth lowpass filter and Tukey window $\mathrm{Fs}=1 / \mathrm{dt} ; \%$ - sampling frequency $[\mathrm{Hz}], \quad[$ samples $/ \mathrm{s}]$

$[\mathrm{X}, \mathrm{Y}]=\operatorname{butter}\left(5,\left(2{ }^{*} \mathrm{~W} 2 /\left(2{ }^{*} \mathrm{pi}\right)\right) / \mathrm{Fs}{ }^{*} 1.2\right.$, ' $\mathrm{low}$ ');

$\mathrm{w}=\operatorname{tukeywin}($ length $(\mathrm{t}), 0.05)$;

a_filt $=[]$;

\% Applying filter and window to the acceleration data

for node $=1: \mathrm{nn}$

$a w=w$. *ddu_v $(\text { node },:)^{\prime}$;

filtacc $=$ filtfilt $(X, Y$, aw $)$;

end

a_filt $(:$, node $)=$ filtacc ${ }^{\prime}$; 
\% Finding maximum vertical acceleration $a=\max \left(\operatorname{abs}\left(a_{-} f i l t\right)\right)$;

$[X, I]=\max (a)$;

a_max $(\mathrm{ai}, \mathrm{:})=[\mathrm{X}, \mathrm{I}]$;

\% Finding maximum bending moment in every node $\mathrm{m}=[\mathrm{]}$;

$\mathrm{n}=1$;

for element=1: ne

$\%$ Calculating section forces in every element

$f=k p r i m * u($ edof (element, : ) , : );

$m(n: n+1,:)=f(2: 2: 4,:)$;

$\mathrm{n}=\mathrm{n}+2$;

end

$\mathrm{M}=[\mathrm{]}$;

$M(1,:)=m(1,:)$;

$\mathrm{n}=2$;

for element $=2: 2: 2^{*}$ ne-2

$\%$ Calculating mean values of bending moments in every $\%$ node

$M(n,:)=(m($ element $+1,:)-m($ element,$:)) / 2$;

end $\mathrm{n}=\mathrm{n}+1$;

$M(n,:)=m(2 *$ ne, : $)$;

m_min=zeros $(\mathrm{nn}, 1)$;

m_max $=\operatorname{zeros}(\mathrm{nn}, 1)$;

for row=1:nn

$\%$ Finding maximum and minimum bending moment in every

$\%$ node for one train passage

m_min $($ row, 1$)=\min (M($ row,$:))$;

end

m_max $(\operatorname{row}, 1)=\max (M($ row,$:))$;

\% Saving maximum and minimum bending moment for every

$\%$ train passage

M_min $($ : , ai $)=$ m_min ;

M_max $(:$, ai $)=m \_m a x$;

$\mathrm{ai}=\mathrm{ai}+1$

spd=speed $(1): 1: \mathrm{vel}$;

$x=(0:(L+2 *$ Les $) /$ ne: $L+2 *$ Les $)$ ';

save ( [ 'acc_mom_speed_', num2str( L), 'm_', num2str(Les) , . .

-', num2str(set), '_,', num2str $(\mathrm{dx}),{ }^{\prime}, \mathrm{t}$ trid_k= ', . .

num2str(k/1e8), 'e8.mat'], 'a_max', 'spd', 'M_min',...

end

'M_max', 'x', 'ai')

end

end

end 


\section{A.2 Functions}

\section{ray_damp}

\% Function calculating Rayleigh damping matrix.

$\%$ Input

$\%$ M : global mass matrix

$\% \mathrm{~K}:$ global stiffness matrix

\% w1 : fundamental circular frequency ( $\mathrm{rad} / \mathrm{s}$ )

$\%$ w2 : circular frequency for third mode ( $\mathrm{rad} / \mathrm{s})$

$\%$ xsi : damping ratio

function C=ray_damp (M, K, w1, w2, xsi)

alpha_d $=x s i{ }^{*} 2^{*} w 1{ }^{*} w 2 /(w 1+w 2)$;

beta_d=xsi*2/(w1+w2);

$C=a l p h a \_d^{*} M+b e t a \_d^{*} K$;

\section{HSLM_A1}

\% Function generating an HSLM-A1 train. Returns axle distances and loads.

function [LL, axle_load]=HSLM_A1

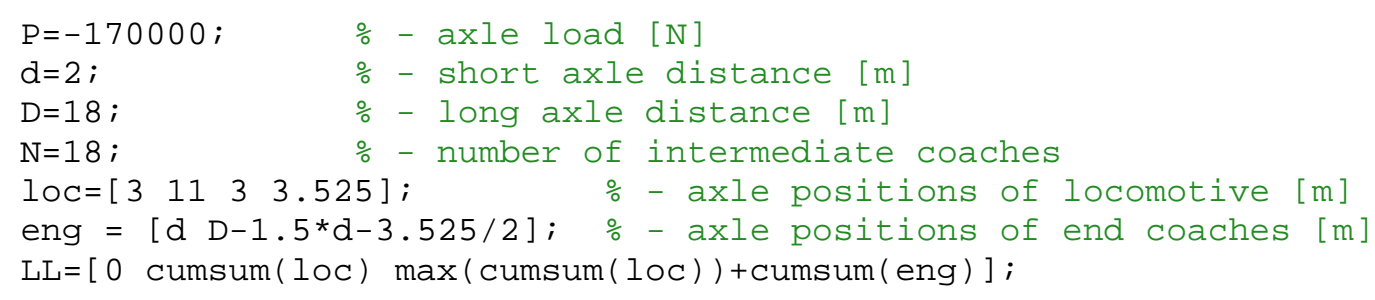




\section{spread_ec}

\% Function generating and returning a load distribution as prescribed in \% Eurocode EN 1991-2 for every axle of a train. The load acting on each $\%$ sleeper can be divided into an arbitrary, odd number of point loads, Np. $\%$ For $\mathrm{Np}=1$ the sleeper distribution is neglected.

$\%$ Input

$\%$ axle : vector containing the position of every train axle [m] $\%$ axle_load : vector containing the load of every train axle [N]

$\% \mathrm{~Np} \quad$ : number of point loads for each axle, only odd numbers

$\% \mathrm{~h} \quad$ : depth of ballast layer [m]

function [axle_spread, axle_load_spread]=spread_ec(axle, axle_load, Np, h)

\% Track properties

bs $=0.280 ; \%$ - width of sleeper [m]

$\mathrm{cc}=0.65 ; \quad \%$ - distance between sleepers [m]

$\mathrm{b}=\mathrm{h} / 2+\mathrm{bs} ; \%$ - total length over which each sleeper load will be $\%$ distributed [m]

axle_spread=zeros $\left(\right.$ length $\left.(\operatorname{axle}) * \mathrm{~Np}^{*} 3,1\right)$;

axle_load_spread $=$ zeros $($ length $($ axle_load $) * N p * 3,1)$;

\% Calculating the magnitudes of the point loads beneath each sleeper $\mathrm{P}=\mathrm{axle} \_\mathrm{load}(1)$;

$\mathrm{p} 1=\mathrm{P} /\left(4^{*} \mathrm{~Np}\right)$;

$\mathrm{p} 2=\mathrm{p} 1 * 2 ;$

$\mathrm{p} 3=\mathrm{p} 1$;

$\%$ - point loads beneath sleeper 1
$\%$ - point loads beneath sleeper 2
$\%$ - point loads beneath sleeper 3

\% Assembling the output vectors. Gives position and corresponding magnitude $\%$ of every point load for every train axle, $j$.

$j=1$;

for $i=N p * 3 / 2+0.5: N p * 3:$ length (axle_spread)

$\%$ Load positions

$\operatorname{ccp}=z e r o s(1, N p) ; \%$ - distances to each point load from the middle $\%$ point load

coeff $=-(N p-(N p+1) / 2): N p-(N p+1) / 2$;

for $k=1: N p$

end $\operatorname{ccp}(k)=\operatorname{coeff}(k) * b / N p$;

axle_spread $(i-(N p-1) / 2: i+(N p-1) / 2)=\operatorname{axle}(j) * \operatorname{ones}(1, N p)+c c p$;

axle_spread $\left(i-\left(3^{*} \mathrm{~Np}-1\right) / 2: i-(\mathrm{Np}+1) / 2\right)=\operatorname{axle} \_\operatorname{spread}(\mathrm{i}-(\mathrm{Np}-1) / 2: i+\ldots$ $(\mathrm{Np}-1) / 2)-\mathrm{CC}$;

$\operatorname{axle\_ spread}(i+(N p+1) / 2: i+(3 * N p-1) / 2)=\operatorname{axle} \_\operatorname{spread}(i-(N p-1) / 2: i+\ldots$ $(\mathrm{Np}-1) / 2)+\mathrm{CC}$;

$\%$ Load magnitudes

axle_load_spread $(i-(N p-1) / 2: i+(N p-1) / 2)=p 2 *$ ones $(1, N p)$;

axle_load_spread $\left(i-\left(3^{*} \mathrm{~Np}-1\right) / 2: \mathrm{i}-(\mathrm{Np}+1) / 2\right)=\mathrm{p} 1^{*}$ ones $(1, \mathrm{~Np})$;

axle_load_spread $\left(i+(N p+1) / 2: i+\left(3^{*} \mathrm{~Np}-1\right) / 2\right)=p 3^{*}$ ones $(1, N p)$;

end

$j=j+1$ 


\section{spread_ec_dist}

\% Function generating and returning a load distribution as prescribed in \% Eurocode EN 1991-2 for every axle of a train. Every axle is represented $\%$ by three uniformly distribued line loads that can be divided into $\%$ intervals of arbitrary size, $\mathrm{dx}$.

$\%$ Input

$\%$ axle : vector containing the position of every train axle $\%$ axle_load : vector containing the load of every train axle

$\% \mathrm{dx} \quad:$ interval size to divide distributed loads into [m]

$\% \mathrm{~h} \quad$ : depth of ballast layer [m]

function [axle_spread, axle_load_spread]=spread_ec_dist(axle,axle_load,... $d x, h)$

$\%$ Track properties

bs=0.280; \% - width of sleeper [m]

$\mathrm{cc}=0.65 ; \quad \%$ - distance between sleepers [m]

$\mathrm{b}=\mathrm{h} / 2+\mathrm{bs} ; \%$ - total length over which each sleeper load will be $\%$ distributed [m]

axle_spread=zeros (length $($ axle $) * \operatorname{round}(b / d x) * 3,1)$; axle_load_spread=zeros $($ length $($ axle_load $) * \operatorname{round}(\mathrm{b} / \mathrm{dx}) * 3,1)$;

\% Calculating the magnitudes of the distributed line loads beneath each $\%$ sleeper

$\mathrm{P}=\mathrm{axle} \_\mathrm{load}(1)$;

$\mathrm{q} 1=\mathrm{P} /\left(4^{*} \mathrm{~b}\right)$ * ones $(1$, round $(\mathrm{b} / \mathrm{dx})) ; \quad \%$ - line load beneath sleeper 1

$\mathrm{q} 2=\mathrm{q} 1 * 2$;

$\mathrm{q} 3=\mathrm{q} 1 ;$

$\%$ - line load beneath sleeper 2

$\%$ - line load beneath sleeper 3

$\%$ Assembling the output vectors. Divides the line loads into intervals of $\%$ size $d x$ and gives corresponding magnitues for every train axle, $j$.

$a=1$;

$i=[-b / 2+d x / 2-c c: d x: b / 2-d x / 2-c c-b / 2+d x / 2: d x: b / 2-d x / 2-b / 2+d x / 2+\ldots$ $c c: d x: b / 2-d x / 2+c c]$;

for $j=1: 3^{*}$ round $(b / d x)$ : length (axle_spread) axle_spread $\left(j: j+3^{*}\right.$ round $\left.(b / d x)-1\right)=a x l e(a)+i$;

axle_load_spread $(j: j+3 * \operatorname{round}(b / d x)-1)=\left[\begin{array}{lll}q 1 & q 2 & q 3\end{array}\right]$;

end $a=a+1$;

axle_spread=flipud $(-$ axle_spread);

end

\section{spread_tri}

\% Function generating and returning a triangular load distribution for $\%$ every axle of a train. The load can be divided into an arbitrary, odd $\%$ number of point loads, $\mathrm{Np}$. For $\mathrm{Np}=1$ the function returns the input $\%$ vectors with no load distribution.

$\%$ Input 


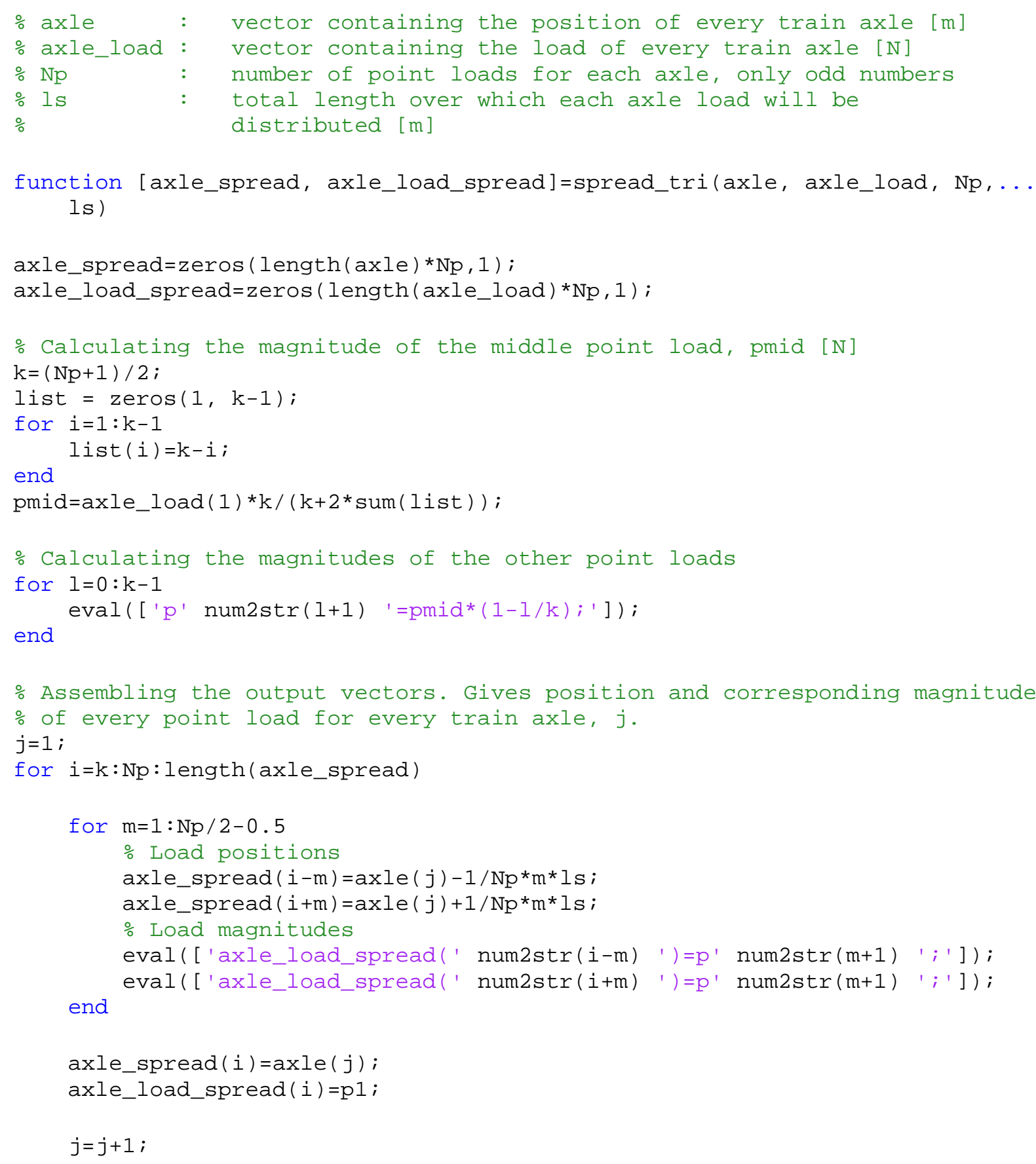

end

\section{spread_tri_dist}

\% Function generating and returning a triangular load distribution for $\%$ every axle of a train. Every axle is represented by two linearly

$\%$ distributed line loads that can be divided into intervals of arbitrary

$\%$ size, $d x$.

$\%$ Input

\% axle : vector containing the position of every train axle 
\% axle_load : vector containing the load of every train axle

$\%$ ls : total length over which each axle load will be distributed

$\% \mathrm{dx} \quad$ : interval size to divide distributed loads into [m]

function [axle_spread, axle_load_spread]=spread_tri_dist(axle,axle_load,... ls, $d x)$

axle_spread=zeros $($ length $(\operatorname{axle}) * 1 s / d x, 1)$;

axle_load_spread=zeros $($ length $($ axle_load $) * 1 s / d x, 1)$;

pmid=axle_load(1)；

$\%$ Assembling the output vectors. Divides the line loads into intervals of $\%$ size $d x$ and gives corresponding magnitues for every train axle, $j$.

$\mathrm{a}=1$;

$i=-1 \mathrm{~s} / 2: \mathrm{dx}: 1 \mathrm{~s} / 2$;

try

$\mathrm{q} 1=2 * \mathrm{pmid} / 1 \mathrm{~s} *(2 / 1 \mathrm{~s} * i(1:($ end +1$) / 2)+1)$;

$\mathrm{q} 2=2 * \mathrm{pmid} / 1 \mathrm{~s} *(1-2 / 1 \mathrm{~s} * \mathrm{i}(($ end +1$) / 2+1:$ end $))$;

for $j=1: l s / d x+1:$ length (axle_spread)

axle_spread $(j: j+l s / d x)=\operatorname{axle}(a)-1 s / 2: d x: \operatorname{axle}(a)+l s / 2$;

axle_load_spread $(j: j+l s / d x)=\left[\begin{array}{ll}q 1 & q 2\end{array}\right]$;

end

$a=a+1$

catch me

$\mathrm{q} 1=2 * \mathrm{pmid} / 1 \mathrm{~s} *(2 / 1 \mathrm{~s} * \mathrm{i}(1:$ end $/ 2)+1)$

$\mathrm{q} 2=2 * \mathrm{pmid} / 1 \mathrm{~s}^{*}(1-2 / 1 \mathrm{~s} * \mathrm{i}($ end $/ 2+1$ : end $))$;

for $j=1: 1 s / d x+1:$ length (axle_spread)

$\operatorname{axle} \_s p r e a d(j: j+l s / d x)=\operatorname{axle}(a)-1 s / 2: d x: \operatorname{axle}(a)+l s / 2$;

axle_load_spread $(j: j+1 s / d x)=[q 1$ q2 $]$;

end

$a=a+1$

end

axle_spread=flipud $(-$ axle_spread $)$;

end

\section{force_matrix_timo}

\% Function generating a force matrix with Timoshenko shape functions.

$\%$ Input

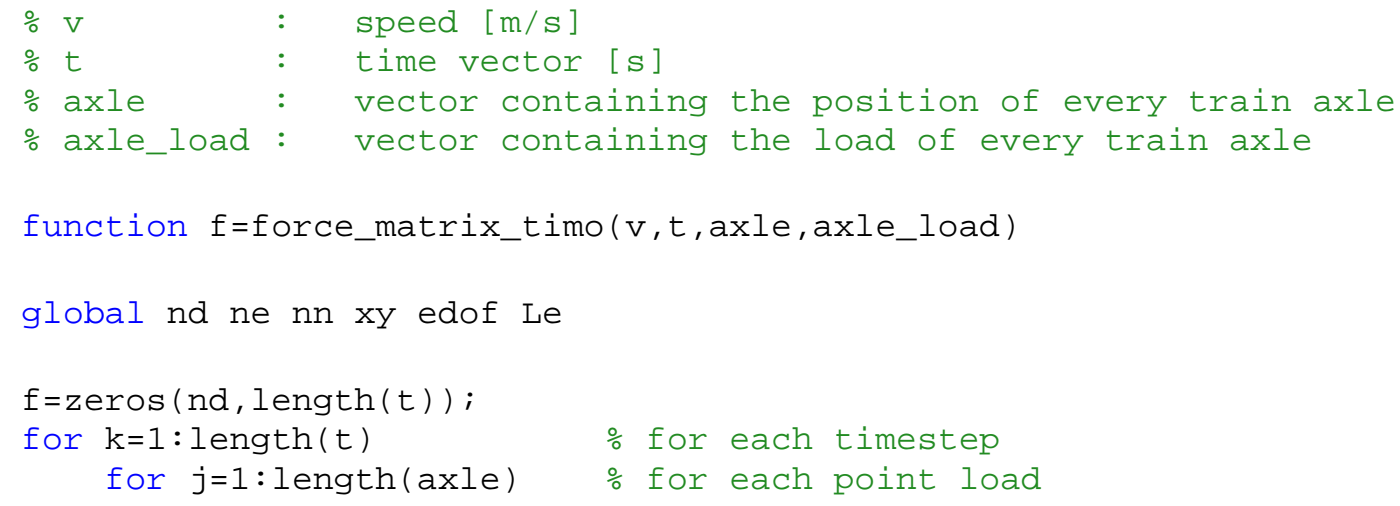




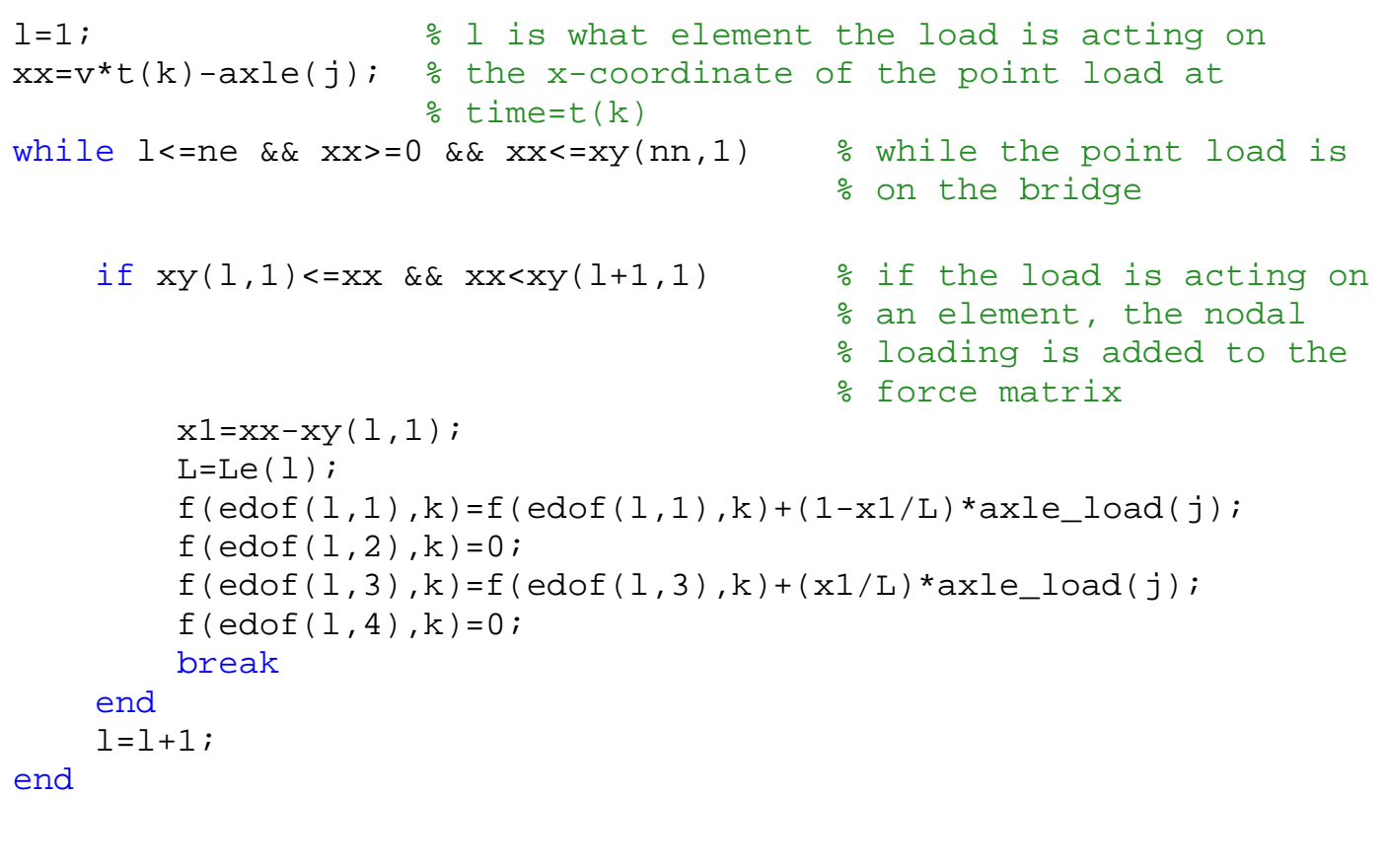

\section{force_matrix_eul_dist}

\% Function generating a force matrix with Euler-Bernoulli shape functions.

$\%$ Input

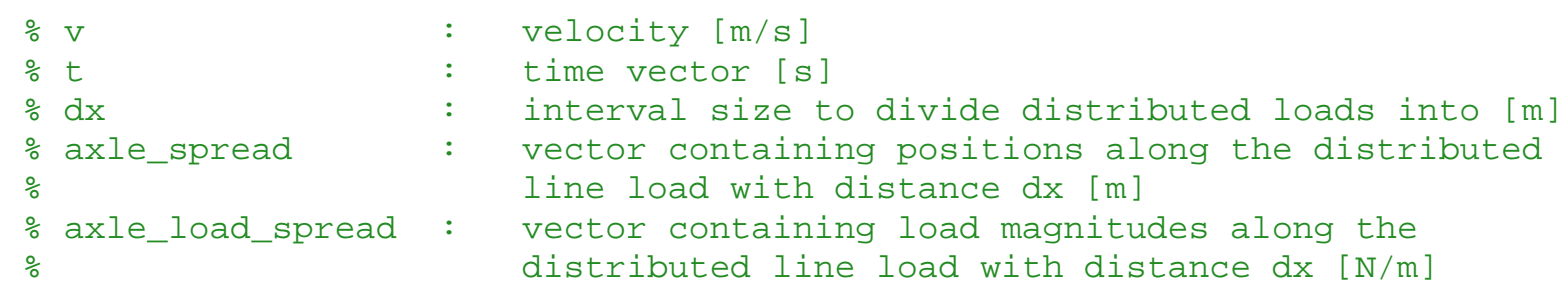

function f=force_matrix_eul_dist( $\left.v, t, d x, a x l e \_s p r e a d, a x l e \_l o a d \_s p r e a d\right)$

global nd ne nn xy edof Le

$f=\operatorname{zeros}($ nd, length $(t))$;

for $k=1$ : length( $t)$

for $j=1:$ length (axle_spread)

$\%$ for each timestep

$1=1$;

$\%$ for each load position

$\% 1$ is what element the load is

$\%$ acting on

$\mathrm{x} x=\mathrm{v}^{*} \mathrm{t}(\mathrm{k})+\mathrm{axle} \_\operatorname{spread}(j) ; \quad \%$ the $\mathrm{x}$-coordinate of the load

while $1<=$ ne \&\& $x x>=0 \quad \& \& x x<=x y(n n, 1) \%$ while the load is on

$\%$ the bridge

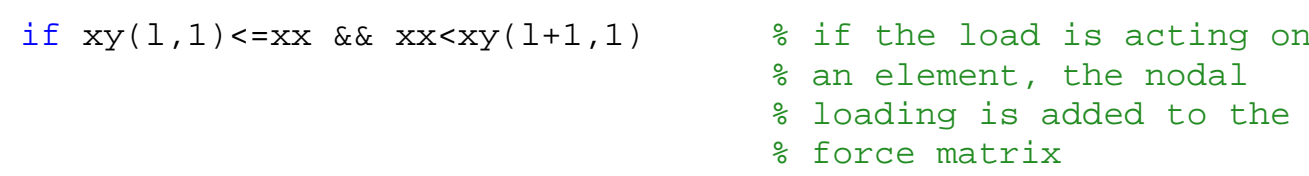




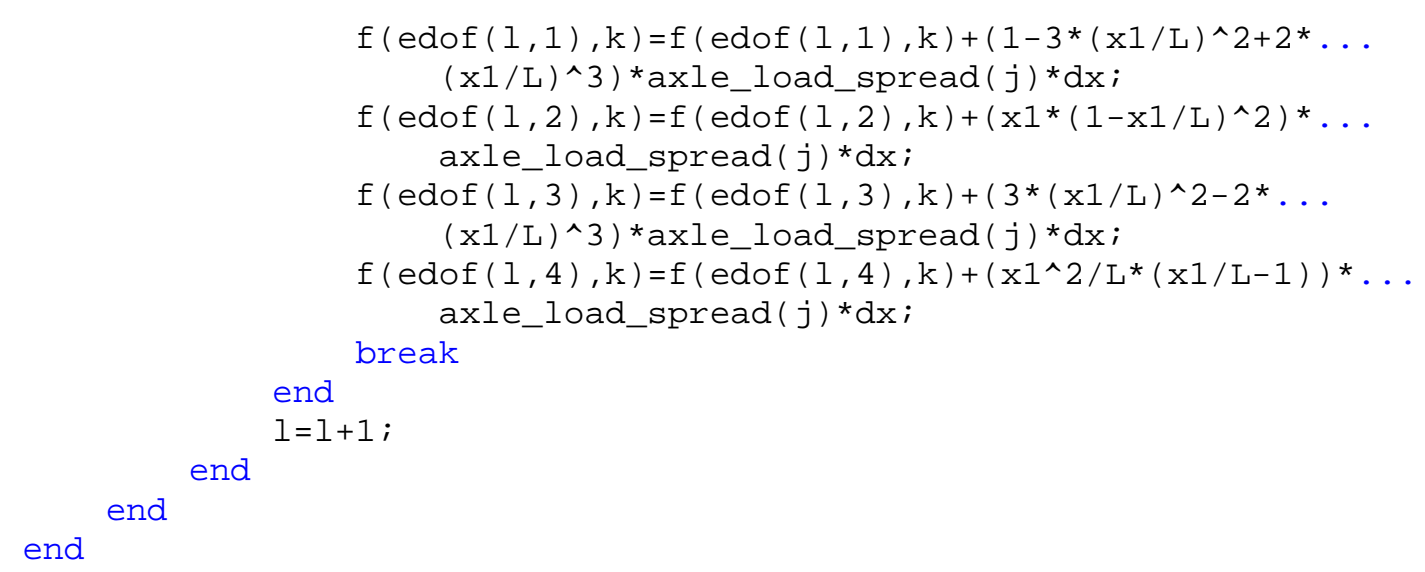

\title{
A.3 Fast Fourier Transform
}

\author{
fast_fourier_transform \\ \% Script performing a fast fourier transform (FFT) on acceleration \\ $\%$ data loaded from file and plotting the acceleration in time and \\ $\%$ frequency domain. \\ clear all, close all, clc \\ \% Loading file with acceleration vector $a$, time vector $t$ and time step $d t$ \\ load('frequency_data_5m_1_tri21_140.mat')

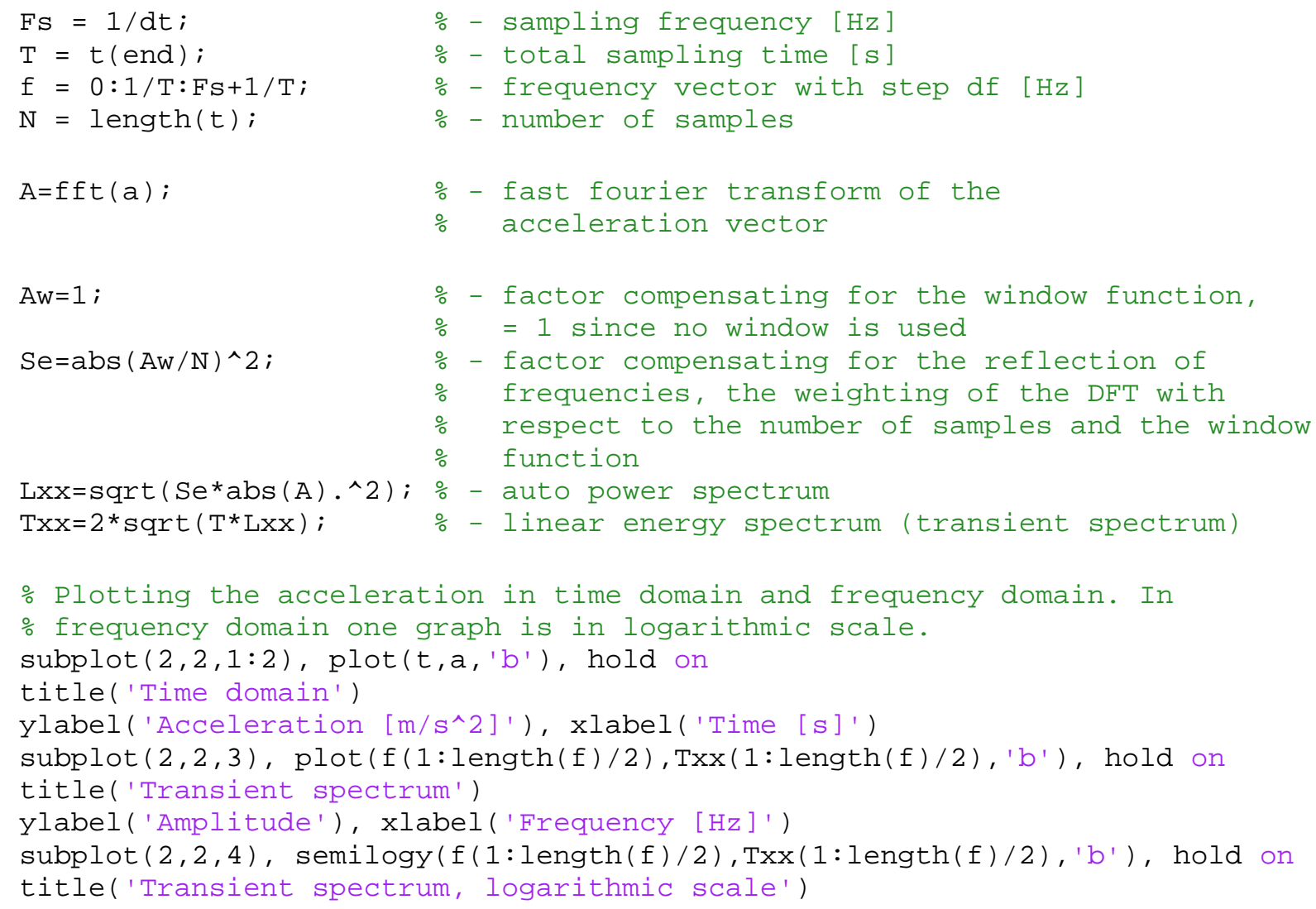


TRITA-BKN. Master Thesis 391, Structural Design and Bridges 2013 ISSN 1103-4297 ISRN KTH/BKN/EX-391-SE 